


\title{
The Making and Unmaking of Opportunity: Educational Mobility in 20th Century-Denmark
}

\author{
Kristian B. Karlson ${ }^{+} \quad$ Rasmus Landers $\emptyset^{\dagger}$
}

February 17, 2021

\begin{abstract}
We study intergenerational educational mobility in Denmark over the 20th century during which the comprehensive Danish welfare state was rolled out. While mobility initially was low, schooling reforms benefiting children from disadvantaged backgrounds led to dramatic increases in mobility for cohorts born between 1940 and 1960. However, the college expansion affecting cohorts born from 1970 onward has mainly benefited children from affluent backgrounds, resulting in rapidly declining mobility. Comparisons to educational mobility trends in the U.S. reveal that the two countries converge in mobility levels for the most recent cohorts despite the dramatically different welfare policies in place.
\end{abstract}

JEL: H0, I0, J0

Keywords: educational mobility, inequality, schooling reforms, skills

* We are indebted to generous feedback from many, especially Jesper Birkelund, Richard Breen, Steven Durlauf,
Gøsta Esping-Andersen, James J. Heckman, Anders Hjorth-Trolle, Erik Lykke Mortensen, Helena Skyt Nielsen,
Hans Henrik Sievertsen, and seminar participants at the ASA conference 2020, the Copenhagen Education Network,
the Life-cycle working group at the University of Chicago, the University of Copenhagen, and the 5th IZA Workshop:
The Economics of Education. We thank educational historians Jakob Linnet Schmidt, Ning de Coninck-Smith, and
Signe Holm-Larsen for assistance with coding education degrees during the early 20th century. We also thank M.
Osler, K. Christensen, D. Molbo, E. L. Mortensen, and T. I. A. Sørensen who established the Danish Constriction
Database at the University of Copenhagen, Department of Public Health.
+: Department of Sociology, University of Copenhagen, kbk@soc.ku.dk
${ }_{\dagger}^{+}$: ROCKWOOL Foundation Research Unit, Ny Kongensgade 6, DK-1472, Copenhagen, +45 20704429, rl@rff.dk 


\section{Introduction}

The causes and consequences of inequality in schooling constitute key concerns in current political debates. In this context, Denmark is often highlighted as a model example, as it provides a wide range of universal public programs with the purpose of promoting, among other things, equal access to education and social mobility (e.g., Björklund and Salvanes, 2011; Black and Devereux, 2011; Corak, 2013, Roemer and Tranmoy, 2015). But to which extent does a country's level of inequality in schooling depend on its welfare policies?

To address this question, this paper analyzes total population register data supplemented by historical survey data to trace educational attainment and mobility for cohorts born over the course of the 20th century in Denmark during which today's comprehensive Danish welfare state materialized with, for example, universal high-quality childcare, access to (free) colleges and universities, and generous public education support. We contrast these changes in Denmark to the corresponding ones in the U.S., which in terms of key welfare policies has taken a route very different from Denmark 1

Fig. 1 summarizes the key finding of the paper by contrasting educational mobility estimates and education levels for Denmark to those in the U.S. across the 20th century. Fig. 17 shows the estimates from linear regressions of children's years of schooling on parents' years of schooling for cohorts born in 1911 through 1985 in the two countries. Educational mobility changed dramatically over the century in Denmark compared to the U.S. where overall mobility levels have been relatively stable. Although Denmark was characterized by very low levels of educational mobility early in

\footnotetext{
${ }^{1}$ For example, public expenses and income transfers relative to GDP were approximately $21 \%$ in Denmark and 15\% in the U.S. in 1958. In 1990 the corresponding fractions were around $48 \%$ and 25\%, respectively (Statistics Denmark, 2001, White House Office of Management and Budget, 2020)
} 
the century (a coefficient of almost 0.6), in tandem with major schooling reforms, educational mobility increased dramatically over a 25-year period (to a coefficient of roughly 0.3 ), substantially surpassing mobility levels in the U.S. However, among Danes born in the 1970s and 1980s, mobility has declined rapidly, and for the youngest cohorts born in the mid-1980s, the estimates are similar to those reported for the U.S. at $0.45 .^{2}$ As Fig. 1 b shows, we see a very similar development when we instead of regression coefficients consider absolute upward educational mobility (defined as children having more years of schooling than their parents).

What explains this convergence between the two countries for the most recent cohorts? Denmark and the U.S. have not become more alike in terms of policies associated with equality of opportunity - if anything the opposite is true. Nonetheless, despite these pronounced policy differences, educational mobility show very similar rates in the two countries today.

The only area in which the two countries have become more alike is education levels. Figs. $1 \mathrm{c}$ and $1 \mathrm{~d}$ present for each country trends in average years of schooling among children and their parents, for children born from 1955 onward. Fig. 17 shows that in Denmark, average years of schooling increased from a level below 12 years for children and below 10 years for parents to almost 14 years and 12 years, respectively. In contrast, in the U.S. the large educational expansion took place earlier in the 20th century (Goldin, 1998, Goldin and Katz, 1999). As Fig. 1k shows, average years of schooling in the U.S. changed much less and were far higher than in Denmark until the most recent cohorts. Thus, mobility estimates for the two countries are by no means comparing like with like until, possibly, for cohorts born during the 1980s.

Moreover, not only are the overall changes in education levels between generations central to estimated educational mobility but so are the parts of the distributions that drive these changes. We

\footnotetext{
${ }^{2}$ The results we report for the U.S. correspond to those reported by Cameron and Heckman $(1998)$, Hilger $(2017)$ and Hout and Janus (2011).
} 
show that, on the one hand, the increase in educational mobility in Denmark among the cohorts born in the 1940s, 1950s, and 1960s is rooted in a substantial expansion at the bottom of the schooling distribution following major schooling reforms coupled with stagnating college completion rates. On the other hand, the declining mobility experienced by the youngest cohorts born in the 1970s and 1980s is associated with stagnating high school completion rates and increasing college and university completion rates - increases that are mainly driven by children born to well-educated parents.

Our study contributes to the literature studying differences in social mobility among countries, regions within countries, or across birth cohorts (e.g., Breen and Jonsson, 2005; Chetty et al., 2018, 2014: Corak, 2013, Erikson and Goldthorpe, 2002, Guell et al., 2018, Hertz et al., 2008). Our key finding of recent convergence in educational mobility between Denmark and the U.S. suggests that geographical or temporal differences in social mobility need not reflect fundamental differences in welfare policies. Furthermore, using full population conscription records, we show that the association between parental schooling and income, and children's cognitive skills is virtually constant from cohorts born in the 1950s through those born in the 1980s in Denmark, the latter cohort being exposed to universal high-quality childcare, increased access to (free) colleges and universities, and generous public education support $3^{3}$ Our results instead point to that overall changes in the distribution of schooling (as produced by educational expansion) may be a central driver of changes in educational mobility. Thus our study also contributes to the literature focused on education expansion (e.g., Goldin, 1998, Goldin and Katz, 1999) and to studies of schooling reforms such as Black et al. (2005); Lundborg et al. (2014); Meghir and Palme (2005) by investigating

\footnotetext{
${ }^{3}$ In contrast, parental background — via the influence on children's education - has become increasingly important for outcomes such as employment and income, family formation, and crime.
} 
how schooling reforms and education expansion shape intergenerational mobility $4^{4}$

The paper proceeds as follows: Section 2 describes the data, provides a brief institutional background, and reports key descriptive results on education levels across the 20th century. Section 3 examines the trends in educational mobility in two steps. In the first step, we study the marked increases in educational mobility experienced by cohorts born from 1940-1960 with particular focus on the impact of schooling reforms from the late 1950s to the early 1970s. In the second step, we examine how and why educational mobility has decreased among cohorts born in the 1970s and 1980s. Section 4 exploits data on conscription records spanning more than 50 years to examine how the associations between children's cognitive skills, their education, and parental background have changed over the second half of the 20th century. This section also provides additional analyses pointing to a growing importance of noncognitive skills in education-based inequalities. In Section 5, we conclude the paper.

\section{Background and data}

\section{$2.1 \quad$ Data}

We base our analyses on two data sources. The first source is the total population register data for cohorts born from 1921 through 1988 in Denmark $5^{5}$ Our starting point is the demographic register

\footnotetext{
${ }^{4}$ Contributions to the literature on education expansions also include Currie and Moretti (2003), Oreopoulos et al. (2003), Chevalier (2004), and Piopiunik (2014) studying college openings, changes minimum school leaving ages / compulsory schooling in the U.S., the U.K., and Germany on children's outcomes. A separate line of research has studied the impact of schooling reforms on outcomes such as earnings of the generation affected: Bhuller et al. (2017) uses changes in compulsory schooling in Norway to estimate the effect of education on lifetime earnings. Oreopoulos (2006) compares the effects of U.K. and U.S. reforms, and Pischke and von Wachter (2008) study German reforms.

${ }^{5}$ We consequently omit immigrants from our analyses. Cohorts born 1957-1985 in Fig. 1 a, and all of Figs. 1 b, 313 and Panel B in Table 1 are based on register data. Cohorts born before 1957 in Fig. 17, Panel A in Table 1. and Table 2 are based on survey data.
} 
in which we obtain date and parish of birth, allowing us to analyze differences in education across place of birth for the entire population born throughout most of the 20th century. ${ }^{6}$ For cohorts born from 1956 onward, we use the link to their parents in the register data (information on parents is not included in the register data for cohorts born before 1956). We subsequently link these data to the education register, which is available from 1981 through 2017, providing us with information on the final completed educational degree and years of completed schooling.

To study the earnings-schooling associations across time, we also include wage earnings from the 1980-2018 income registers. We measure wage earnings as the average from ages 32-36. We use this age range for income to proxy lifetime earnings (Nybom and Stuhler, 2016). Expanding the age range in either direction would reduce the number of cohorts for which we are able to measure wage earnings, thereby eroding the purpose of using earnings data. We also link the data to the demographic registers, which contain information on marital status, and to the crime registers to measure youth crime (defined as a criminal charge from age 15 to 17).

We merge the register data with conscription records that include cognitive test scores for all men born in 1940-1988, excepting the 1959-1969 period for whom records are unavailable.7 A unique feature of the conscription test is that all cohorts were administered the exact same test. However, as a result of administrative processing errors in the past, the full-range test scores have been lost for cohorts born in 1970-1986. Thus, for these cohorts, we have available only a dichotomized

\footnotetext{
${ }^{6}$ As the register data are first available in 1980, our data is based on persons surviving to 1980. We do not explore variation in education for cohorts born earlier than 1921, as mortality rates increase rapidly after age 60.

${ }^{7}$ The conscription records come from three different sources: the historical conscription register for cohorts born in 1940-1958 (The Danish Conscription Database at the Department of Public Health, University of Copenhagen) (Christensen et al. 2015), the register for cohorts born 1970-1986, and the register for cohorts born after 1987. The test is composed of four types of tasks related to logical reasoning: a matrix test (based on letters), number sequences, spatial relations (based on figures), and word relations (Kousgaard, 2015). The conscription test score is highly correlated with the The Wechsler Adult Intelligence Scale (with a correlation of 0.82 Mortensen et al., 1989).
} 
version of the original test that sorts individuals into normal- and low-intelligence groups $8^{8}$

The conscription data from cohorts born 1970 onward also contain information from the health assessment across four domains (physical performance, upper extremities, lower extremities, and mental health), which we (1) define as 0 to 4 counting the number of domains in which health is assessed as normal and (2) use for assessing whether health in each of the four domains is assessed as very problematic (coded 1 for very problematic and 0 for otherwise). Appendix B describes the coding and data sources of the Danish data in detail. Appendix C describes the U.S. data.

Fig. A.1 presents data coverage by year of birth, and Table A.1 presents summary statistics for outcomes considered in the paper other than education. Fig. A.2 presents the register data sample size by birth cohort. The solid line presents the total sample size and the dashed line presents the sample size for the conscription data. Cohort sizes vary from 42,000 to 82,000. For selected cohorts, Fig. A.2b shows the sample size by birth cohort and whether birth was registered in an urban or rural area. All sample sizes in the analyses based on register data exceed 10,000 individuals.

The second data source is based on nationally representative surveys. The primary set of surveys were conducted between 1970 and 2010. They allow us to trace educational mobility further back than possible with the register data. In all of these (seven) surveys, respondents provide information about their own and their father's schooling, and their region of birth. The pooled data comprise 8,650 respondents born in 1911 through 1976. In addition, we use information from two longitudinal surveys of cohorts born in 1954 and 1995, respectively (the Danish Longitudinal Study of Youth born in 1954 and the Danish Longitudinal Study of Children born in 1995). We use these surveys

\footnotetext{
${ }^{8}$ Table $\mathrm{B} .3$ maps the cognitive test scores to the IQ scale. A test score below 36 corresponds to an IQ below 90 . As the 1988-cohort is the first cohort after the 1958-cohort for which the data include the full-range test scores, we use this cohort to test the robustness of the trends identified using the dummy category from 1970 to 1986, even though we have to measure education for the 1988-cohort at age 29 , as the most recent year of education information is 2017 .
} 
because they include identical measures of children's cognitive and noncognitive skills in adolescence.

Measuring education Most of our analyses are based on years of schooling. This measure facilitates a comparison of educational levels and mobility throughout a century during which the educational system was reformed, degrees disappeared, and new ones emerged. As the increase in educational attainment for cohorts born from the mid-1960s onward relates to transitions into academic high school, college, and university, we additionally examine how the transitions and sorting between those levels change over time. We also present results using categorical schooling measures and alternative estimation strategies (e.g., polychoric correlations, proportional reductions in entropies, log-multiplicative layer effect models). The results are very similar to those based on years of schooling and highlight the robustness of our conclusions. We measure years of schooling in terms of the highest degree completed at age 30. We convert this highest degree into years of completed schooling using the minimum number of years it takes to complete the degree (e.g., today a 3-year college degree takes $9+3+3=15$ years to complete as compulsory schooling lasts 9 years, academic high school 3 years, and college 3 years)..$^{9}$ Parents' years of schooling are defined in the same way ${ }^{10}$ In some of the surveys, schooling is reported in levels and degrees, not in years of schooling. For these reports, we assign each educational category the associated years of schooling when the respondents (and their parents) completed their education.

\footnotetext{
${ }^{9}$ Fig. B.3 compares the main results using education measured at age 30 and 32 and shows no substantial differences. Estimates increase slightly (i.e. estimated mobility decreases) when education is measured at age 32 , as a small additional fraction completes tertiary educations during the two extra years from age 30 to 32 .

${ }^{10}$ We measure parents' education in 1981, which is the first available year, until the cohort born in 1977 for whom we measure parents' education the year the child turns five. We define parents' years of schooling as the average between the two, except in Fig. 1p (to align the Danish data with the U.S.) and when we use estimation strategies based on education degrees for which we define it as the parent with the highest completed education.
} 


\subsection{The Danish education system at a glance}

Fig. 2 provides a stylized illustration of the Danish education system. Before a schooling reform in 1972 increased the years of compulsory schooling from 7 to 9 , students had to decide whether to leave school after 7 years (primary schooling), complete 9 years of schooling (lower secondary schooling), or complete a vocational apprenticeship-based degree. After the 1972 reform, the dashed lines in the figure disappear from the opportunity set, and students had to decide whether to leave school after 9 years of schooling (lower secondary schooling) or continue to upper secondary education, which consists of either an academic high-school track (the Gymnasium) or a vocational apprenticeshipbased track 11 Completing the academic high-school track makes students eligible for enrolling in tertiary education (college or university).12 As we later report, changes in educational mobility during the 20th century are driven by the horizontal path in Fig. 2 with the expansion from 7 to 9 years of schooling, and the further expansion of academic high school, college, and university education in more recent times 13

While the 1972 schooling reform formally increased the years of compulsory schooling, it merely followed a more fundamental and consequential schooling reform from 1958. Before the 1958 reform, the Danish educational system was divided into a rural and urban school system. 14 . In the rural

\footnotetext{
${ }^{11}$ This 1972 reform corresponds to the Norwegian and Swedish schooling reforms studied in, for example, Black et al. (2005); Meghir and Palme (2005). However, the Norwegian and Swedish counterparts were introduced in the 1960 s and gradually rolled out across regions, whereas the Danish reform was introduced later and implemented nationally at a single point in time.

${ }^{12}$ College-level education in Denmark consists of two branches: semi-professional degrees such as teaching or nursing of 3-4 years duration, and bachelor degrees that feed directly into master's programs of 5-6 years duration.

${ }^{13}$ One of the most striking features of the Danish education system is the absence of direct financial costs for parents. While education has been "free" throughout the period studied, strong selectivity bias into who had the opportunity to go beyond 7 or 9 years of schooling was a barrier until cohorts born during the mid-1960s. As we show below, it is only for later cohorts that tertiary education becomes prevalent. Moreover, public education support was introduced in 1970 but was substantially expanded only later, in particular in 1988 (studied in Nielsen et al. 2010).

${ }^{14}$ During the 20th century, six reforms of primary and lower secondary schooling were implemented. Appendix B.1 provides details of all six reforms.
} 
school system, children had very few opportunities for continuing into lower and upper secondary education after completing primary school. Schools in rural areas only provided primary schooling from grades 1 through 7, with substantially fewer school days per year, and fewer grade levels (e.g., a grade for "young children" and another for "old children").15 The 1958 reform abolished the rural school system, and rural municipalities (the local administrative units in Denmark) were now required to offer schooling at least through grade 9. Thus, all children in rural Denmark now had - for the first time - the opportunity to attend schooling beyond the minimum required 7 years. All schools also became obligated to supply all relevant grade-levels, and all children should attend school for the same number of days. The reform was also supplemented by a large increase in public school funding, particularly in rural areas ${ }^{16}$ As we report below, the 1958 report had major impacts on both average educational attainment and educational mobility.

\subsection{Trends in schooling levels}

Fig. 3 shows average years of completed schooling by birth year for persons born in 1921-1987, based on the administrative registers. Fig. 3a shows highest completed levels of education and average years of schooling, Fig. 3b shows the proportion who completed a specific degree or higher, and Fig. 3c shows the year-by-year change in the various educational levels (i.e., the slope in Fig. 3b)

As Fig. 3 illustrates, although average years of schooling increases almost linearly during this period, the trend is driven by educational expansions at different discrete schooling levels. For those born in the 1921-1957 period, the downward trend in the share with no more than 7 years

\footnotetext{
${ }^{15}$ The institutional setup of the schooling system before 1958 reflects the the country's strong dependence on the agricultural sector - a dependence that continued well into the 20th century. For example, $50 \%$ of adult men worked in farming in 1911, and in 1948 more than $25 \%$ of the workforce were employed in the agricultural sector. Children also contributed to the agricultural workforce; $20 \%$ of family breadwinners in farm households in 1911 were children aged 10-15 (Statistics Denmark, 2001, 2015).

${ }^{16}$ See Appendix B.1 and Bingley and Martinello (2017).
} 
of schooling dominates. While $60 \%$ of the 1921 birth cohort completed no more than 7 years of schooling, 40\% of the 1941 cohort and only 4\%-5\% of the 1956 cohort did so (the 1956 cohort is the last cohort not affected by the 1972 reform that increased the minimum required years of schooling from 7 to 9). The share completing high school increased modestly for those born during the first half of the 20th century (10 percentage points for the 1921-1940 cohorts), and more rapidly for those born in 1950-1965 (30 percentage points). Cohorts born in 1965-1987 experienced significant expansion at the college and university levels. While roughly $10 \%$ of the 1965 cohort obtained a college degree as their highest completed education, slightly more than $20 \%$ of the 1987 cohort obtained such degree. Similarly, whereas only 5\% of the 1965 cohort completed a university degree, this fraction increased to almost $20 \%$ in the 1987 cohort.

In other words, the education expansion has occurred in different parts of the distribution over the century. Figs. 3b and 3e show that the lower tail - completing at least 9 years of schoolingchanged drastically until cohorts born in the mid-1950s. The figure further shows that the fraction completing high school increased throughout the century, but the increase became more rapid among those born after WWII, only to slow down in the two most recent decades of cohorts. The proportion with a college or university degree is almost constant throughout the first two-thirds of the century, and only increases for cohorts born from 1965 onward. ${ }^{17}$ While the uptake in all major fields at the university level has increased, the expansion has been most pronounced for degrees within the humanities (which increased from $7 \%$ of university degrees in the 1965 cohort to around $25 \%$ two decades later).

\footnotetext{
${ }^{17}$ As a comparison, we plot the corresponding marginal schooling distribution for the U.S. in Fig. A.3. The figure shows that average years of schooling increased rapidly and linearly from 1913 through 1950. From 1950 through 1984, however, the annual growth rate in years of schooling declined significantly. Rapid growth from 1913 through 1950 was driven by, on the one hand, a decline among those with less than a high school degree (i.e., less than 12 years of schooling) and, on the other hand, an increase among those with at least some college. This evolution corresponds to education trends presented in, for example, Goldin and Katz (2007).
} 
To supplement the reported trends in schooling, Fig. A.4 illustrates the development in mean cognitive test scores in cohorts born 1940-1988 using the conscription records. It shows that, while mean cognitive test scores (among men) increased until those born in the late 1960s when progress gradually halted, they have remained stable from the 1975 cohort onward.

\section{Educational mobility}

We divide the analysis of trends in educational mobility into two subsections. In the first, we analyze the dramatic increase in educational mobility among those born in the late 1940s through the mid-1960s. The second subsection analyzes the declines in educational mobility for those born during the $1970 \mathrm{~s}$ and $1980 \mathrm{~s} .{ }^{18}$

\subsection{Toward higher educational mobility}

At the turn of the 20th century, Denmark had two separate school systems: the rural and the urban system. As described in Section 2, children living in rural areas had much poorer access to education than those living in urban areas. Fig. 4 illustrates how dramatically the 1958 reform impacted schooling levels in Denmark. Fig. 4 a shows the proportion with no more than 7 years of schooling by rural-urban origin for cohorts born in 1921-1965. Among cohorts born in 1921-1941, children from both urban and rural areas gradually became less likely to obtain only 7 years of schooling. However, starting from the birth cohort of 1942 - the first cohort affected by the 1958

\footnotetext{
${ }^{18} \mathrm{Fig}$. A.5 shows the regression intercepts and correlation coefficients corresponding to the estimates reported in Fig. 1. To show that the different trends in estimated educational mobility is not an artifact of changing data source for cohorts born before and after 1956, in Fig. A.6 we present estimates for Denmark based on survey data only extending the cohorts to all available cohorts born in 1911-1976. The trend for those born in 1956-1976 is virtually identical, suggesting that differences in underlying data sources do not drive our results. In addition, Fig. A.7 shows that the trends do not arise from changing nonlinearities across parents' years of schooling.
} 
reform - the rural-urban gap at this schooling margin was virtually closed in approximately 15 years. Figs. $4 c$ and $4 \mathrm{~d}$ show similar trends in average years of schooling. For those born before 1942, the gap was stable at around 1 year of schooling, but 15 years later the gap was less than one-fifth of a year (which was due to differences in the prevalence of college and university degrees, not shown here).

We next illustrate the 1958 reform's impact on the rural-urban gap in cognitive skills using the conscription records. Figs. 4e and 4 f show average cognitive test scores by rural-urban origin and birth year. For the 1940 cohort, we find a substantial rural-urban gap in the skill distribution. However, for the 1958 cohort, the rural-urban gap has been reduced by around 75\%, suggesting that the impact of the 1958 reform not only equalized formal schooling but also cognitive skill levels among regions in Denmark 19

The 1972 reform formally changed the years of compulsory schooling from 7 to 9 . While this reform corresponds to the reforms in Norway and Sweden studied in Black et al. (2005); Lundborg et al. (2014); Meghir and Palme (2005) among others, the Swedish and Norwegian reforms were rolled out somewhat earlier during the late 1950s and 1960s. As a result of the strong downward trend in the proportion completing only 7 years of schooling in Denmark, around $95 \%$ of a cohort already completed more than 7 years of schooling on the eve of the 1972 reform (which affected the

\footnotetext{
${ }^{19}$ This result follows e.g., Brinch and Galloway (2012) and Banks and Mazzonna (2012) who find that compulsory schooling reforms increase cognitive test scores in Norway and England, respectively. Furthermore, Fig. A.8 shows cognitive test score distributions by rural-urban origin for birth cohorts 1940 and 1958 . The distribution in 1940 for children from rural areas is right-skewed and significantly shifted to the left compared to the distribution for children from urban areas, whereas the 1958 distributions only show a smaller rural-urban gap.
} 
second half of the 1957 cohort onward).20 21

Fig. 5 illustrates how the 1972 reform affected education outcomes. As previously described, the 1972 reform followed a long upward trend in completed education driven by rising completion of lower secondary schooling. As the figure shows, before enactment of the reform around $95 \%$ completed at least 8 years of schooling and almost $90 \%$ completed 9 years of schooling. The reform led to a discrete jump in education levels with the result that virtually all completed more than 7 years of schooling and around 95\% completed at least 9 years. Moreover, the reform also led to a discrete reduction in the standard deviation of years of schooling (cf. Fig. 5d). 22

To formally test how educational expansion at the bottom of the schooling distribution affected overall mobility levels, we report by year of birth estimates from linear regressions of children's years of schooling on parents' years of schooling (henceforth labeled the education IGE) and the corresponding correlations (labeled education correlation):

$$
E_{i, t}^{C}=\alpha_{t}+\beta_{t} E_{i, t}^{P}+u_{i, t} \quad \text { and } \quad \operatorname{corr}\left(E_{i, t}^{C}, E_{i, t}^{P}\right)
$$

\footnotetext{
${ }^{20}$ Similarly, Oreopoulos (2006) shows that two consecutive compulsory schooling laws in the U.K. had a different impact; the first resulted in a strong increase in schooling enrollment while the second only had minor impact as it coincided with an existing trend.

${ }^{21}$ While the reform's main impact affected the 1957 cohort, the reform was not completely binding until the 1959 cohort as some had dropped out at the time of its enactment - these children were not forced to go back to school. Appendix B.1 describes the reform in detail.

${ }^{22}$ To further examine the differential impact of the two reforms (in 1958 and 1972), Fig. A.9 presents the cumulative distributions of cognitive test scores for birth cohorts 1940, 1941 (the two last cohorts not affected by the 1958 reform), 1942 (the first cohort affected by the 1958 reform), 1956 (the last cohort not affected by the 1972 reform), and 1957 and 1958 (the first two cohorts affected by the 1972 reform). While we see no differences between the distributions of the 1940 and 1941 cohorts, the 1942 cohort's distribution is clearly shifted upward. As the difference between the 1942 and 1956 cohorts shows, the following decade saw a further increase in cognitive skills. However, as the pronounced overlap in test score distributions of the 1956, 1957, and 1958 cohorts indicate, the compulsory schooling reform of 1972 did not appear to increase cognitive skills.
} 
where $E_{i, t}^{C}$ are children's years of schooling and $E_{i, t}^{P}$ are parents' years of schooling. Panel A of Table 1 shows educational mobility estimates for the cohorts not affected by the 1958 reform (those born in 1932-1941) and the first 10 cohorts after the reform (cohorts born in 1942-1951). Panel B of Table 1 similarly shows estimates for the last cohort not affected by the 1972 reform (1956 cohort) and the first cohort affected by the reform (1958 cohort). The table presents estimates for the entire country and by rural-urban origin. Panel A shows that mobility increased significantly around the 1958 reform. This result holds irrespective of whether we examine the education IGE or education correlation. Panel A also shows that cohorts born before 1942 in rural areas experienced less mobility with an education IGE estimate of 0.58 compared to those born in urban areas with an estimate of 0.48. However, among those born after 1942, the rural-urban gap completely disappears. Thus, while educational mobility for those who grew up in urban areas remains roughly constant over the entire period, mobility increases significantly for those born in rural areas. Panel B shows equivalent estimates for the 1972 reform. However, the compulsory schooling reform of 1972 affected only a small fraction of children, with its largest impact affecting the variance in years of schooling (cf. Fig. 5d). As a consequence, Panel B shows that the 1972 reform is associated with only a minor decline in the education IGE and no changes to the education correlation.

\subsection{Toward lower educational mobility}

To visualize the extent of the reversal from high levels of mobility toward lower levels seen in Fig. 1a, Fig. 6 plots by year the education IGE and education correlation for those born in 1956-1987. The figure shows that the 1956-1958 cohorts experienced the lowest education correlation in our entire data set of cohorts born throughout the 20th century. Beginning with the 1958 cohort, the education correlation increases gradually. The figure also shows that the education IGEs continue to decline 
beyond the correlation low-point into the mid-1960s (the discrepancy in trends in the 1960s is driven by declining variance in years of schooling; see Fig. 5d). The result was unprecedented levels of educational mobility.

Yet, Fig. 6 also documents stark increases in the education IGE and education correlation for cohorts born in the mid-1960s through the mid-1980s. This trend is remarkable in light of the welfare policies that were rolled out during this period. These are the cohorts who were the first to have access to state-provided childcare early in life (introduced during the late 1960s through the early 1970s), who benefited from generous income redistribution via progressive taxation and social transfers, and who faced no direct financial costs for education at all levels. All of these factors are often emphasized as being central parts of the Scandinavian welfare regime, and have been shown to increase educational attainment (e.g., Havnes and Mogstad, 2011; Nielsen et al., 2010).23 Our findings do not imply that policies such as universal childcare did not have positive effects for those from the lowest socioeconomic backgrounds as found in earlier studies. By way of contrast, it shows the potent impact of the overall changes to the educational distribution at this point in time.

To test the robustness of the declining educational mobility finding, we conduct a range of supplementary analyses based on categorical measures of education and different ways of summarizing

\footnotetext{
${ }^{23}$ The decreasing mobility trend is perfectly mirrored in changing schooling dispersion. Fig. A.10a shows the standard deviation in years of schooling for cohorts born in 1921-1985. Danes born in 1942 (i.e., those affected by the 1958-reform) through 1957 (i.e., those affected by the 1972 compulsory schooling reform) experienced a very large decline in educational inequality, and this decline continued at a lower rate for those born in the mid $1960 \mathrm{~s}$. However, for cohorts born in 1965-1984, inequality began increasing. Fig. A.10p provides another way of illustrating this finding by plotting the average years of schooling for the bottom and top $30 \%$ of the schooling distribution by birth year. The figure shows a similar rapid decline in inequality caused by the 1958 reform, reaching an all-time low in the mid-1960s, from where it begins increasing again through the mid-1980s.
} 
the overall parent-child schooling association using the categorical data. ${ }^{24}$ These analyses all show that our finding in Fig. 6 is highly robust to alternative ways of measuring both education and educational mobility, suggesting that all evidence points to that mobility decreased substantially for Danes born after the mid-1960s. To further examine this decline, we first show how transitions from high school into higher education change drastically for cohorts born in the mid-1960s when the upper-tail expansion of the education distribution begins. We then turn to the long-run growth of college and university degrees and how these changes are related to parental schooling.

\section{Changing transitions into higher education}

As a first step in further analyzing the reversal in the mobility trend for cohorts born after the mid1960s, Fig. 7 plots by birth year the percentages transitioning to academic high school, to college after academic high-school completion, and to university after college completion, for cohorts born in 1921-1987.25 The transition probabilities are calculated conditional on being eligible for enrollment

\footnotetext{
${ }^{24}$ In Fig. A.11 a, we show trends over the century using Kruskal-Goodman's gamma coefficient, a nonparametric correlation coefficient for ordinal variables, the polychoric correlation coefficient (which takes schooling as an ordinal measure of an underlying normally distributed latent variable), and taking education distributions as an ordinal measure of underlying skills (as in Fletcher and Han 2019). In Fig. A.11b, we report Theil's J (information theory multigroup index) estimates by birth year for cohorts born in 1957-1988 estimates (Reardon and Firebaugh, 2002). The index compares the average conditional entropy of children's schooling given parents' schooling to the unconditional entropy of children's schooling, and can thus be considered a measure similar to the R-squared in linear regression (Theil, 1973, p. 173). We estimate this index using a highly granular measure of education for both parents and children. Fig. A.11p shows the estimated index both for dissaggregate education degrees (around 1,000 categories in total) and for the aggregate degrees (20 categories in total). We find a clear upward trend in coefficients over time. Fig. A.11 also replicates the overall finding using the log-multiplicative layer-effect (unidiff) model (Erikson and Goldthorpe 2002), which summarizes how the overall origin-destination (parent-child) association in a cross-tabulation of education levels changes over time relative to an index period.

${ }^{25}$ As completing academic high school is a prerequisite for college enrollment, this next section specifically examines the completion of this academic track and not the completion of all types of high school (which would include also analyzing the vocational track). Several studies have examined the importance of transition probabilities in shaping overall education trends in the U.S., such as documenting an increasing share (of males) graduate with a GED instead of a formal high school degree (Heckman and LaFontaine, 2010), a substantial drop in college graduation rates for men, which is matched by an increase for women (Card and Lemieux, 2001) and decreasing college graduation rates conditional on college enrollment (Bound et al., 2010)
} 
as illustrated in the stylized model of the Danish educational system in Fig. 2f completion of 9th grade is required for enrolling in academic high school, completion of academic high school is required for enrolling in college, and college completion is required for university enrollment. The figure shows that only around $20 \%$ of those completing the 9 th grade went on to complete academic high school until the 1940 cohort. For those born in 1940-1965, the conditional probability of completing academic high school doubled. As the proportion of eligible persons in the cohort completing at least 9 years of schooling increased from around $60 \%$ to 100\%, this implied that overall (unconditional) academic high-school completion increased from approximately $15 \%$ to $40 \%$. Yet, as the figure also shows, completing a college degree conditional on completing an academic high-school degree dropped dramatically, as only around $15 \%$ of the additional high school graduates went on to higher education. For the 1950 cohort, $80 \%$ of those completing academic high school completed college afterward - for cohorts born in the early 1960s, this fraction had dropped to around $40 \%$.

Nevertheless, similar to the trend in overall mobility estimates, the cohorts born during the mid-1960s mark a turning point. Academic high-school completion increases from less than $40 \%$ for cohorts born in the mid-1960s to almost 60\% for cohorts born in the mid-1980s. Furthermore, the probability of completing college conditional on graduating from the academic high-school track increases from around $40 \%$ to $70 \%$ over just $20-25$ years. And while the probability of completing university conditional on college completion stagnates until the cohorts born in the mid-1970s, the transition probability increases from around $33 \%$ to almost $50 \%$ for the 10 youngest cohorts. Thus, within a relatively short period, transitions into higher education increase dramatically. Fig. A.12 contrasts the transition probability from high school to college for Denmark with that in the U.S. across the 20th century. In line with the evidence presented earlier the paper, the differences between the two countries for cohorts born early in the 20th century reverse for cohorts born in the 
middle of the 20th century followed by a convergence for the most recent cohorts.

\section{College and university completion by family background}

As a second step in analyzing the reversing mobility trend-which began among those born in the mid-1960s - we link the changes to higher education completion rates in Fig. 7 to parents'

education. Fig. 8a shows the correlation between educational transitions (to high school overall, to the academic high-school track, to college, and to university) and parents' years of schooling among those born in 1956-1987. Fig. 8p shows the same trends in the correlation coefficients as in Fig. 8a with the coefficients being indexed relative to those reported for the 1960 cohort. The figures show pronounced differences in the correlations between children's education and parents' years of schooling during the period in question. Although the correlation between high school completion and parental schooling is roughly constant throughout the cohort window, parents' education correlates increasingly with children's higher education attainment. Parents' education becomes increasingly predictive of children completing college and university degrees for cohorts born after the 1960s. Indeed, over the course of 30 years, the correlation between completing a university degree and parents' years of schooling increases by around $50 \%$. This pattern suggests that children of highly educated parents have benefited more than children of low-educated parents from the college and university expansion.

Fig. 8f focuses on the transitions from high school to college and university. The figure presents the correlation between parents' years of schooling and the conditional probabilities of college completion and university completion. Fig. $8 \mathrm{~d}$ shows the same figures with the correlations indexed relative to the 1965 cohort. The figures show that the transition probabilities increase by 30-40\% over the roughly 20 cohorts in question. Thus, a substantial part of the education expansion appears 
to be driven by an increased propensity to transition from lower to higher levels of education, a change that has been most pronounced for children born to highly educated parents ${ }^{26}$

Fig. A.13 graphs college and university completion rates across parents' education by birth year and field of study. The figure shows that increasing college completion rates for cohorts born in the mid-1960s onward are driven by increases in teacher and pedagogical degrees, and college degrees within the humanities and social sciences. However, increasing gaps across parental education are seen only for the latter type of education. For university completion, degrees in humanities and social sciences increased by around 400\% from the cohorts born in the mid-1960s to those born in the mid-1980s - an increase almost exclusively driven by children born to well-educated parents. ${ }^{27}$

We next examine how much of the decrease in educational mobility for cohorts born between the mid-1960s and the mid-1980s that can be attributed to the differential changes to transition probabilities between education levels. Educational attainment can be expressed as a series of sequential decisions (as shown in Boudon, 1974; Cameron and Heckman, 1998; Mare, 1980, 1981), which, by the Law of Iterated Expectations, makes the probability of completing education level $j$ equal to $p\left(E_{j}=1\right)=\prod_{k=1}^{j} p\left(E_{k}=1 \mid E_{k-1}=1\right)$. Children's average years of schooling $E(Y)$ is then a product of (conditional) education transition probabilities multiplied by the average years

\footnotetext{
${ }^{26}$ As shown in Cameron and Heckman $(\sqrt{1998)}$, an unadjusted analysis of transition probabilities is subject to sample selection bias among different schooling levels. However, 8 $\mathrm{a}$ shows that the correlation between academic high-school completion and parents' education is almost constant across the period in question. Therefore, sample selection bias in this dimension is not likely to affect our results. In Section 4 , we analyze changes to skill-based selection across the educational transition points.

${ }^{27}$ For cohorts born in the mid-1980s, children whose parents are in the lowest tertile of years of schooling make up $8 \%, 13 \%$, and $13 \%$ of degrees within the medical sciences, technical degrees and natural sciences, and humanities and social sciences, respectively. In comparison, children whose parents belong in the top tertile of years of schooling comprise $75 \%, 62 \%$, and $63 \%$ of the three categories.
} 
of schooling associated with each education level from the lowest $j=0$ to the highest $j=J$ :

$$
\begin{gathered}
E(Y)= \\
E\left(Y \mid E_{0}=1\right)+p\left(E_{1}=1 \mid E_{0}=1\right)\left[E\left(Y \mid E_{1}=1\right)-E\left(Y \mid E_{0}=1\right)\right]+\ldots+ \\
\left(\prod_{k=1}^{J} p\left(E_{k}=1 \mid E_{k-1}=1\right)\right)\left[E\left(Y \mid E_{J}=1\right)-E\left(Y \mid E_{J-1}=1\right)\right]
\end{gathered}
$$

Fig. 9 presents the results of four simulations using the decomposition of years of schooling by different transition probabilities across parental education levels. The solid line presents the observed education IGE as a benchmark. The four other lines present the education IGEs (1) if the transition into academic high school had been fixed to the pattern in the 1969 cohort, (2) if the transition from academic high school to college had been fixed to that in the 1969 cohort, (3) if the transition from college to university had been fixed to that in the 1969 cohort, and (4) if all the aforementioned transition probabilities were fixed to the pattern in the 1969 cohort.

As depicted in Fig. 9, the transition into academic high school and the transition from college to university account for only a small portion of the increased education IGE. Results for the former are a consequence of the correlation between academic high-school completion and parents' education being almost unchanged across the period in question (see Fig. 8), whereas results for the latter are a consequence of the relative small proportion of a cohort completing a university degree (i.e., the transition into university has become more selective but it affects only a small percentage of a cohort). The figure shows that the lion's share of the decline in educational mobility is caused by college becoming more selective based on family background over time. Had the selection into college by parental background remained as observed for the 1969 cohort, the education IGE for the 1987 cohort would be 0.41 instead of 0.48 . If all transition probabilities collectively had not 
changed since 1969 cohort, then the education IGE would have reached a level just above 0.35.

\section{Education, skills, and life-course inequalities}

Our analyses show that changes to educational mobility levels in Denmark are strongly related to educational expansion. However, given the dramatic changes to the distribution of schooling, we turn to examining changes in the underlying components of education over time.

During the period in question, Denmark has not only seen dramatic changes in schooling levels but also dramatic expansions of welfare policies relating to transfers, health care, day care, and education support among others. As a first step, we therefore ask to which extent the association between family background and cognitive skills has changed. Fig. 10 shows cognitive test score ranks by parental income ranks for the 1958 and 1988 cohorts, respectively. The associations for the two cohorts born 30 years apart (and on different sides of a massive welfare expansion) are strikingly similar. The figure also shows the association between child cognitive test scores and parents' income for the U.S. using the child supplement of the NLSY79, which comprises children born from the late 1970s to the 1990s. We do not find any striking differences between the two countries. Thus, Fig. 10 suggests that the association between family background cognitive skills, a core aspect of human capital formation, is unchanged across the massive welfare expansion in Denmark, and is even similar to the corresponding association in the U.S. ${ }^{28}$

However, the constancy in skill inequalities coupled with the increasing association between parents' and children's schooling among the youngest cohorts in Denmark begs the question of how the association between skills and schooling have changed over time. We address this question in

\footnotetext{
${ }^{28}$ In addition, as shown in Table A.3 the association between parents' schooling and children's language test scores in grades 2 and 8 for cohorts born around 2000 is similar in Denmark and the U.S. (Hjorth-Trolle and Holm, 2021).
} 
two steps. First, in Section 4.1 we examine whether selection into different education levels proxies the same type of skills today as it did half a century ago in Denmark. Second, in Section 4.2 we describe the changes in how predictive education is of a broader set of life-course outcomes such as earnings, employment, marriage, health, and crime.

\subsection{The relationship between education and skills}

Fig. 11 plots by birth year the correlation between children's cognitive test scores and years of schooling. As Fig. 11 shows, the correlation declines dramatically for cohorts born in 1940-1958. This result holds irrespective of whether we consider the full range of the test score or the test score dummy (the latter covering a broader range of birth cohorts). However, as Fig. 11b shows, the correlation coefficients among the younger cohorts - who have been affected by the expansion of college and university education - have not reversed back toward the levels of older cohorts. In contrast, the correlation appears stable for the younger cohorts.

While Fig. 11 clearly shows a disconnect between overall years of schooling and cognitive skills, our previous findings (related to changing transition probabilities from lower secondary school to high school and from high school to college) raise the question of whether the declinng association between cognitive skills and years of schooling is observed at all educational transitions. Fig. 12 presents the correlation between cognitive test scores and highest level of education by birth year. Fig. 12 presents the associations for years of schooling (as in Fig. 11) for reference, and for high school, college, and university completion separately. As the figure shows, correlations decline until those born in the late 1950s, after which the correlation coefficient is virtually constant. However, as Figs. 12p-d show, the decline is mainly driven by a drop in the association between cognitive skills and completion of lower secondary schooling (grade 9). While Fig. 12b shows a 
drop in the correlation, Fig. 12k, which focuses on high school completion given completion of 9 years of schooling, presents a very different picture: Cohorts born in 1940-1958 start out at a much lower level when considering the correlation between academic high-school completion given 9th grade completion and cognitive skills. Also, the correlation initially increases slightly and subsequently declines. Furthermore, the association between college completion given academic high-school completion and cognitive test scores $(12 \mathrm{~d})$ is low at around $0-0.1$ and almost constant across the period (perhaps mildly increasing for the most recent cohorts). These findings suggest that selection based on cognitive skills into different education levels changes substantially over time as the educational system expands at different levels ${ }^{29}$ Thus, differences in educational attainment for the most recent cohorts do not reflect the same cognitive skill gaps as for the cohorts born, say, during the 1940s.

Non-cognitive skills are also important for educational attainment (Almlund et al. 2011). While the conscription data allow us to study the cognitive skills of cohorts born almost 50 years apart, comparable measures of non-cognitive skills are not available in the register data. However, two Danish longitudinal surveys of the 1954 and 1995 cohorts enable us to analyze the development using measures of non-cognitive skills. Both are nationally representative surveys that include identical measures; the same cognitive test score measured at ages 14-15 (a verbal intelligence test) and the Rosenberg self-esteem scale (Rosenberg, 1965) measured at around age 2030 Table 2 shows the estimated coefficients from regressions of schooling outcomes on cognitive and non-cognitive test

\footnotetext{
${ }^{29}$ Fig. A.14 examines how education expansions across different educational transition points are related to selection on cognitive skills in different parts of the skill distribution. The figure shows that educational expansion was driven by children with low-level cognitive skills until the late 1950s. Yet, from the 1970s onward the education expansion instead involves increasing levels of positive selection where education has expanded mostly for individuals with high-level cognitive skills.

${ }^{30}$ Section B.5 describes data construction. As the 1995 cohort has not yet reached an age where we can measure both college and university completion, we instead define college completion as having completed a college degree (or higher) or being enrolled in college or university.
} 
scores separately for the two surveys. Whereas Panels A and B present coefficients for the 1954 and 1995 cohorts respectively, Panel C shows changes in the coefficients (Panel B minus A).

Column 1 in Table 2 shows that the coefficient of cognitive skills on academic high-school completion decreases between the two surveys, suggesting that selection by cognitive skills at this transition point has become weaker over time. Comparing the estimates for cognitive skills in columns 1,2, and 3, we find that cognitive skills in both cohorts are significantly associated with academic high-school and college completion, but most of the association between college education and cognitive skills is explained by the preceding academic high-school margin. In addition, while the importance of cognitive skills has decreased at the high school margin (column 1), it has increased slightly at the college margin (column 3). These overall patterns corroborate the findings based on the conscription registers reported in Fig. 12.

Table 2 also shows that our non-cognitive measure, self-esteem, is more predictive of educational attainment in the 1995 cohort than in the 1954 cohort 31 While there is no association in the 1954 cohort, self-esteem is significantly associated with both high school and college completion in the 1995 cohort. This finding suggests that the declining relationship between cognitive skills and academic high-school completion appears to have been replaced by a growing selection based on non-cognitive skills, thus mirroring U.S. findings with respect to high school drop outs, GED recipients, and high school graduates for whom non-cognitive skills also play an important role in selection (e.g. Heckman et al., 2011).

Considered together, Fig. 12 and Table 2 show that the importance of skills for selection into education changes over time and across education levels. This finding suggests that the intergenera-

\footnotetext{
${ }^{31}$ Similarly, Blanden et al. (2007) find that non-cognitive skills play a greater role in mediating intergenerational income mobility for more recent cohorts in the U.K., and Edin et al. (2018) find an increasing return to non-cognitive skills in Sweden in recent decades. In addition, Castex and Dechter (2014) find that wage earnings returns to cognitive skills are constant throughout the period in question in the U.S.
} 
tional transmission of education likely proxies a different type of intergenerational skill transmission today than it did 30 or 40 years ago.

\subsection{Education gaps and life-course inequality}

To further examine what education proxies, Fig. 13 plots correlation coefficients between cognitive skills and years of schooling, on the one hand, and within-cohort wage earnings percentiles (13a), employment rates $113 \mathrm{~b})$, an overall health score $(13 \mathrm{c})$, an indicator of health problems by type (13d), the probability of being married at age 35 (13), and youth crime between ages 15-17 (13f) on the other ${ }^{32}$ The figure shows that the respective correlations with years of schooling and cognitive skills follow parallel trends until the late 1950s. For those born from the 1960s onward, however, the trends are characterized by a strong divergence for all six outcomes. Years of schooling have become increasingly predictive of wage earnings, employment rates, mental health, marriage rates, and crime rates, with correlations increasing by $50 \%$ to $100 \%$, whereas the associations between cognitive test scores and the various outcomes remain constant.

Returning to intergenerational mobility, Table 3 shows that the respective relationships between parental schooling and the six life outcomes also change over time and that these changes are mediated by children's schooling. ${ }^{33}$ While the association between parents' years of schooling and child cognitive skills remains unchanged over the period, the associations between parents' years of schooling and the six outcomes increase in magnitude. However, upon adjusting for children's

\footnotetext{
${ }^{32}$ Fig. A.15 links wage earnings and employment (measured at age 29) to full-range scores for the 1988 cohort illustrating that the divergence between how education and cognitive skills are associated with the outcomes also holds when considering the full test scores - that is, the divergence is not a result of the focus on the lower part of the cognitive skills distribution when we use the cognitive test score dummy.

${ }^{33}$ Table 3 shows the estimates $\beta_{t}^{U A}, \beta_{t}^{1}$ from regressions of children's outcomes $y_{i, t}^{C}$ on parents' years of schooling $E_{i, t}^{P}$ unadjusted and conditional on child years of schooling $E_{i, t}^{C}$ :

$y_{i, t}^{C}=\alpha_{t}+\beta_{t}^{U A} E_{i, t}^{P}+u_{i, t}$ and $y_{i, t}^{C}=\alpha_{t}+\beta_{t}^{1} E_{i, t}^{P}+\gamma E_{i, t}^{C}+\hat{u}_{i, t}$
} 
years of schooling, we see substantially muted trends for all outcomes, with several estimates for which differences are only borderline statistically significant (with sample sizes of around 100,000 observations). ${ }^{34}$ In other words, these results suggest that parents' education is increasingly associated with many of the children's life outcomes, but this increase is almost fully accounted for by the increasing association between parents' and children's education (i.e., the recent decrease in educational mobility). Thus, in spite of generous public policies aimed at leveling the playing field in Denmark, family background plays an increasing role in determining both schooling and post-schooling outcomes.

\section{Conclusion}

This paper documents substantial changes to intergenerational educational mobility for cohorts born during most of the 20th century in Denmark using both total population register data and historical survey data.

We link the major changes in educational mobility to how education expanded at different levels across the century. While Denmark is widely regarded as having high levels of educational mobility in international comparisons, our results show that this is only true for a relatively small subset of birth cohorts born in the 1950s and 1960s. These cohorts benefited from the major schooling reforms in 1958 and 1972, which led to a substantial compression of the schooling distribution at its lower tail. For cohorts born before these reforms came into place, educational mobility was much lower. Furthermore, for the youngest cohorts born during the 1970s and 1980s, educational mobility declined in tandem with the expansion of education at the college and university level.

\footnotetext{
${ }^{34}$ In line with these findings, Markussen and Røed (2019) find that economic mobility in Norway has been decreasing over a 20-year period.
} 
An increasing association between parents' education and the probability that children continue to college or university after high school completion is the main driver of the decline in mobility. Thus our overall findings suggest that educational mobility is highly dependent on how schooling distributions change over time.

Throughout the paper we contrast the Danish trends with those for the U.S. While mobility was far higher in Denmark than in the U.S. for the cohorts born during the 1950s and 1960s, educational mobility today is at par in the two countries. The recent convergence in rates of educational mobility between the two countries is surprising given the very different levels and types of welfare policies offered in the two countries. Indeed, because the youngest cohorts in Denmark born in the 1970s and 1980s have experienced - among other welfare services - universal high-quality childcare, free access to colleges and universities, and generous public education support, we would not expect them to experience rates of mobility similar to the US or to cohorts born in the mid-1940s who did not experience similar levels of welfare services.

Our study also draws on rich cognitive skill data from conscription records to examine how the relationship between skills and schooling changes. We find that the compression at the lower tail of the schooling distribution for cohorts born in the 1950s and 1960s strongly reduced the association between education and cognitive skills. We also present evidence suggesting that, while cognitive skills have become less predictive of educational attainment over time, non-cognitive skills appear to become more predictive. Moreover, the associations between education on the one hand and life outcomes such as earnings, employment, health, marital status, or crime on the other have become stronger for more recent Danish cohorts. Parental background is thus - via the mediating role of child education-becoming an increasingly important contributor to inequality across various life domains in Denmark. 
Given that our study documents how rapidly levels of educational mobility can change within a single country over time, it also points to the inherent difficulties in interpreting geographical differences in intergenerational social mobility. For example, levels of educational mobility in Denmark and the U.S. both differ strongly and are very similar within a relative small birth cohort window (e.g., cohorts born in the 1970s compared to those born in the 1980s). Thus snapshot estimates of mobility do not necessarily represent what is occurring in steady-state, and conclusions drawn from comparisons of different geographical areas may be highly dependent on the particular cohorts included.

Our findings highlight some of the challenges that promoting the political ideal of equality of opportunity entails. Despite universal childcare, tuition-free education, and generous public education support, educational mobility has been rapidly declining in Denmark, primarily because children of well-educated parents predominantly are those who have seized the opportunities caused by the expansion of colleges and universities in the most recent cohorts. Insofar as substantial inequalities in life outcomes persist in spite of the equal service procision, then origins of social immobility must lie elsewhere. 


\section{References}

Almlund, M., A. L. Duckworth, J. J. Heckman, and T. Kautz (2011). Personality psychology and economics. In E. A. Hanushek, S. Machin, and L. Wößmann (Eds.), Handbook of the Economics of Education, Volume 4, Chapter 1, pp. 1-181. Amsterdam: Elsevier B. V.

Banks, J. and F. Mazzonna (2012). The effect of education on old age cognitive abilities: Evidence from a regression discontinuity design. PNAS 122(5), 418-448.

Bhuller, M., M. Mogstad, and K. G. Salvanes (2017). Life-cycle earnings, education premiums, and internal rates of return. Journal of Labor Economics $35(4)$.

Bingley, P. and A. Martinello (2017). The effects of schooling on wealth accumulation approaching retirement. Technical Report Working Papers 2017:9, Lund University, Department of Economics.

Björklund, A. and K. G. Salvanes (2011). Education and family background: Mechanisms and policies. The Handbook of Economics of Education. Elsevier.

Black, S. E. and P. J. Devereux (2011). Recent Developments in Intergenerational Mobility, Volume $4 \mathrm{~b}$ of The Handbook of Labor Economics. Elsevier.

Black, S. E., P. J. Devereux, and K. G. Salvanes (2005, March). Why the apple doesn't fall far: Understanding intergenerational transmission of human capital. American Economic Review 95(1), 437-449.

Blanden, J., P. Gregg, and L. Macmillan (2007). Accounting for intergenerational income persistence: Noncognitive skills, ability and education. The Economic Journal 117(519), 43-60. 
Boudon, R. (1974). Education, Opportunity, and Social Inequality: Changing Prospects in Western Society. Wiley-Interscience, New York, New York.

Bound, J., M. F. Lowenheim, and S. Turner (2010). Why have college completion rates declined? an analysis of changing student preparation and college resources. American Economic Journal: Applied Economics 3(2), 129-157.

Breen, R. and J. O. Jonsson (2005). Inequality of opportunity in comparative perspective: Recent research on educational attainment and social mobility. Annual Review of Sociology 31, 223-243.

Brinch, C. and T. A. Galloway (2012). Schooling in adolescence raises iq scores. PNAS 109(2), 425-430.

Cameron, S. V. and J. J. Heckman (1998). Life cycle schooling and dynamic selection bias: Models and evidence for five cohorts of american males. Journal of Political Economy 106(2), 262-333.

Card, D. and T. Lemieux (2001). Dropout and enrollment trends in the post-war period: What went wrong in the 1970s? In J. Gruber (Ed.), Risky Behavior Among Youths : An Economic Analysis, pp. 439-482. Chicago, IL: University of Chicago Press.

Castex, G. and E. K. Dechter (2014). The changing roles of education and ability in wage determination. Journal of Labor Economics 32(4).

Chetty, R., J. N. Friedman, N. Hendren, M. R. Jones, and S. R. Porter (2018). The opportunity atlas: Mapping the childhood roots of social mobility. Technical Report 25147, NBER Working Paper. 
Chetty, R., N. Hendren, P. Kline, and E. Saez (2014). Where is the land of opportunity? The geography of intergenerational mobility in the United States. Quarterly Journal of Economics 129(4), $1553-1623$.

Chevalier, A. (2004). Parental education and child'soutcomes: A natural experiment. Technical Report 1153, IZA.

Christensen, G. T., D. Molbo, L. H. Angquist, E. L. Mortensen, K. Christensen, T. I. A. Sorensen, and M. Osler (2015). Cohort profile: The danish conscription database (dcd): a cohort of 728160 men born from 1939 through 1959. International Journal of Epidemiology 44 (2), 432-440.

Corak, M. (2013, Summer). Income inequality, equality of opportunity, and intergenerational mobility. Journal of Economic Perspectives 27(3), 79-102.

Currie, J. and E. Moretti (2003). Mothers education and the intergenerational transmission of human capital: Evidence from college openings. The Quarterly Journal of Economics 118(4), $1495-1532$.

de Coninck-Smith, N. and L. R. Rasmussen (2015). Dansk skolehistorie, Bind 5 - da skolen blev alles; efter 1970. Dansk Skolehistorie, Hverdag, vilkår og visioner gennem 500 år.

Edin, P.-A., P. Fredriksson, M. Nybom, and B. Ockert (2018). The rising return to non-cognitive skills. Technical Report Working paper 2018:15, Department of Economics, Uppsala University.

Erikson, R. and J. H. Goldthorpe (2002). Intergenerational inequality: A sociological perspective. Journal of Economic Perspectives 16(3), 31-44.

Fletcher, J. M. and J. Han (2019). Intergenerational mobility in education: Variation in geography and time. Journal of Human Capital 13(4), 585-834. 
Gjerløff, A. K. and A. F. Jacobsen (2014). Dansk skolehistorie, Bind 3 - da skolen blev sat $i$ system; 1850-1920. Dansk Skolehistorie, Hverdag, vilkår og visioner gennem 500 år.

Gjerløff, A. K., A. F. Jacobsen, E. Nøgaard, and C. Ydesen (2014). Dansk skolehistorie, Bind 4 da skolen blev sin egen; 1920-1970. ansk Skolehistorie, Hverdag, vilkår og visioner gennem 500 år.

Goldin, C. (1998). America's graduation from high school: The evolution and spread of secondary schooling in the twentieth century. The Journal of Economic History 58(2), 345-374.

Goldin, C. and L. F. Katz (1999). The shaping of higher education: The formative years in the united states, 1890 to 1940. Journal of Economic Perspectives 13(1), 37-62.

Goldin, C. and L. F. Katz (2007). Long-run changes in the wage structure. Technical Report 2, Brookings Papers on Economic Activity.

Guell, M., M. Pellizzari, G. Pica, and J. V. R. Mora (2018). Correlating social mobility and economic outcomes. The Economic Journal 612(2), F353-F403.

Havnes, T. and M. Mogstad (2011). No child left behind: Subsidized child care and children's long-run outcomes,. American Economic Journal: Economic Policy, American Economic Association 3(2).

Heckman, J. J., J. E. Humphries, and N. Mader (2011). The GED. In E. A. Hanushek, S. Machin, and L. Wößmann (Eds.), Handbook of the Economics of Education, Volume 3, Chapter 9, pp. 423-484. Amsterdam: North Holland, Elsevier.

Heckman, J. J. and P. A. LaFontaine (2010, May). The American high school graduation rate: Trends and levels. Review of Economics and Statistics 92(2), 244-262. 
Hertz, T., T. Jayasundera, P. Piraino, S. Selcuk, N. Smith, and A. Verashchagina (2008, January). The inheritance of educational inequality: International comparisons and fifty-year trends. B. E. Journal of Economic Analysis 65 Policy 7(2), 1-46.

Hilger, N. G. (2017). The great escape: Intergenerational mobility in the united states, 1930-2010.

Hjorth-Trolle, A. and A. Holm (2021). Double (dis)advantage: The development of socioeconomic gaps in academic achievement in the u.s. and denmark. Technical report, Working paper.

Hout, M. and A. Janus (2011). Educational Mobility in the United States since the 1930s, pp. 165-185. Whither Opportunity? Rising Inequality, Schools, and Children's Life Chances. Russell Sage Foundation.

Kousgaard, E. (2015). 50 år med intelligensprøven. Technical report, Institut for militaerpsykologi, Forsvarsakademiet.

Lundborg, P., A. Nilsson, and D.-O. Rooth (2014). Parental education and offspring outcomes: Evidence from the swedish compulsory school reform. American Economic Journal: Applied Economics 6(1).

Mare, R. D. (1980). Social background and school continuation decisions. Journal of the American Statistical Association 75 (370), 295-305.

Mare, R. D. (1981). Change and stability in educaitonal stratification. American Sociological Review 46(1), 72-87.

Markussen, S. and K. Røed (2019). Economic mobility under pressure. Journal of the European Economic Association 18(4), 1844-1885. 
Meghir, C. and M. Palme (2005, March). Educational reform, ability and family background. American Economic Review 95(1), 414-424.

Mortensen, E. L., J. M. Reinisch, and T. W. Teasdale (1989). Intelligence as measured by the wais and a military draft board group test. Scandinavian Journal of Psychology 30(4), 318-318.

Nielsen, H. S., T. Sorensen, and C. Taber (2010). Estimating the effect of student aid on college enrollment: Evidence from a government grant policy reform. American Economic Journal, Economic Policy 2(2), 185-215.

Nybom, M. and J. Stuhler (2016). Heterogeneous income profiles and lifecycle bias in intergenerational mobility estimation. The Journal of Human Resources 51(1), 239-268.

Oreopoulos, P. (2006, March). Estimating average and local average treatment effects of education when compulsory schooling laws really matter. American Economic Review 96(1), 152-175.

Oreopoulos, P., M. E. Page, and A. H. Stevens (2003). Does human capital transfer from parent to child? the intergenerational effects of compulsory schooling. Technical Report 10164, NBER Working Paper.

Piopiunik, M. (2014). Intergenerational transmision of education and mediating channels: Evidence from a compulsory schooling reform in germany. The Scandinavian Journal of Economics 116(3), 878-907.

Pischke, J.-S. and T. von Wachter (2008). Zero returns to compulsory schooling in germany: Evidence and interpretation. Review of Economics and Statistics 90(3).

Reardon, S. F. and G. Firebaugh (2002). Measures of multigroup segregation. Sociological Methodology 32, 33-67. 
Roemer, J. E. and A. Tranmoy (2015). Equality of Opportunity, Volume 2 of Handbook of Income Distribution. Elsevier.

Rosenberg, M. (1965). Society and the Adolescent Self-Image. Princeton, NJ: Princeton University Press.

Statistics Denmark (2001). 50-year review. Technical report.

Statistics Denmark (2015). Kvinder og maend i 100 aar - fra ligeret mod ligestilling. Technical report.

Theil, H. (1973). Statistical decomposition analysis; with applications in the social and administrative sciences. North-Holland, London.

White House Office of Management and Budget (2020). Table 14.5-total government expenditures by major category of expenditure as percentages of gdp: 1948-2019. Technical report. 
Figure 1: Educational mobility and education levels by child birth year and country

\section{Educational mobility}

a) Children's years of schooling regressed on parents' years of schooling

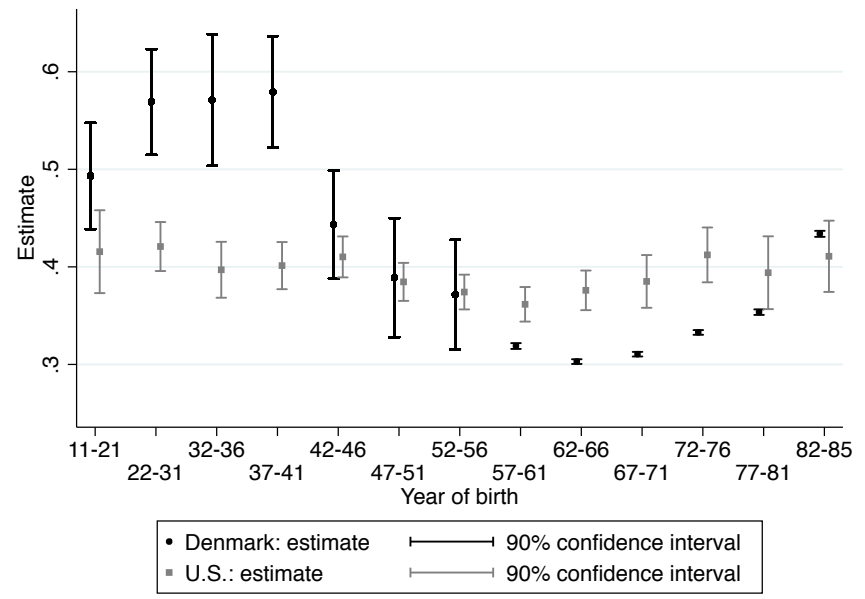

Average years of schooling

c) Denmark

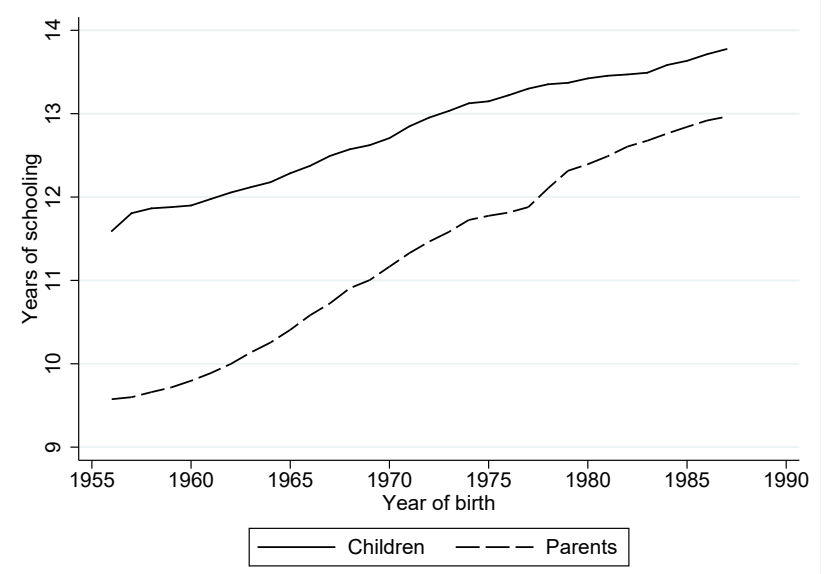

b) Upward mobility, children's years of schooling higher than parents' years of schooling

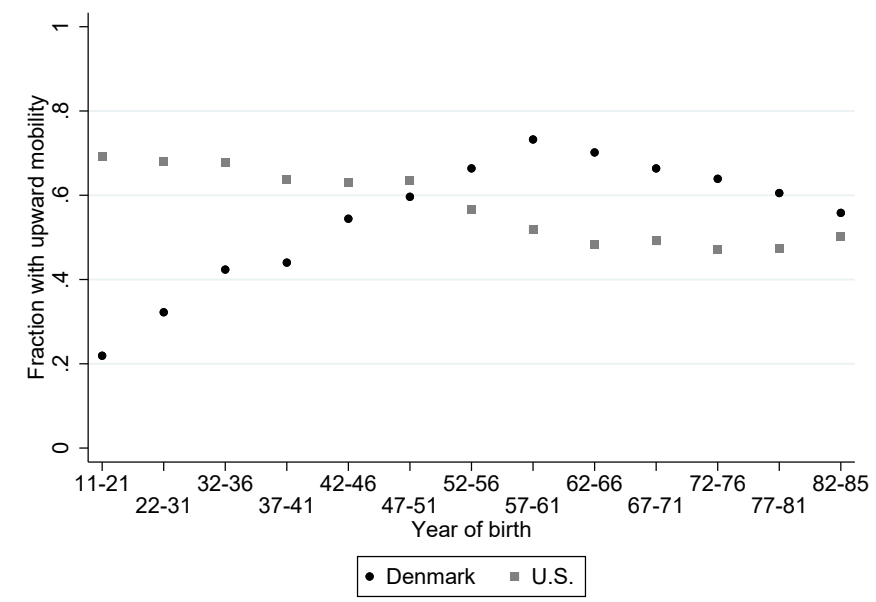

d) U.S.

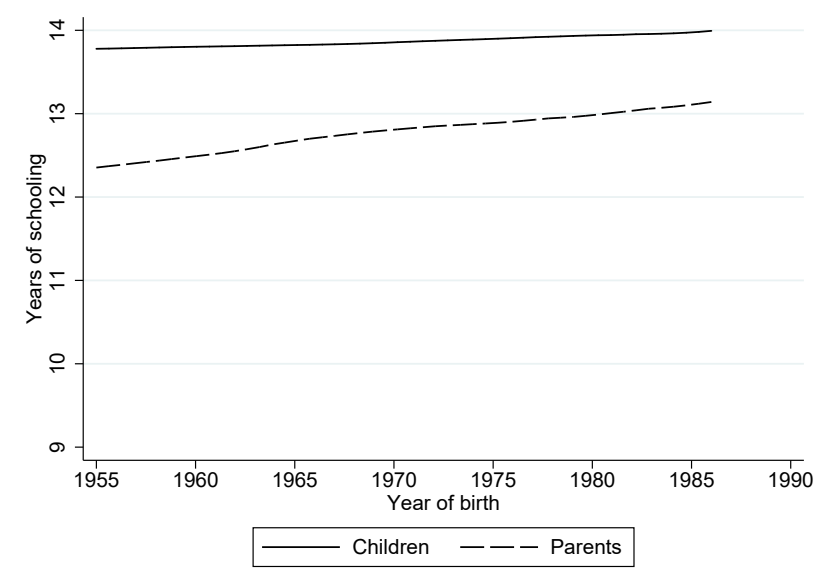

Note: Fig. a) shows educational mobility by birth year for Denmark and the U.S. estimated as the $\beta_{t}$ 's in: $E_{i, t}^{C}=\alpha_{t}+\beta_{t} E_{i, t}^{P}+u_{i, t}$, where $E_{i, t}^{C}, E_{i, t}^{P}$ are years of schooling of children and parents (max. of father and mother) in cohort bin $t$. Fig. b) shows upward mobility (the fraction with $E_{i, t}^{C}>E_{i, t}^{P}$ ). Figs. c) and d) show average years of schooling for children and their parents (highest level of father and mother) by birth year. Danish estimates are based on survey and register data, and U.S. estimates are based on the General Social Surveys (GSS). The data are described in Section 2 . 
Figure 2: The Danish education system at a glance

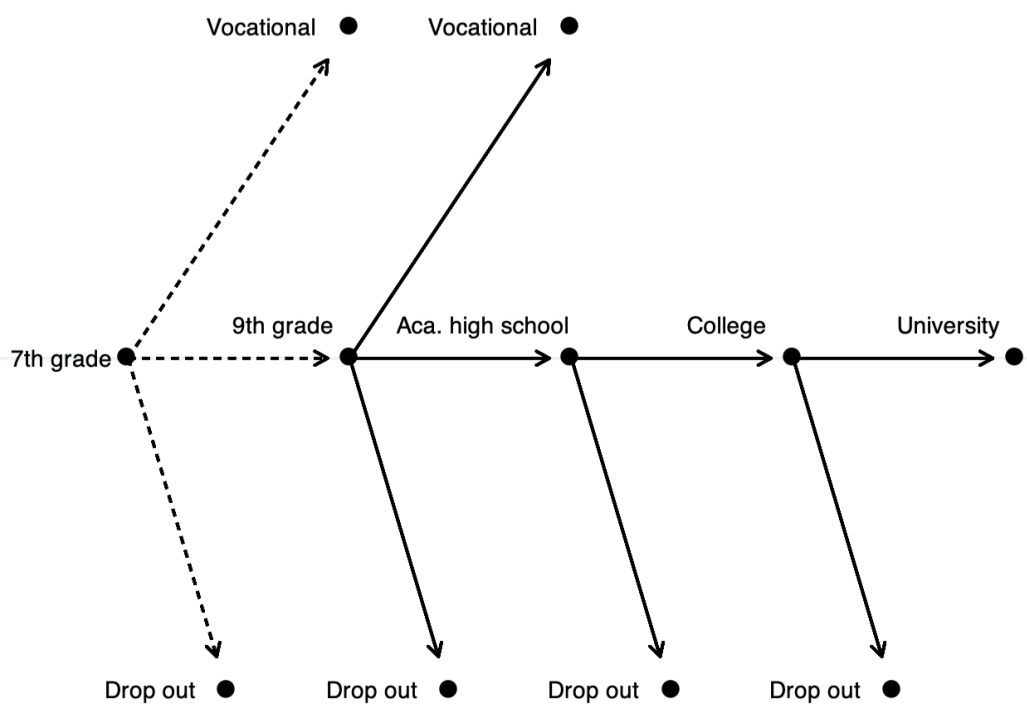

Note: The figure shows a stylized overview of the Danish educational system. The dashed line corresponds to education levels (decisions) that were available until the 1972 reform when compulsory schooling was increased to 9 years. 
Figure 3: Education levels by child birth year

a) Education levels, Denmark

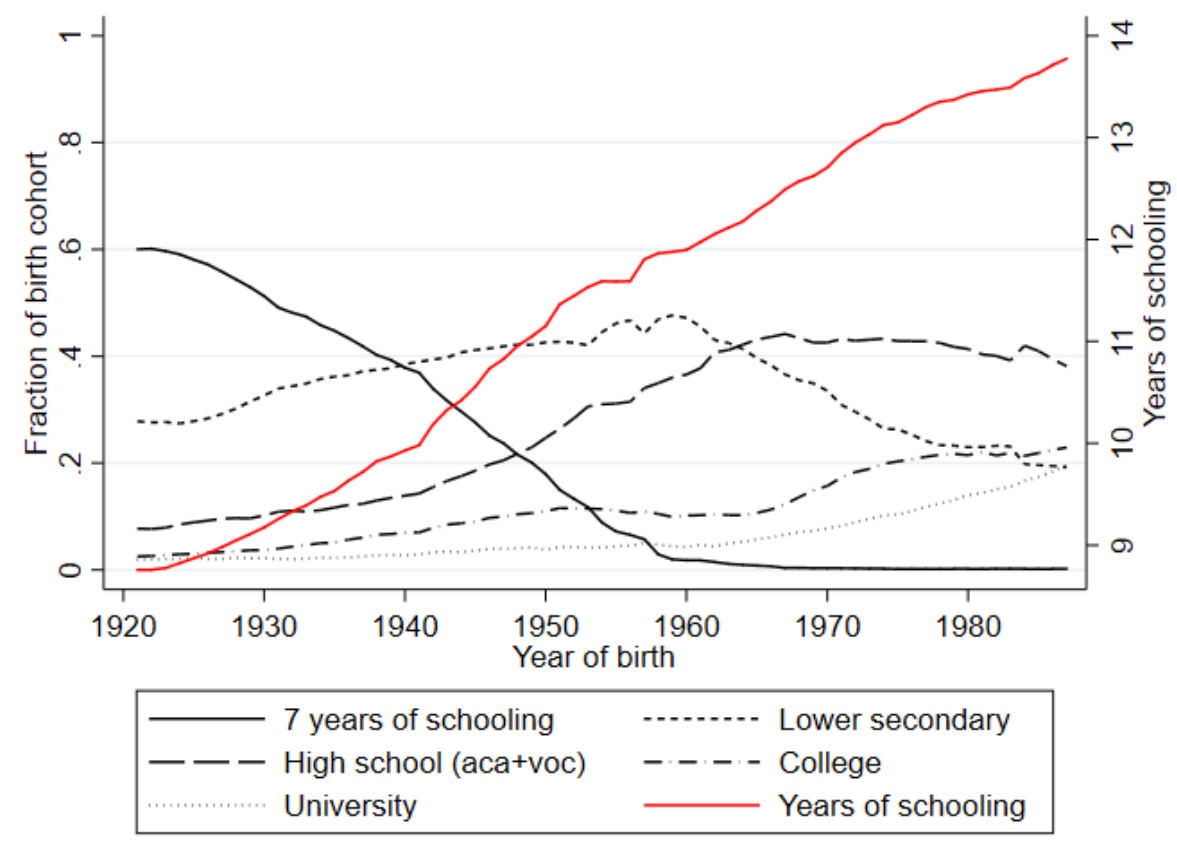

b) Aggregate education levels

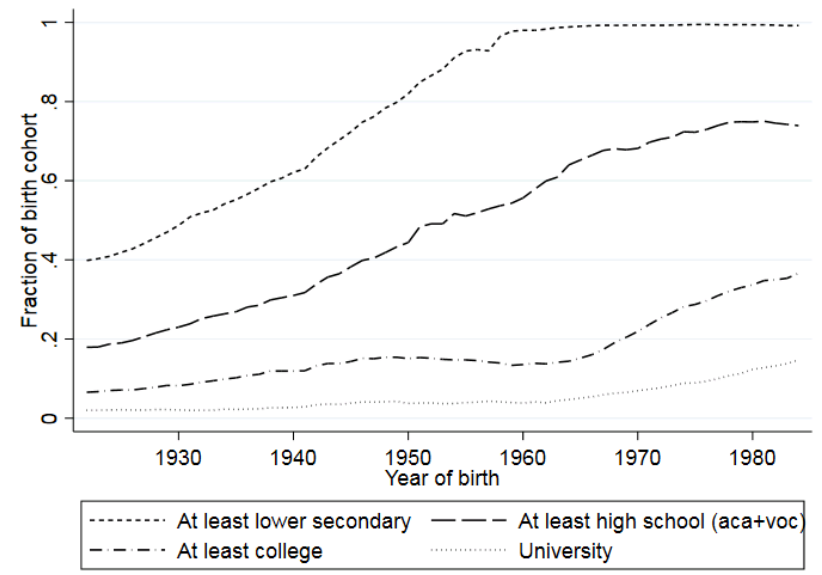

c) Year-by-year change in aggregate education levels

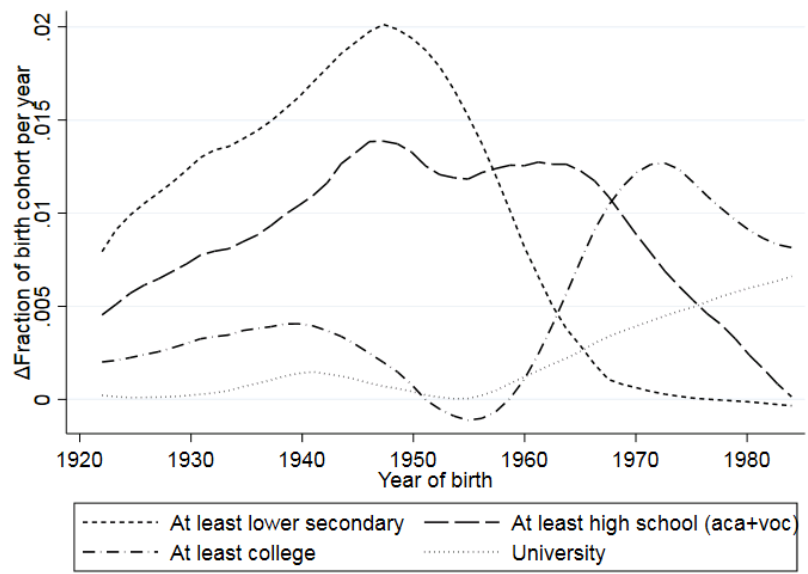

Note: Fig. a) shows discrete education levels and years of schooling by child birth cohort. Fig. b) shows aggregate education levels by birth cohort. Fig. c) shows year-by-year changes (i.e., the slopes in a). Education is measured in 1981 for cohorts born before 1951, and at age 30 for cohorts born after 1950. Lower secondary: 8-11.9 years; High school: 12-14.9 years; College: 15-16.9 years; University: 17-21.5 years. 
Figure 4: Impact of the 1958 reform on education and urban-rural gap

Proportion with no more than 7 years of schooling

a) Urban and rural areas

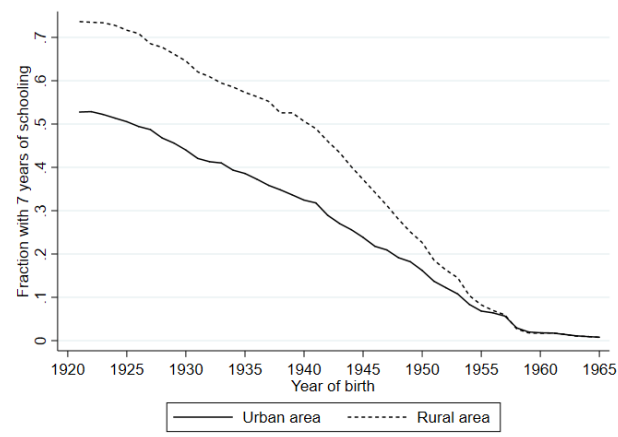

b) Urban-rural gap

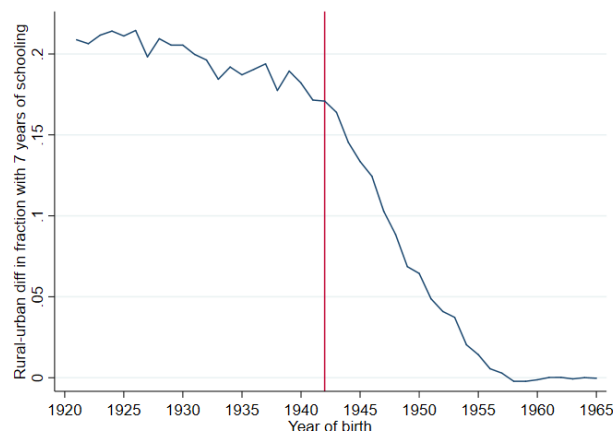

Average years of schooling

c) Urban and rural areas

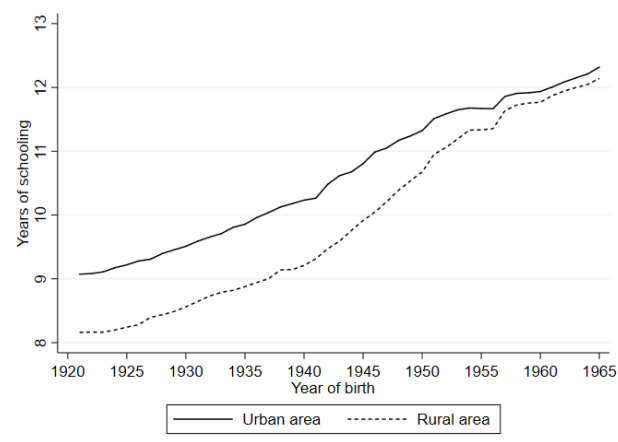

d) Urban-rural gap

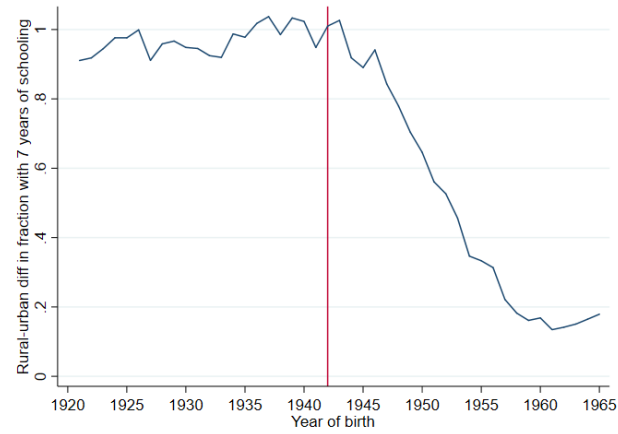

Average cognitive test scores

e) Urban and rural areas

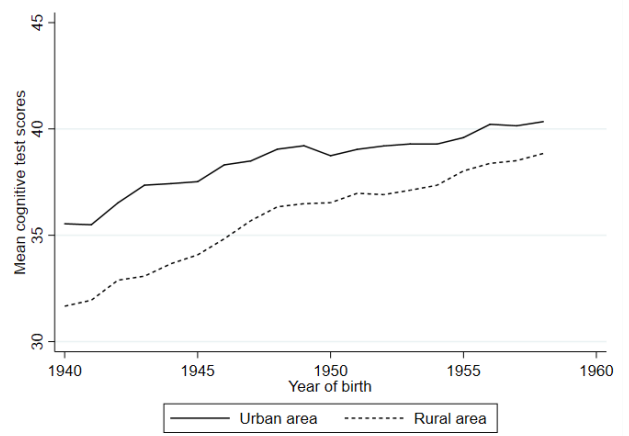

f) Urban-rural gap

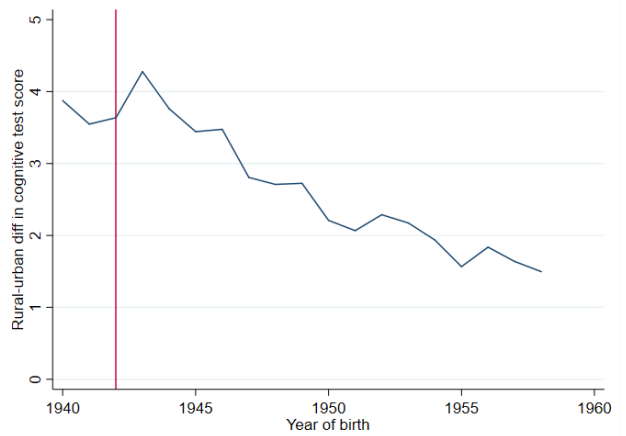

Note: Figs. a), c), and e) show the proportion with 7 years of schooling, total years of schooling, and average cognitive test scores by urban or rural areas by birth cohort from 1921 to 1962 (1940-1958 for test scores). Figs. b), d), and f) show the corresponding urban-rural gap. Education is measured in 1981 for cohorts born before 1951, and at age 30 for cohorts born after 1950. Fig. A.8 shows the full cognitive test score distribution in rural and urban areas for the birth cohorts 1940 and 1958. 


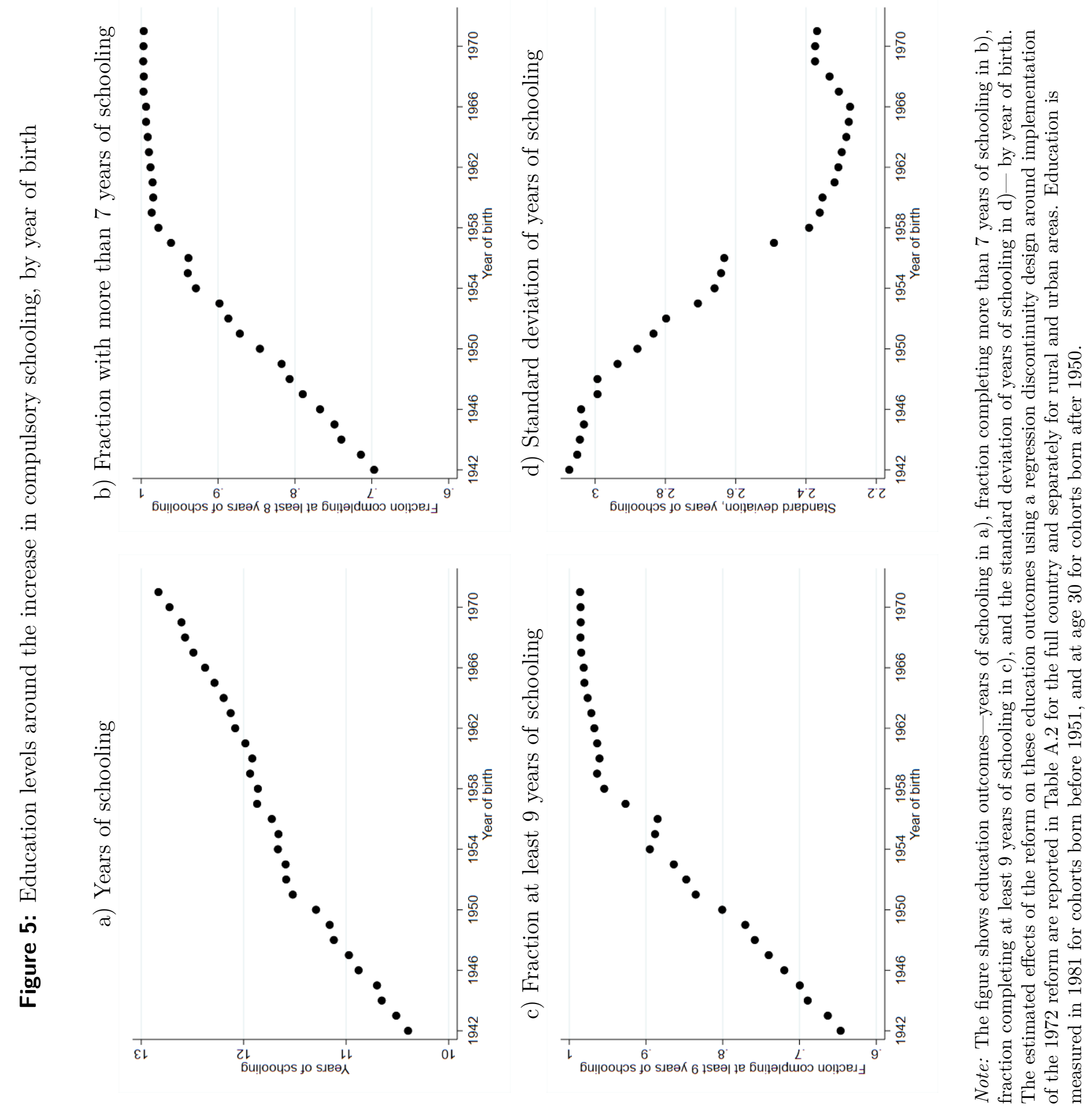


Figure 6: Education IGE by child birth year (1955-1987 birth cohorts)

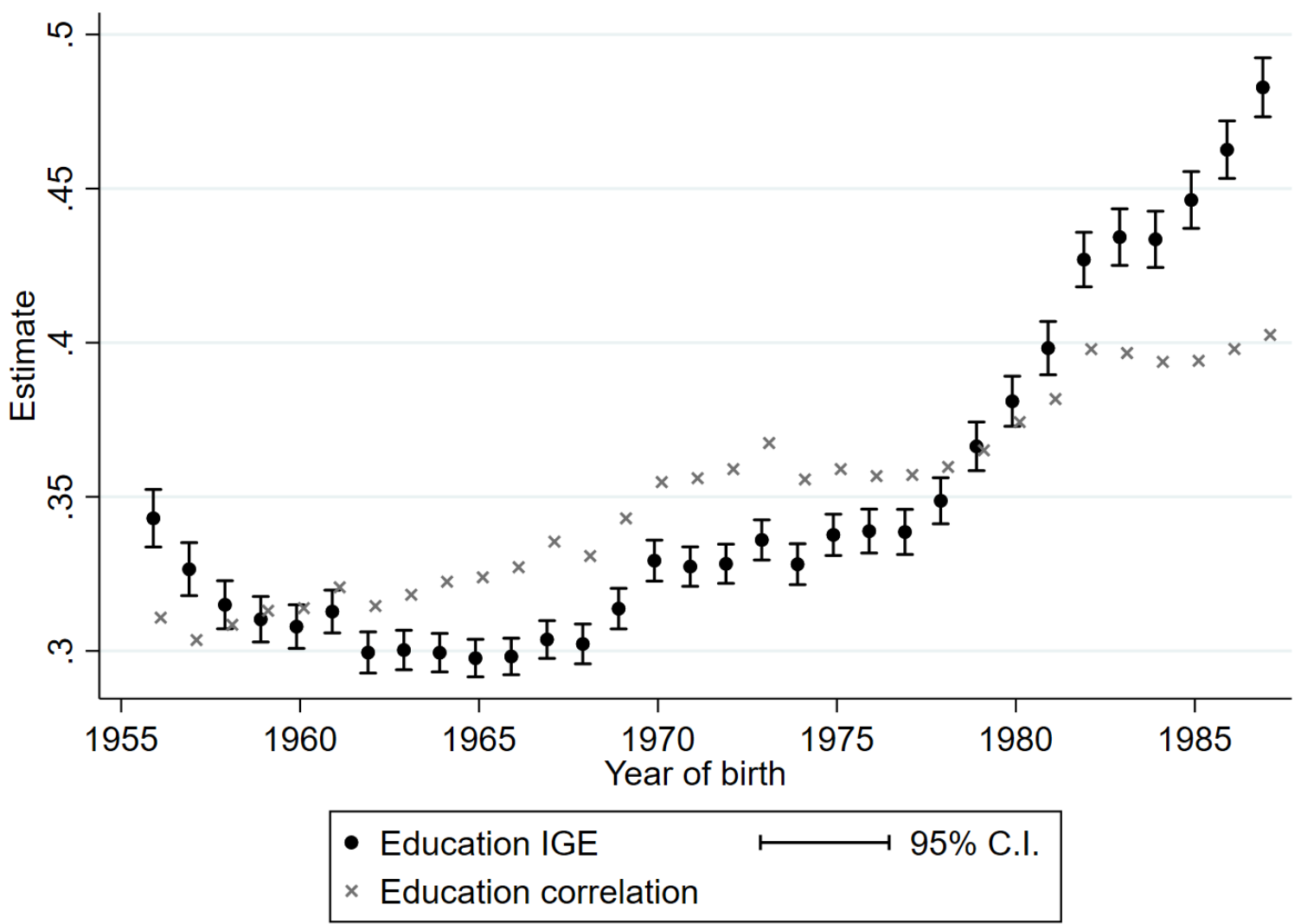

Note: The figure shows regression coefficients for a child years of schooling on parents' average years of schooling, and the correlation coefficients between parents' average years of schooling and child years of schooling, by child birth year. 
Figure 7: Percentages of birth cohorts making three education transitions

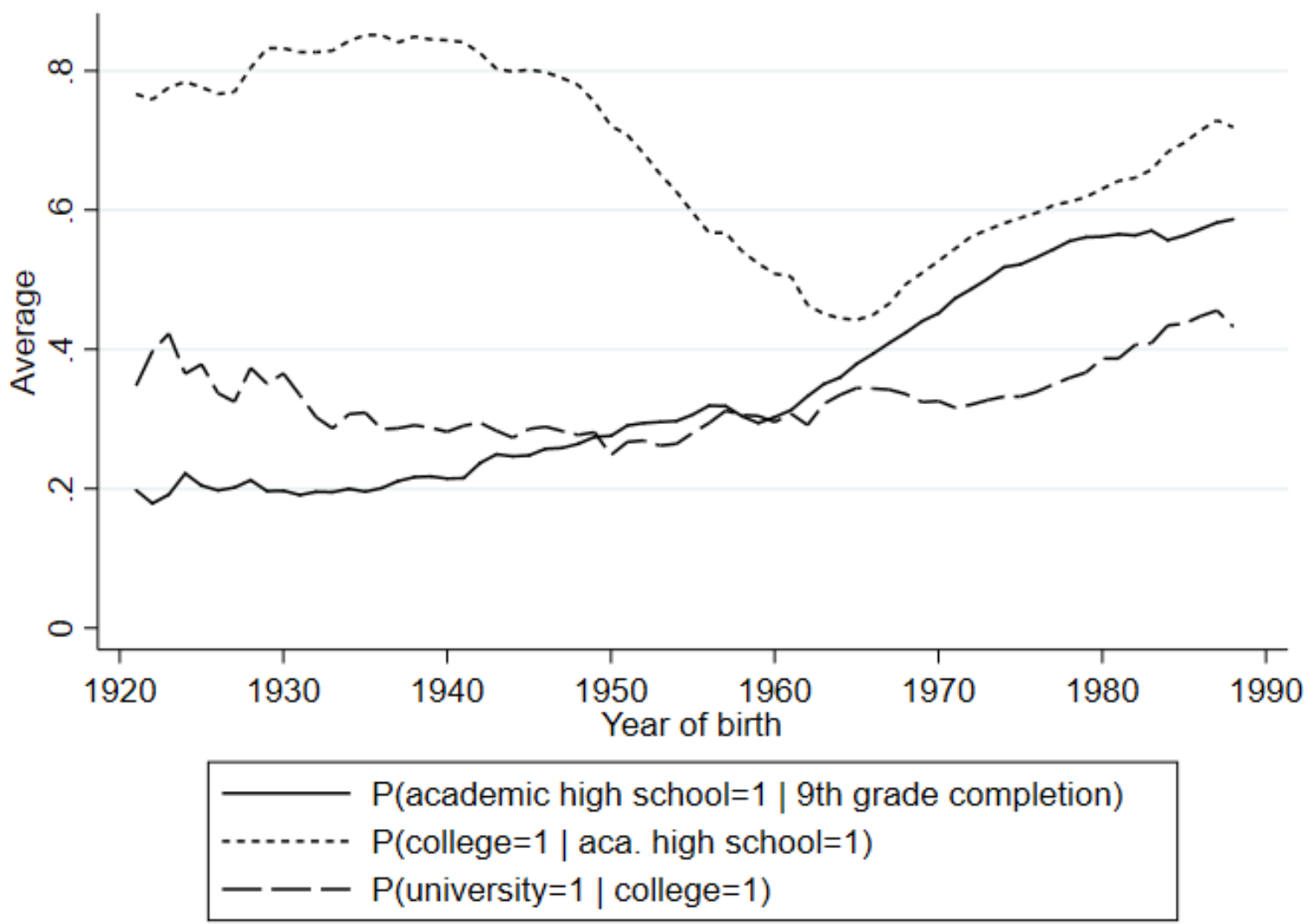

Note: Figure shows average education levels by birth year for cohorts born in 1921-1987. The solid line shows average academic high-school completion conditional on completion of 9th grade (which is the eligibility criterion). Short dashes show the probability of college completion conditional on academic high-school completion, and the long dashes show the probability of university completion conditional on completing a college degree. 


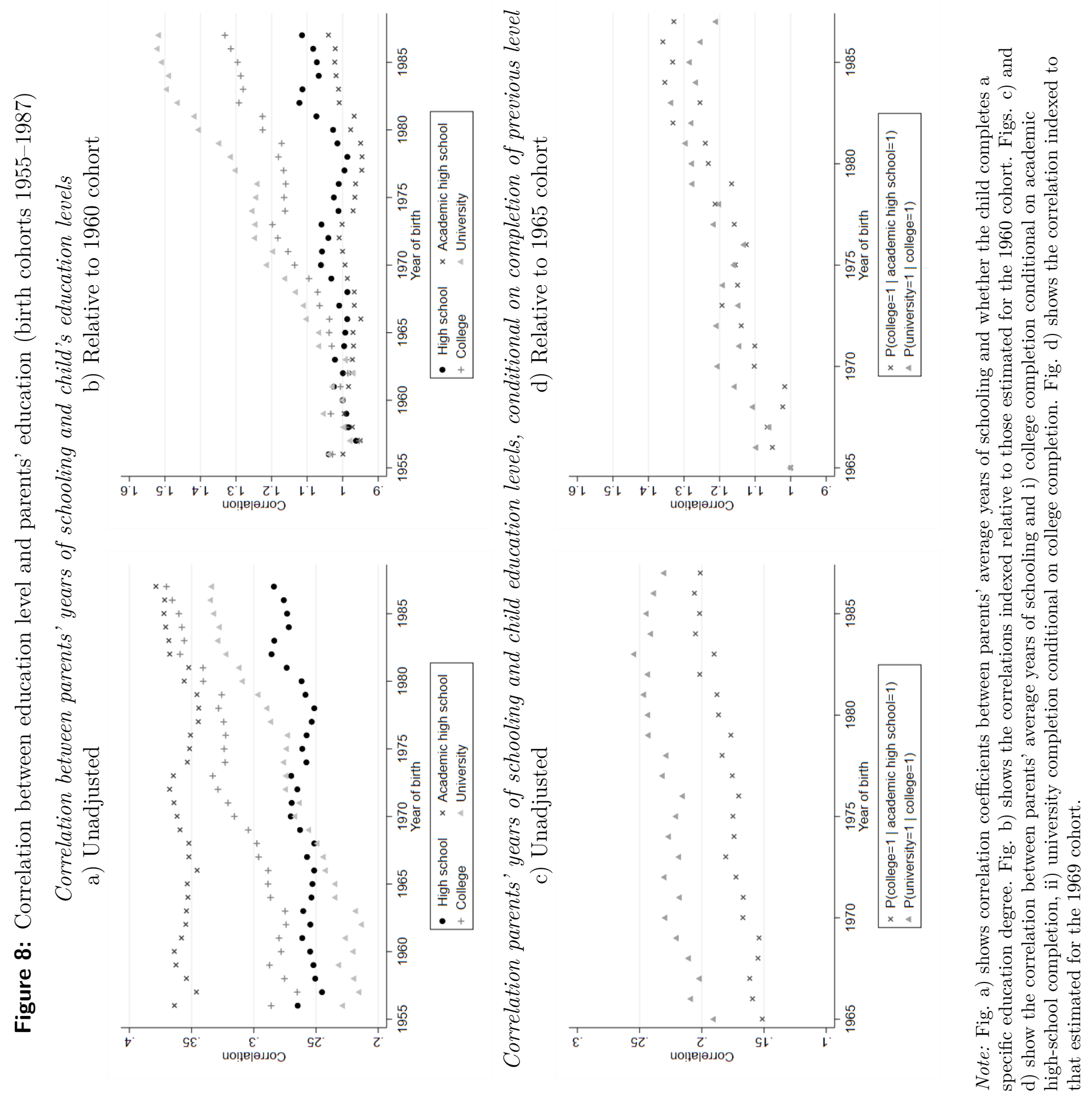


Figure 9: Simulated Education IGE by child birth year (1969-1987 birth cohorts)

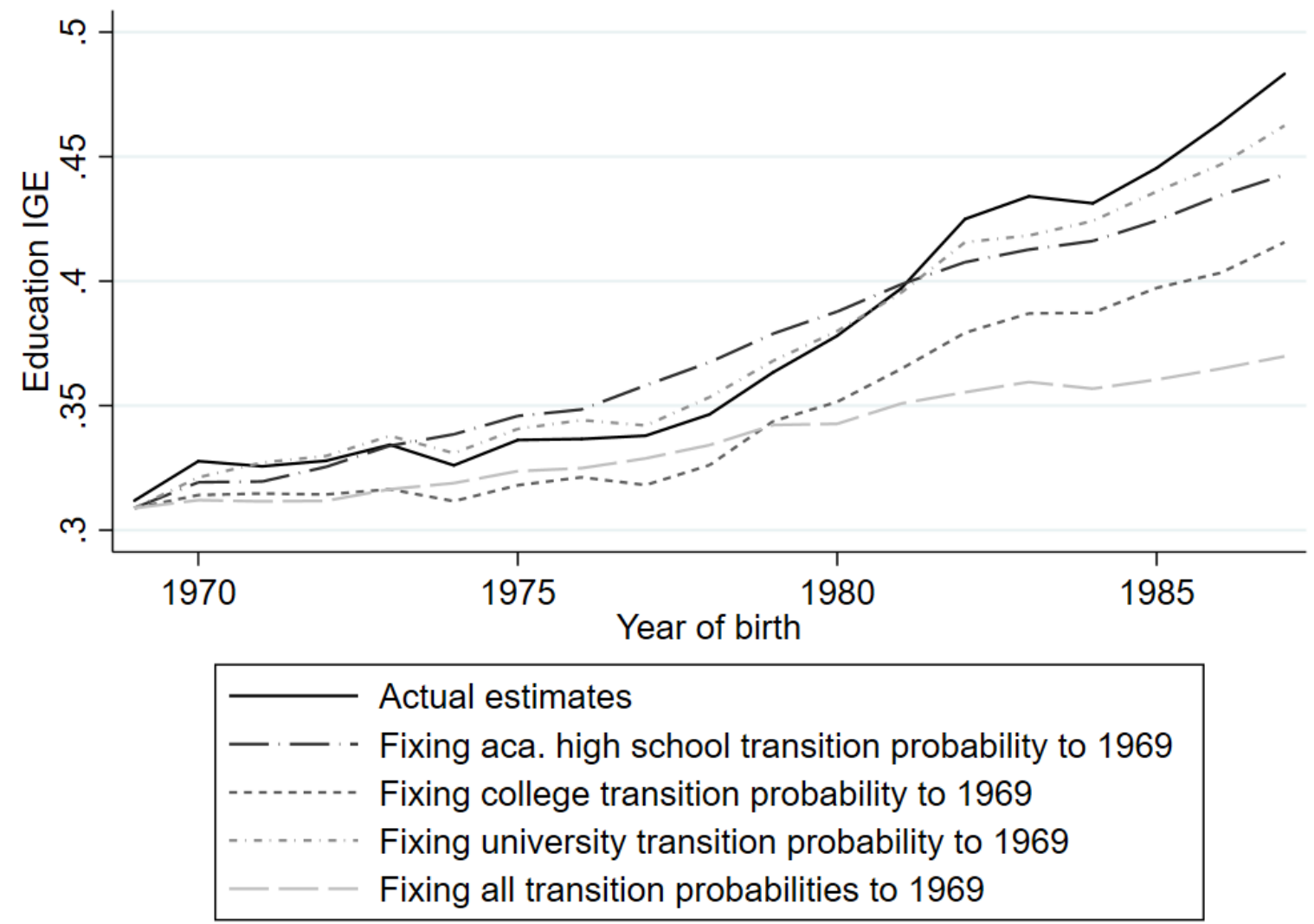

Note: The figure shows regression coefficients from regressions of child years of schooling on parents' average years of schooling, and the correlation coefficients between parents' average years of schooling and child years of schooling, by child birth year. 
Figure 10: Cognitive test score ranks, by birth year and country

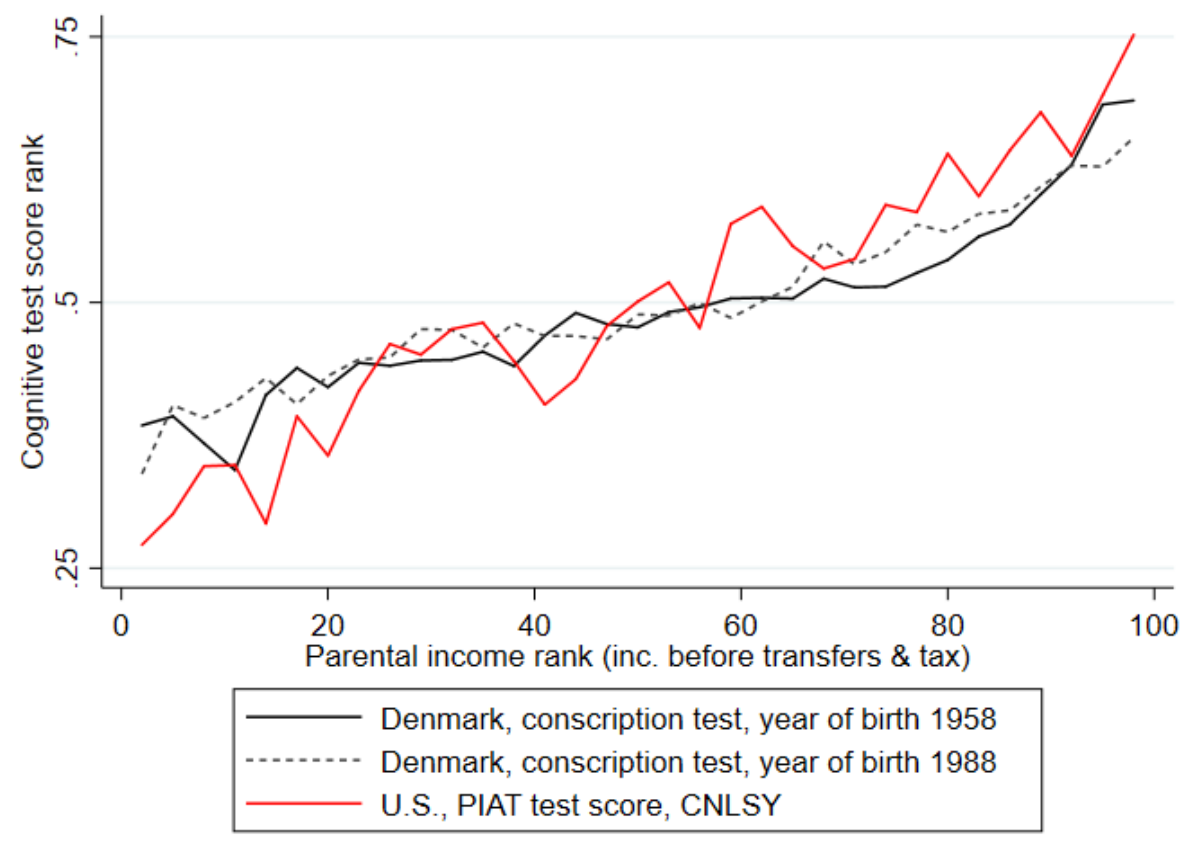

Note: The figure shows the correlation coefficient between children's cognitive test scores ranks (Denmark: measured at conscription at age 18. U.S.: PIAT test scores measured at age 14 from the CNLSY by their parents' income rank (total gross income excluding public transfers). 


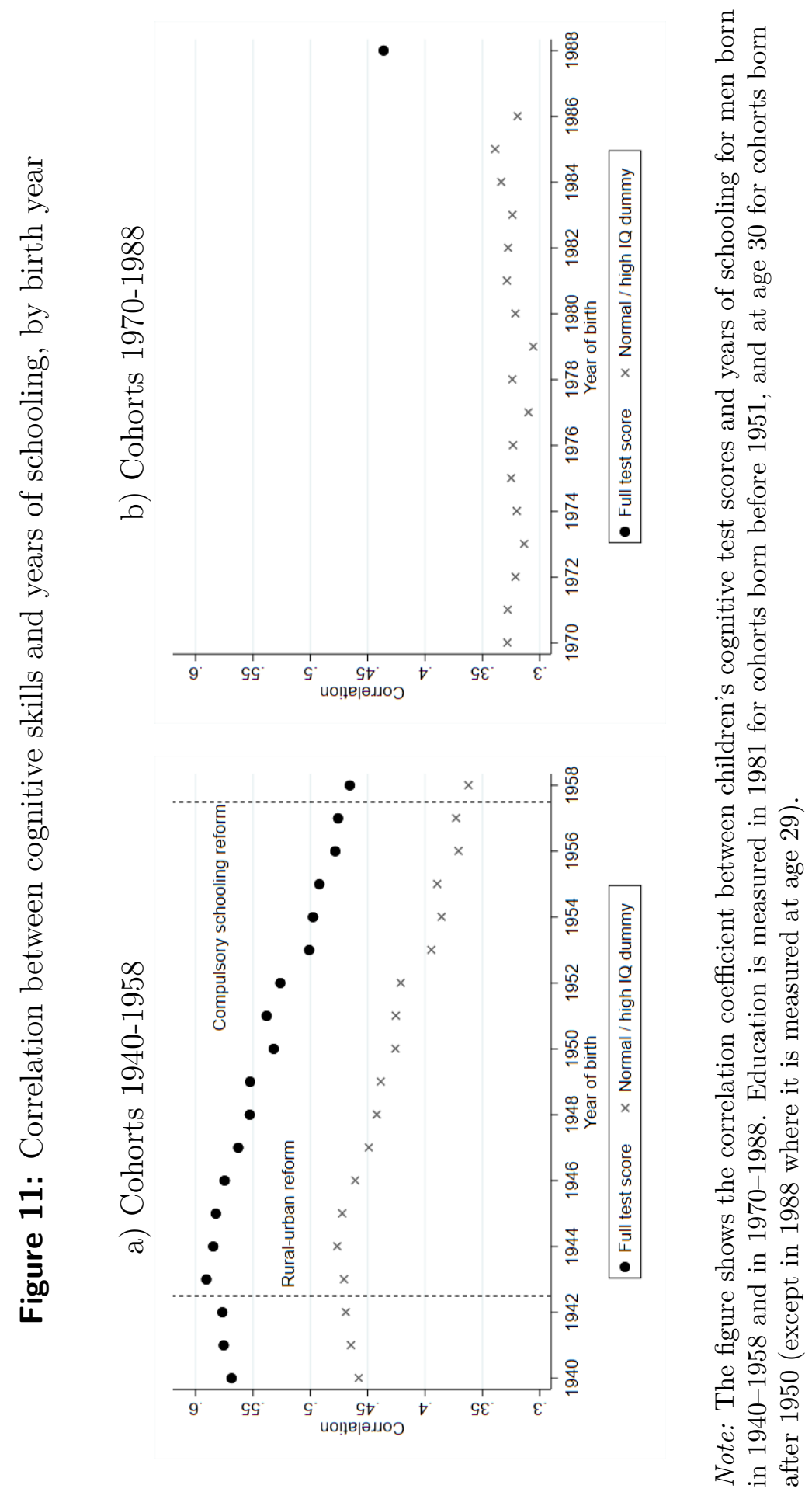




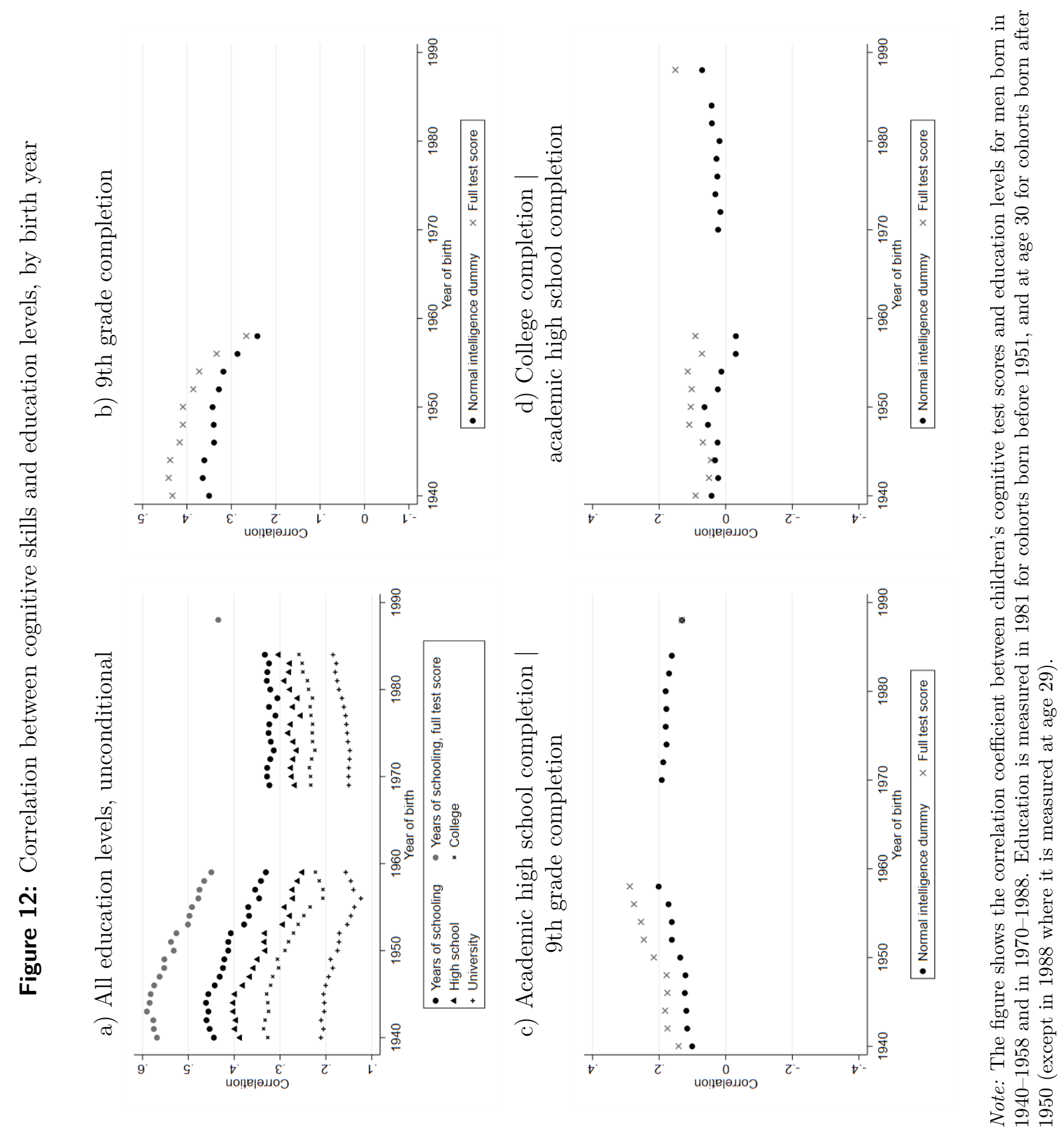


Figure 13: Correlation between years of schooling/cognitive skills and other outcomes

a) Wage earnings percentile, age 34-36

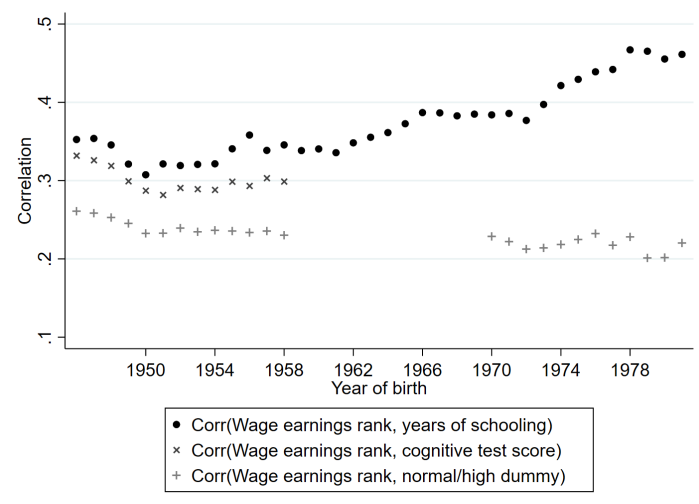

c) Health score, age 18

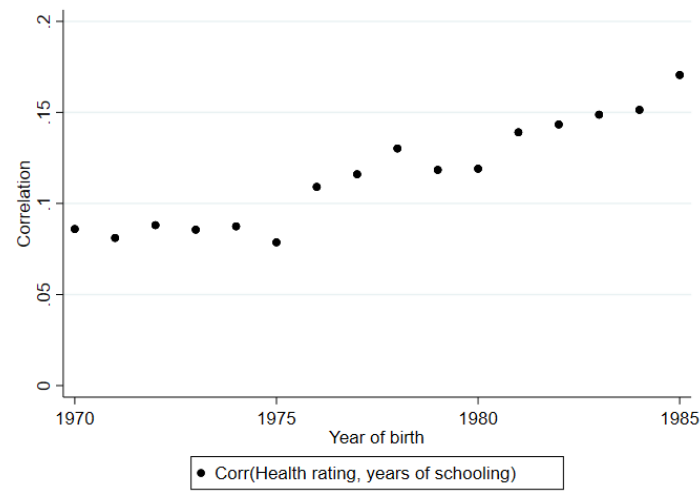

e) $\mathrm{P}$ (married), age 35

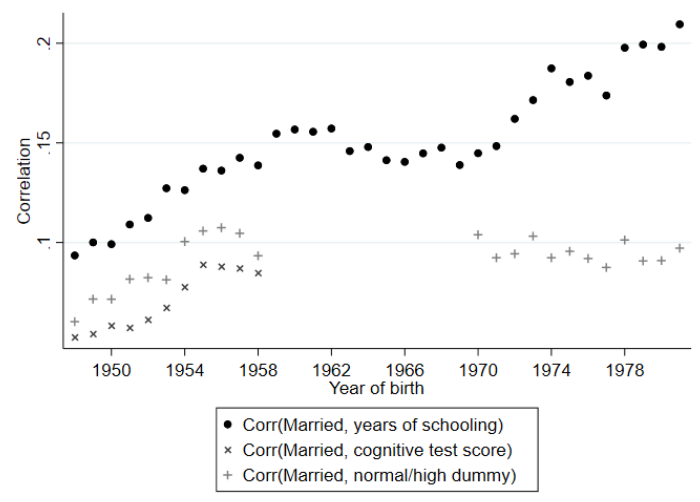

b) $\mathrm{P}$ (employment), age 34-36

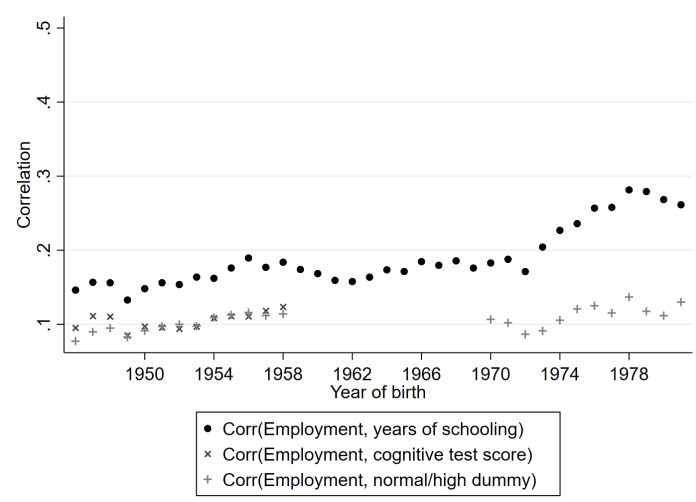

d) Health, problems age 18

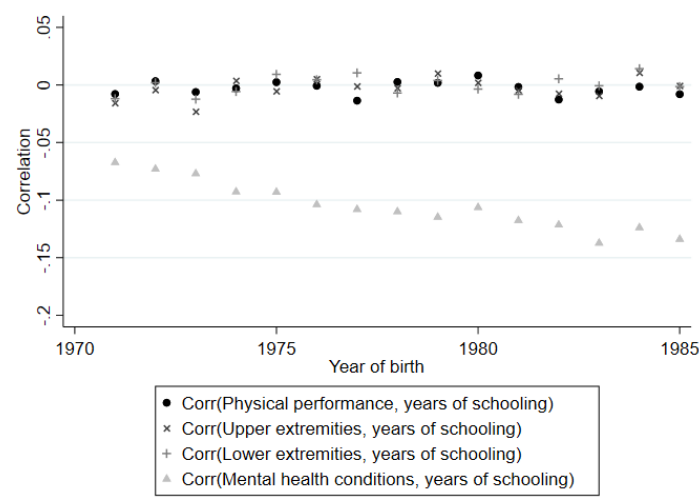

f) $\mathrm{P}$ (Youth crime), age 15-17

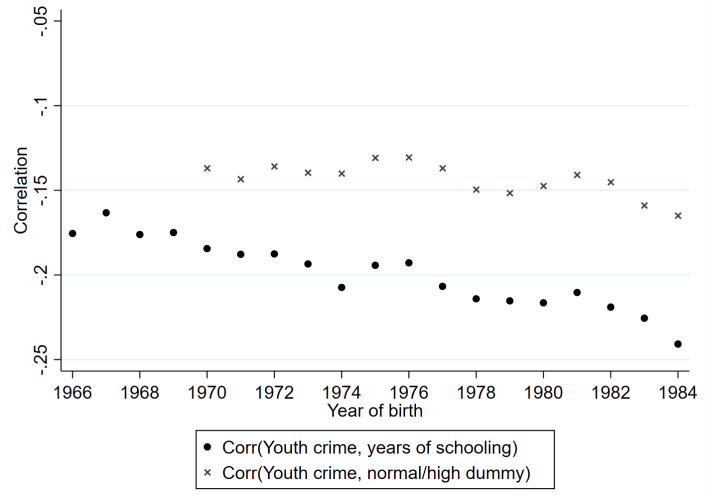

Note: The figure shows correlation coefficients between outcomes (wage earnings percentiles / employment / health / marriage / youth crime) and years of schooling, full cognitive test scores (when available), and the normal cognitive test score dummy. Education is measured in 1981 for cohorts born before 1951, and at age 30 for cohorts born after 1950 . 
Table 1: Education IGE by rural-urban origin and child birth year

\begin{tabular}{|c|c|c|c|c|c|c|}
\hline & \multicolumn{3}{|c|}{ A) 1958 reform (survey data) } & \multicolumn{3}{|c|}{ B) 1972 reform (register data) } \\
\hline & $\begin{array}{c}\text { Pre-reform } \\
1932-1941\end{array}$ & $\begin{array}{c}\text { Post-reform } \\
1942-1951\end{array}$ & $\begin{array}{l}\text { Pre-post } \\
\text { Difference }\end{array}$ & $\begin{array}{c}\text { Pre-reform } \\
1956\end{array}$ & $\begin{array}{c}\text { Post-reform } \\
1958\end{array}$ & $\begin{array}{l}\text { Pre-post } \\
\text { Difference }\end{array}$ \\
\hline Full country & & & & & & \\
\hline$\beta^{I G E}$ & $\begin{array}{c}0.579 \\
(0.027)\end{array}$ & $\begin{array}{c}0.424 \\
(0.025)\end{array}$ & $\begin{array}{c}-0.156^{* * *} \\
(0.037)\end{array}$ & $\begin{array}{c}0.343 \\
(0.005)\end{array}$ & $\begin{array}{c}0.315 \\
(0.004)\end{array}$ & $\begin{array}{c}-0.028^{* * *} \\
(0.006)\end{array}$ \\
\hline Correlation & 0.517 & 0.410 & $-0.107^{* * *}$ & 0.311 & 0.309 & -0.002 \\
\hline Urban areas & & & & & & \\
\hline$\beta^{I G E}$ & $\begin{array}{c}0.476 \\
(0.038)\end{array}$ & $\begin{array}{c}0.438 \\
(0.039)\end{array}$ & $\begin{array}{l}-0.039 \\
(0.054)\end{array}$ & $\begin{array}{c}0.350 \\
(0.005)\end{array}$ & $\begin{array}{c}0.326 \\
(0.004)\end{array}$ & $\begin{array}{c}-0.023^{* * *} \\
(0.007)\end{array}$ \\
\hline Correlation & 0.449 & 0.395 & -0.054 & 0.326 & 0.326 & 0.000 \\
\hline Rural areas & & & & & & \\
\hline$\beta^{I G E}$ & $\begin{array}{c}0.584 \\
(0.040)\end{array}$ & $\begin{array}{c}0.382 \\
(0.034)\end{array}$ & $\begin{array}{c}-0.203^{* * *} \\
(0.052)\end{array}$ & $\begin{array}{c}0.317 \\
(0.013)\end{array}$ & $\begin{array}{c}0.292 \\
(0.011)\end{array}$ & $\begin{array}{l}-0.024 \\
(0.017)\end{array}$ \\
\hline Correlation & 0.544 & 0.419 & $-0.125^{* * *}$ & 0.225 & 0.232 & 0.007 \\
\hline Observations & 1,518 & 1,650 & & 48,452 & 59,660 & \\
\hline
\end{tabular}

Note: The table shows coefficients from regressions of child years of schooling on fathers' years of schooling by child birth year and rural-urban origin. The table also show the corresponding correlation coefficients. The correlation coefficients are tested nonparametrically based on 1,000 bootstraps. Child cohorts are grouped into 1932-1941 and 1942-1951 in panel A (before and after the 1958 reform, respectively) and are based on survey data (controlling for survey fixed effects in regressions). Panel B is based on register data, and the panel shows results for the last cohort before and the first cohort after the 1972 reform.

${ }^{*}: \mathrm{p}<0.05{ }^{* *}: \mathrm{p}<0.01 ;{ }^{* *}: \mathrm{p}<0.001$ 
Table 2: Estimated association between cognitive and non-cognitive skills, and academic highschool completion and college completion

\begin{tabular}{lccc}
\hline \hline & $\begin{array}{c}(1) \\
\text { Academic high school }\end{array}$ & $\begin{array}{c}(2) \\
\text { College }\end{array}$ & $\begin{array}{c}(3) \\
\text { College } \mid \\
\text { academic high school }\end{array}$ \\
\hline A: 1954 cohort & $0.209^{* * *}$ & $0.134^{* * *}$ & 0.025 \\
Cognitive test score & $(0.008)$ & $(0.007)$ & $(0.023)$ \\
Non-cognitive (Rosenberg scale) & 0.007 & -0.005 & -0.029 \\
& $(0.008)$ & $(0.007)$ & $(0.023)$ \\
\hline B: 1995 cohort & & & $0.081^{* * *}$ \\
Cognitive test score & $0.155^{* * *}$ & $0.130^{* * *}$ & $(0.012)$ \\
& $(0.007)$ & $(0.008)$ & $0.032^{* *}$ \\
Non-cognitive (Rosenberg scale) & $0.059^{* * *}$ & $0.054^{* * *}$ & $(0.010)$ \\
\hline C: $1995-1954$ difference & $(0.007)$ & $(0.008)$ & $0.056^{*}$ \\
Cognitive test score & & & $0.061^{* *}$ \\
Non-cognitive (Rosenberg scale) & $-0.054^{* * *}$ & -0.004 & $0.059^{* * *}$ \\
\hline
\end{tabular}

Note: The table shows regression coefficients of academic high-school completion (1), college completion/enrollment (2), and college completion/enrollment (3), on cognitive test scores, and the Rosenberg self-esteem scale in Panel A and Panel B. Panel C shows the differences between the 1995 and 1954 estimates. All regressors have been standardized to mean 0 and std. dev. 1. All regressions models control for gender. The table is based on data from the Danish Longitudinal Study of Youth born in 1954 and the Danish Longitudinal Study of Children born in 1995 linked to information on educational attainment and enrollment from register data. Table B.5 presents correlations between the Rosenberg scale and cognitive test score used in this table and alternative measures of skills and traits. Observations: Danish Longitudinal Study of Youth 2,551, 2,551, and 729, in columns 1,2, and 3, respectively; Danish Longitudinal Study of Children 3,711, 3,711, and 2,642, in columns 1, 2, and 3, respectively.

${ }^{*}: \mathrm{p}<0.05 ;{ }^{* *}: \mathrm{p}<0.01 ;{ }^{* * *}: \mathrm{p}<0.001$ 
Table 3: Regression coefficients of child outcomes on parents' years of schooling conditional on child years of schooling and child cognitive test scores

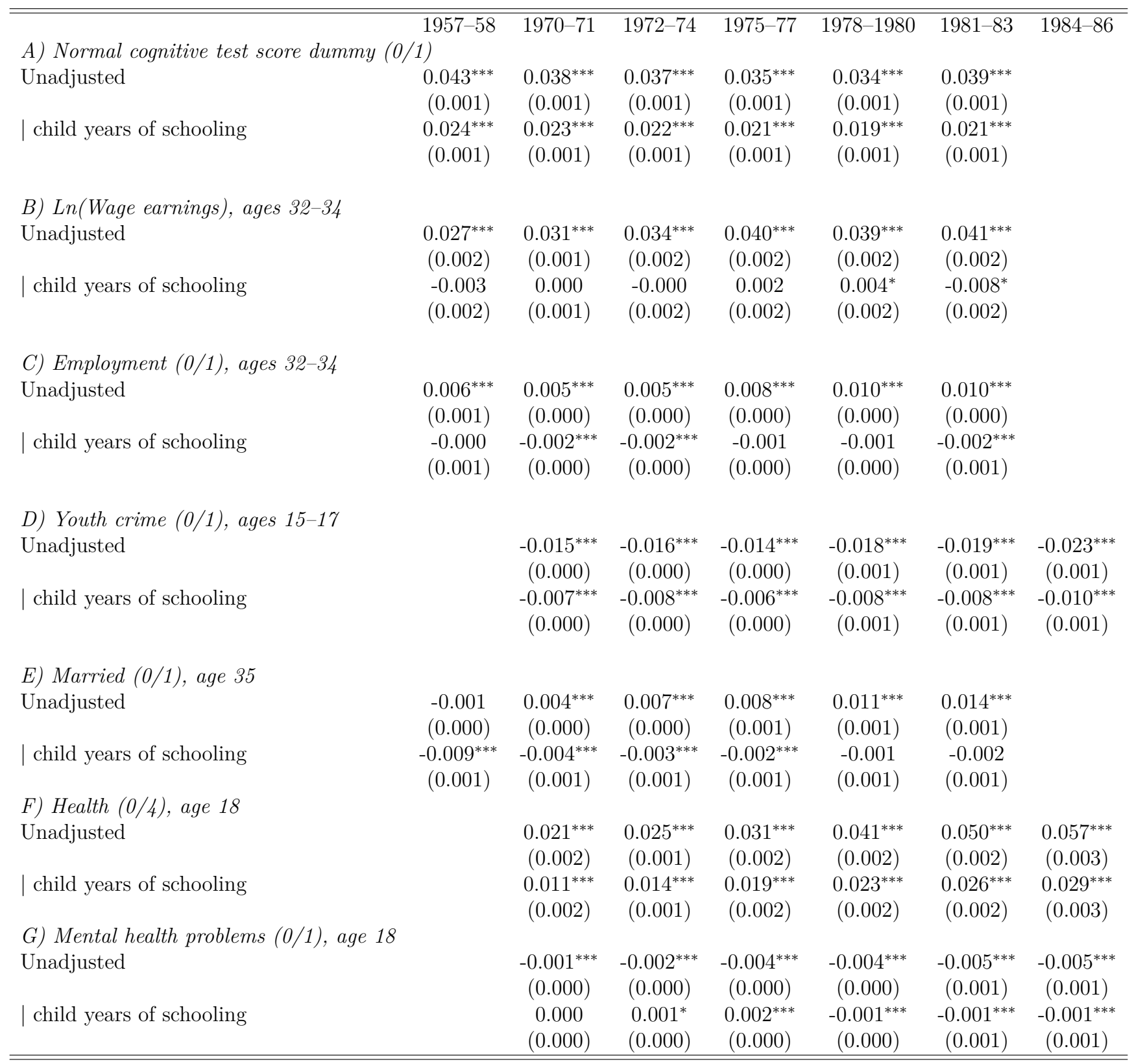

Note: Table shows coefficients from regressions of the outcomes in question on parents' average years of schooling (the rows unadjusted) and conditional on child years of schooling (the rows | child years of schooling).

${ }^{*}: \mathrm{p}<0.05 ;^{* *}: \mathrm{p}<0.01{ }^{* *}: \mathrm{p}<0.001$ 


\section{For online publication:}

\section{A Additional results}

Figure A.1: Summary of register data, by birth cohort

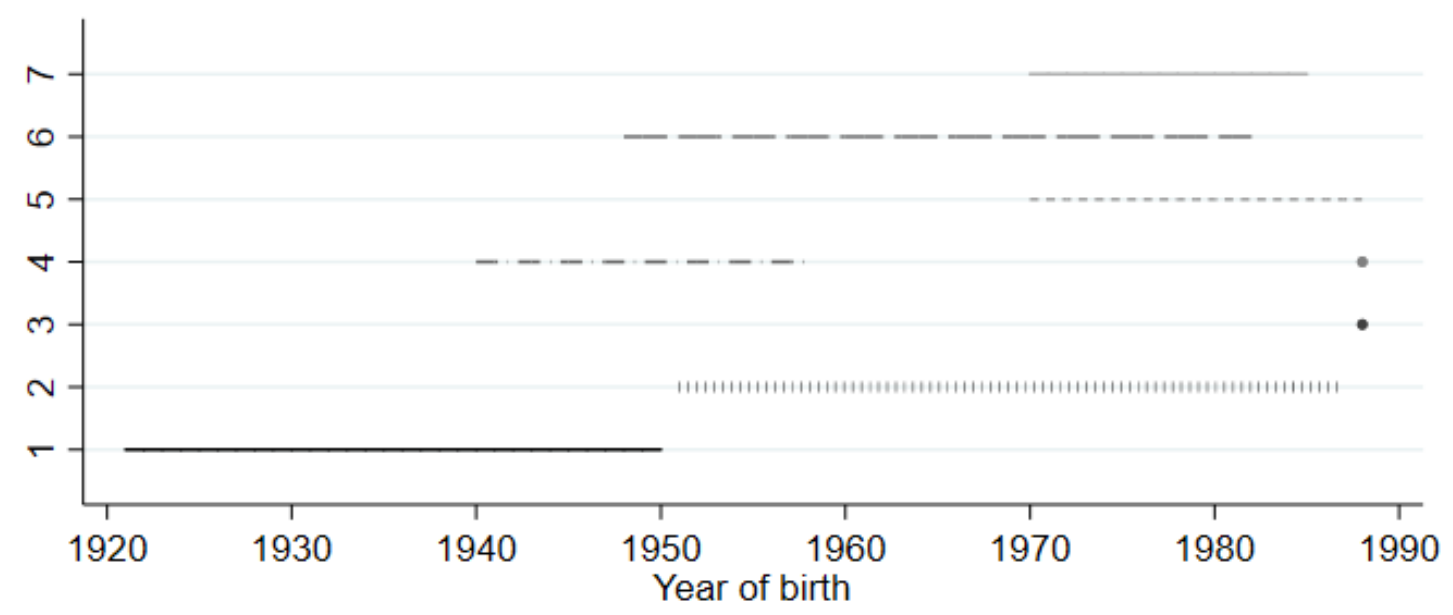

1: Education data measured in 1981

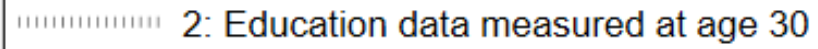

- 3: Education data measured at age 29

$-\ldots-4$ : Full cognitive test score

-... 5: Low/normal dummy from cognitive test

--1 : Wage earnings measured from age 32-36

7: Health assessment

Note: The figure summarizes the availability of register data across cohorts for key variables used in the paper. 


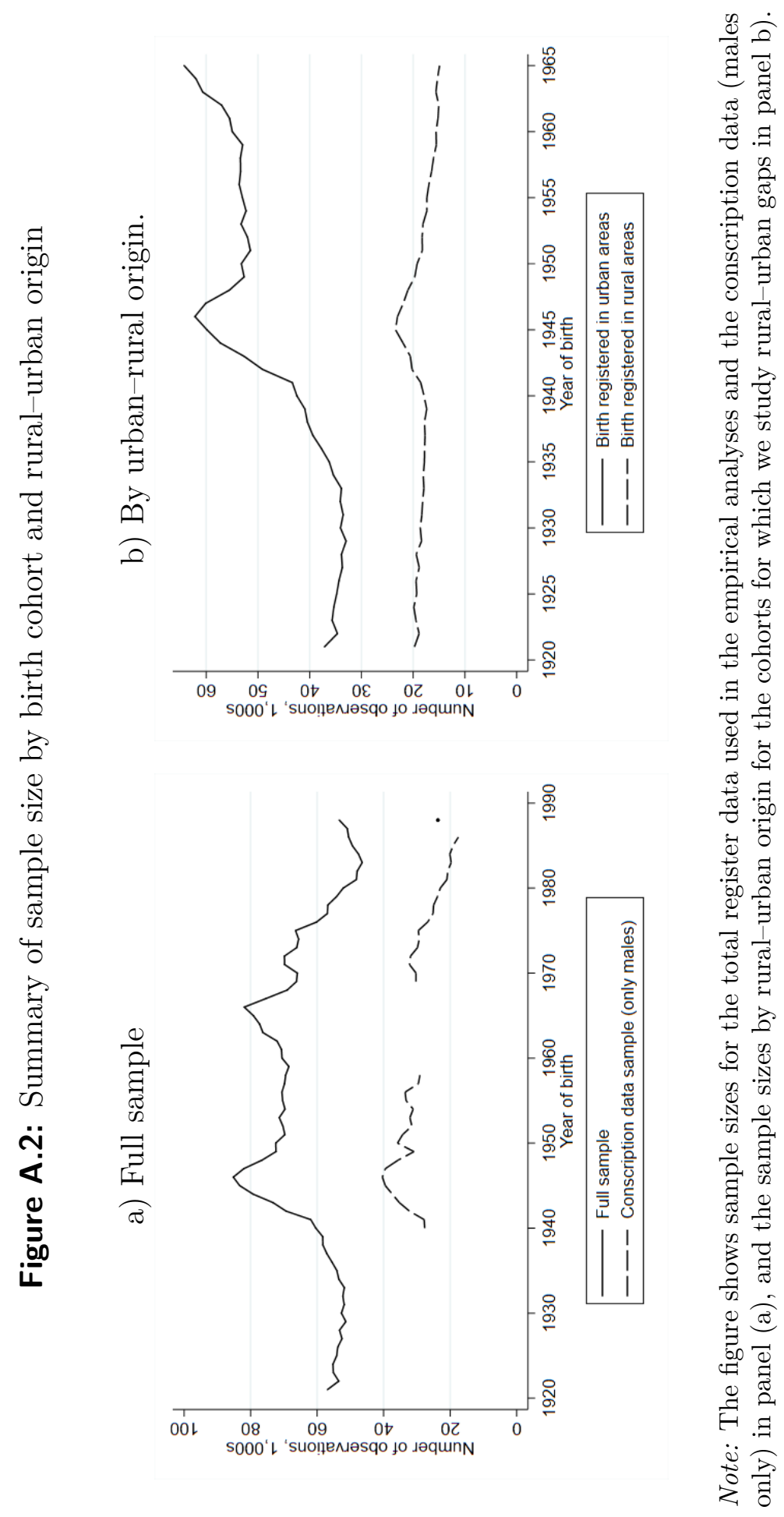




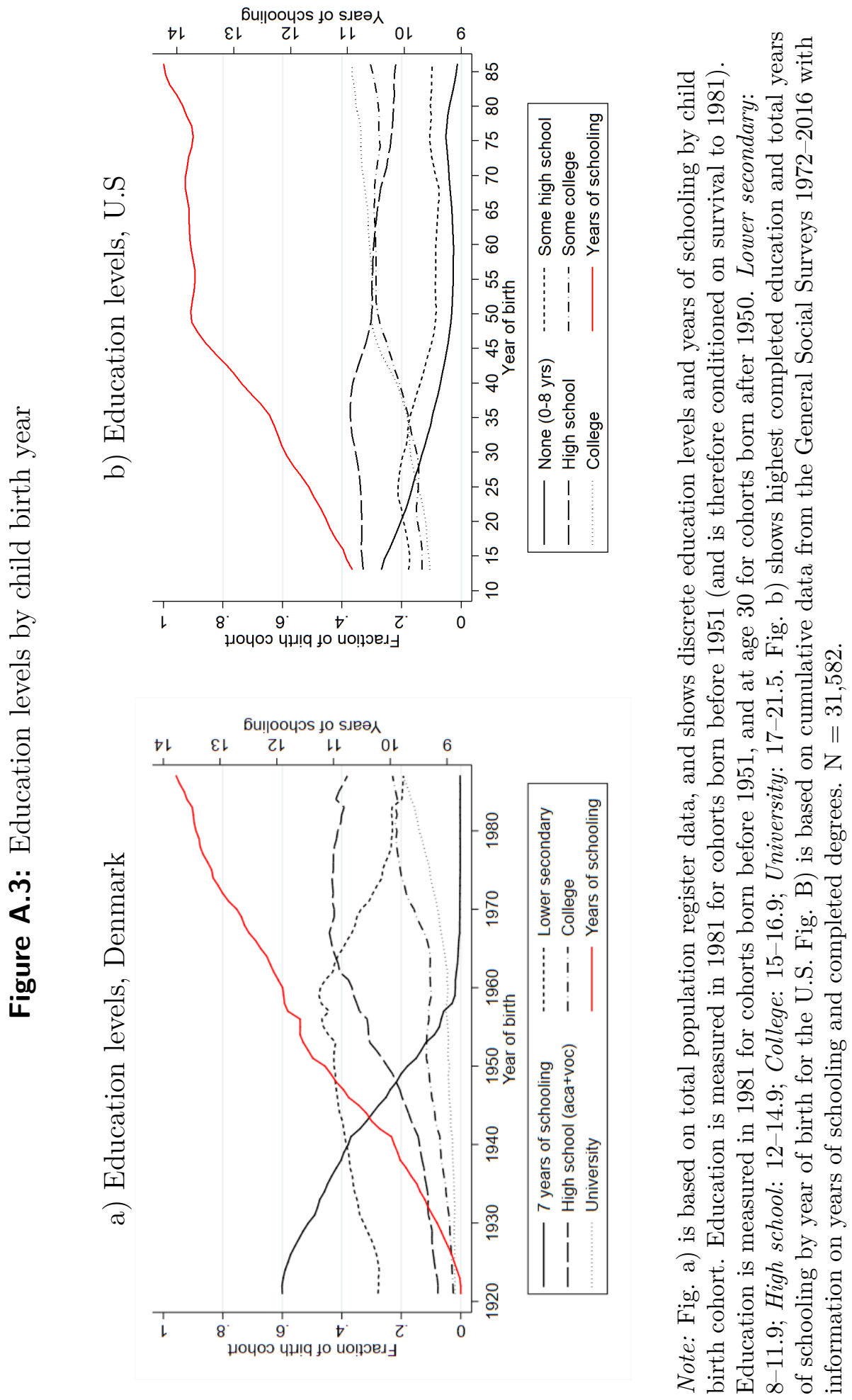


Figure A.4: Cognitive test scores by child birth year

a) Test score distributions, cohorts of 1940, 1958, 1988

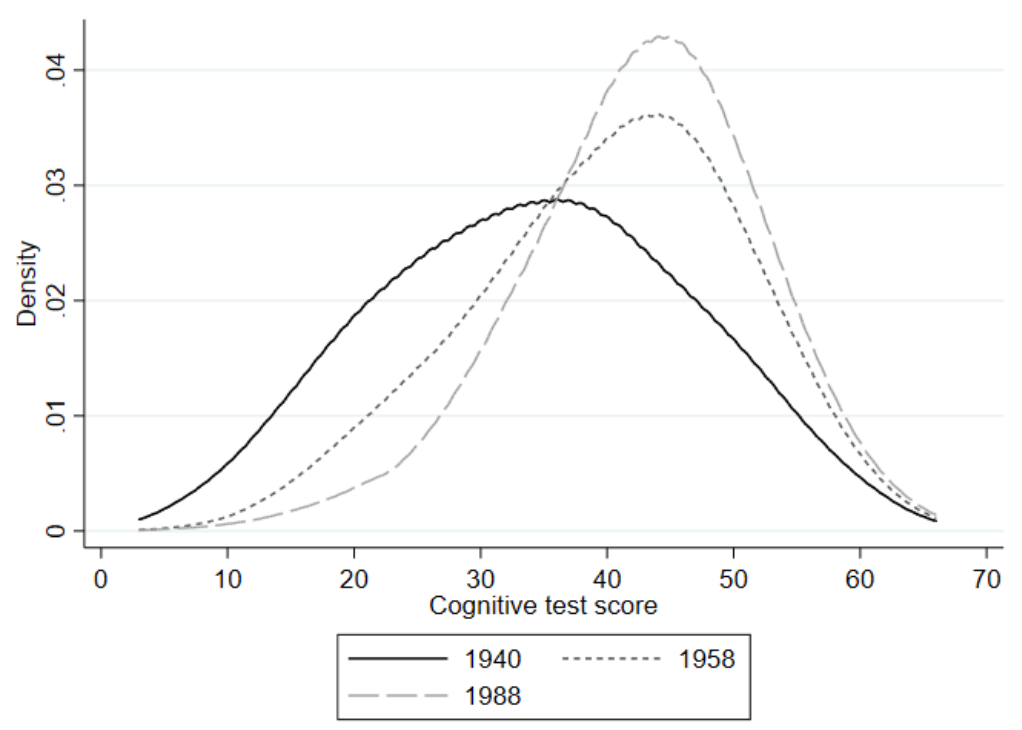

b) Average test scores and proportion with at normal test score

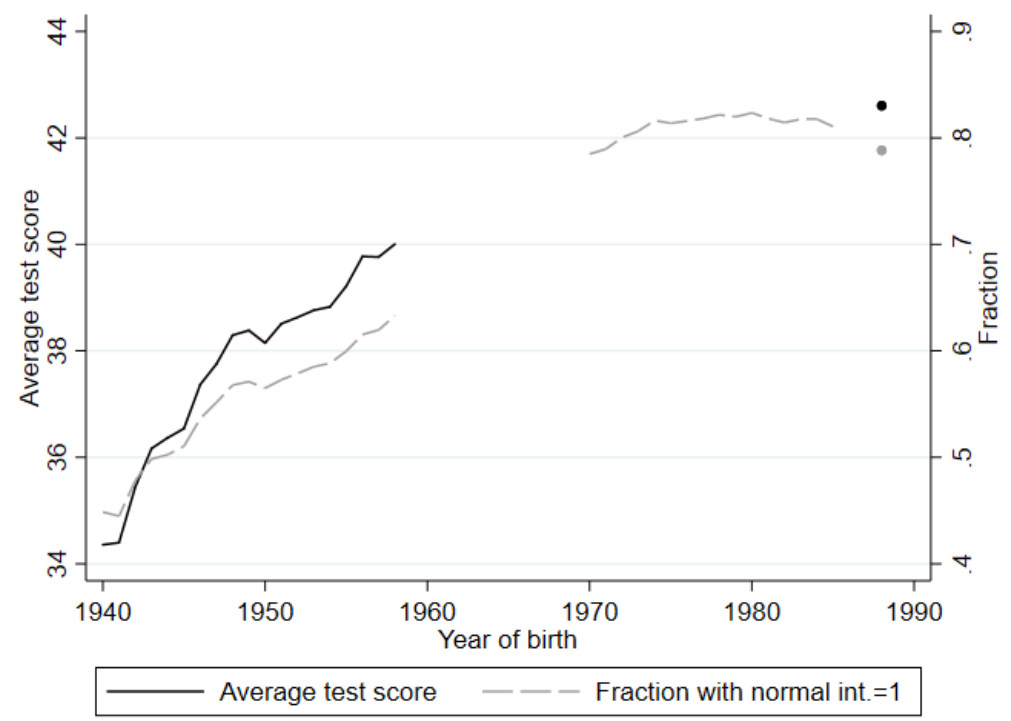

Note: The figure shows cognitive test scores distribution for cohorts 1940, 1958 and 1988 in Fig. a), and in Fig. b) the average test scores for a subset of cohorts (cohorts 1940-1958 and 1988) and the normal test score dummy (a test score of at least 36) for cohorts 1940-1958, 1970-1986, and 1988. 


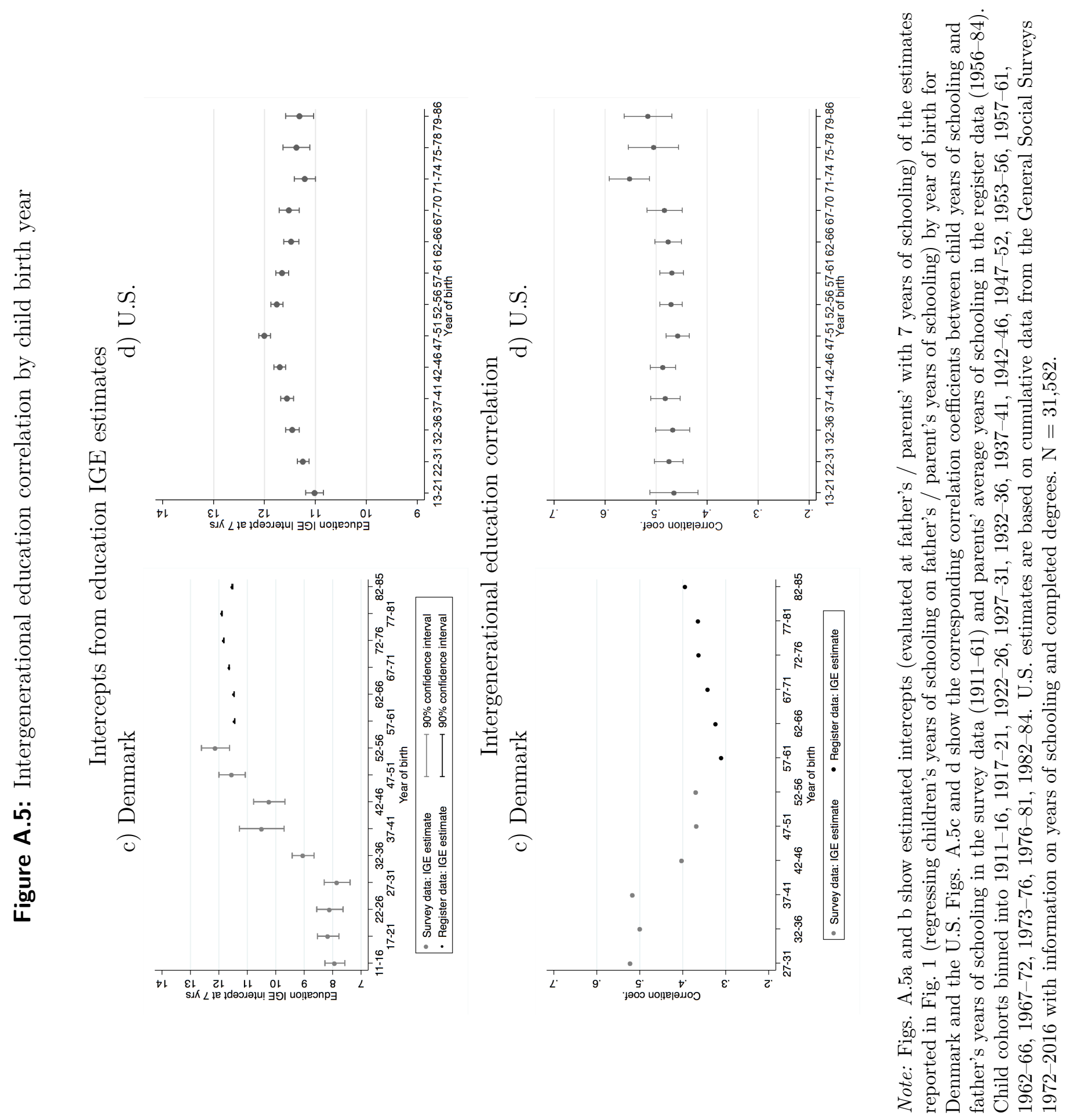


Figure A.6: Intergenerational educational mobility estimates based on survey data only, by child year of birth (birth cohorts 1911-1976)

a) Without sampling weights

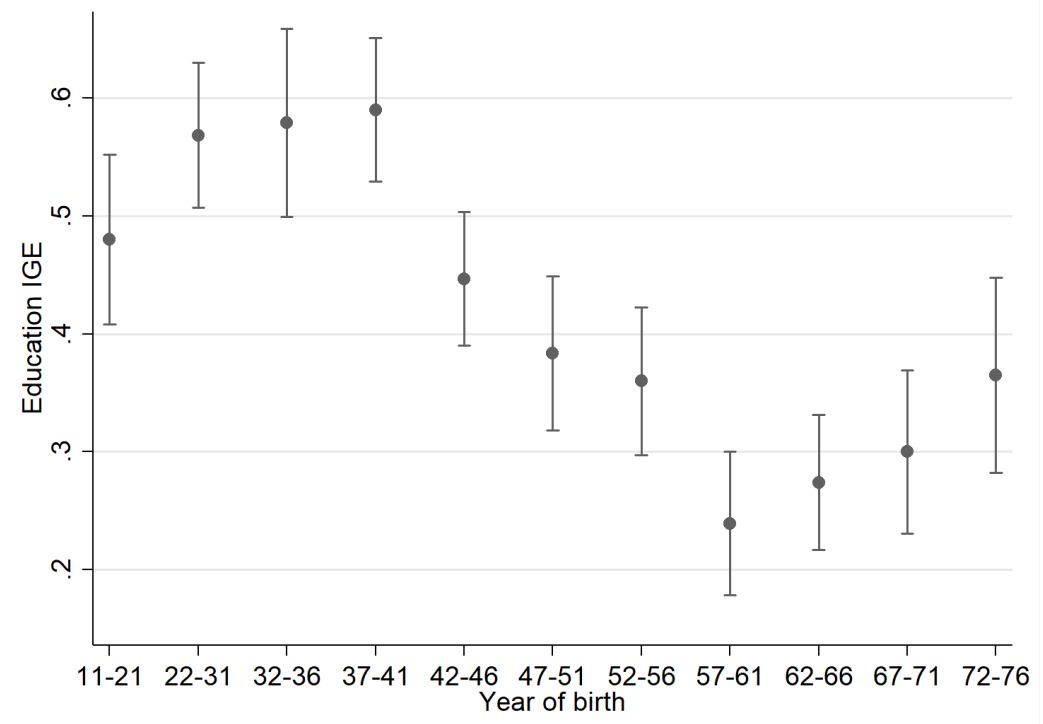

b) With sampling weights

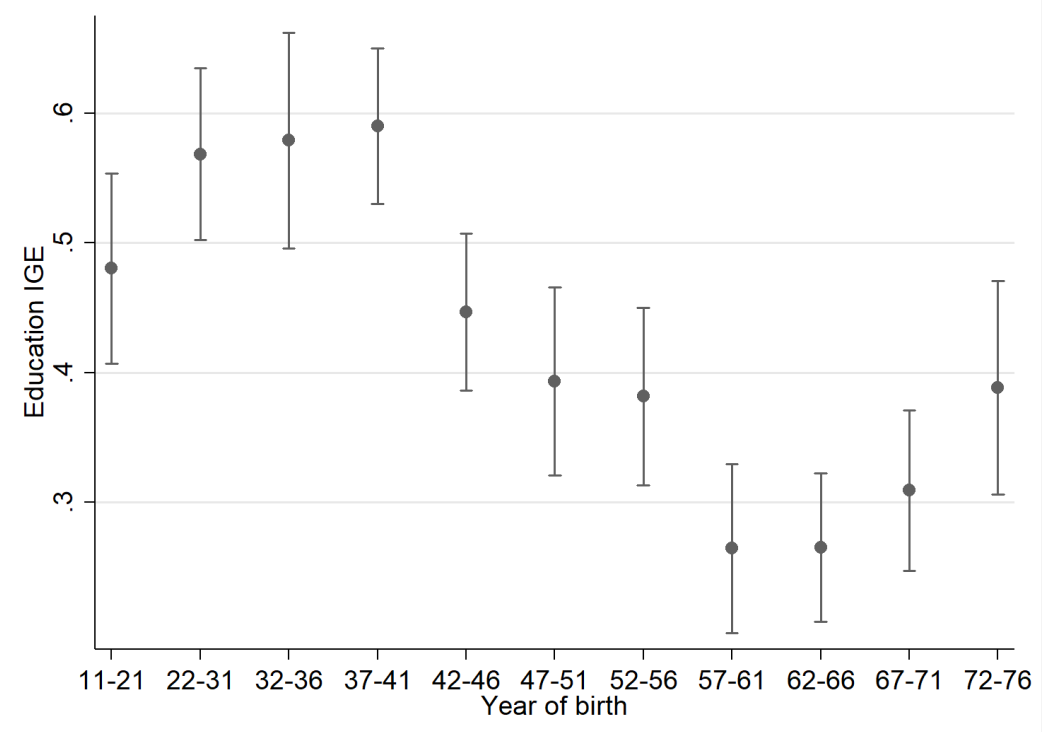

Note: The figure is based on survey data only and shows education IGE estimates by birth cohort bins. Estimates are controlled for survey fixed effects. $N=8,650$. Sampling (post-stratification) weights pertain to the European Social Survey (rounds 4 and 5). For each survey, we standardize the sampling weights by dividing them with their mean 
Figure A.7: Nonlinear intergenerational educational mobility by child birth year

a) Survey data for cohorts born 1911-1957

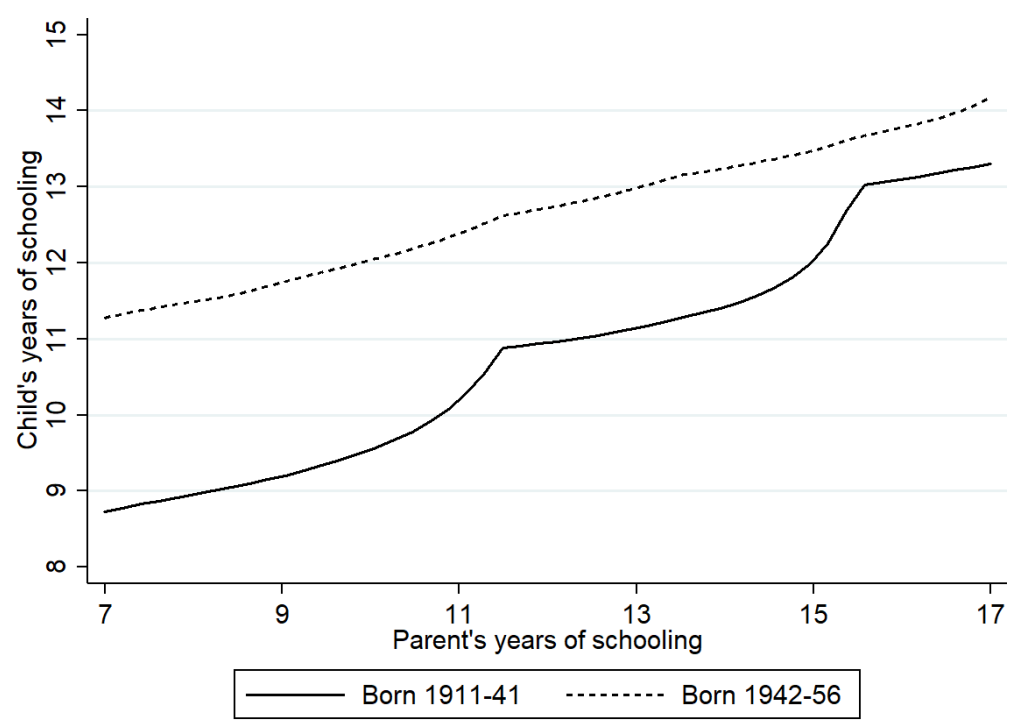

b) Register data for cohorts born 1958-1986

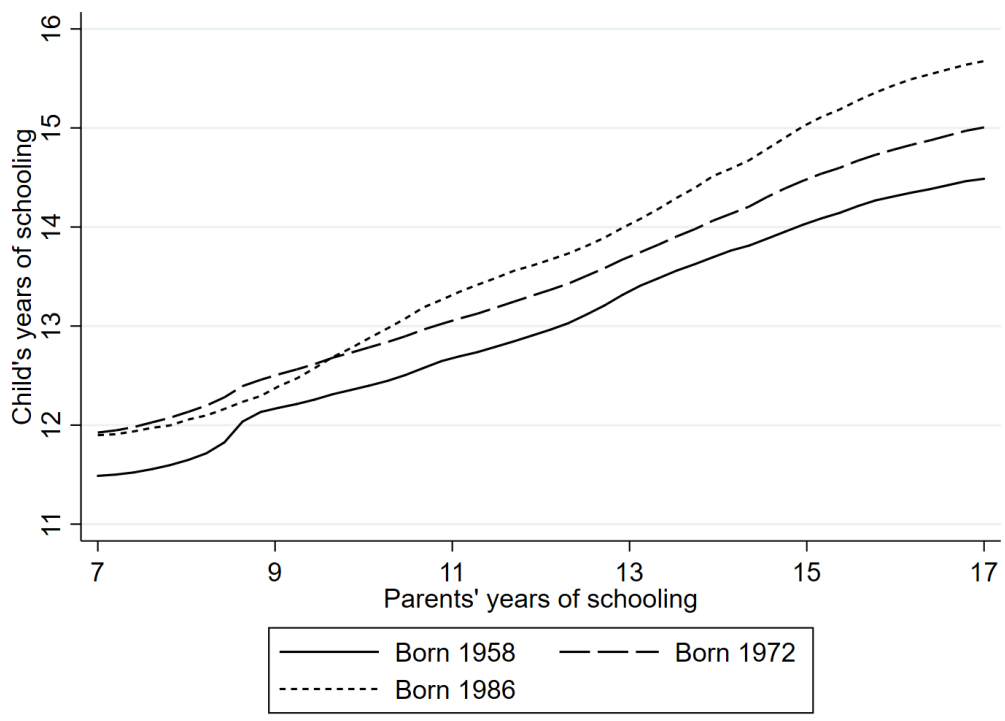

Note: The figures shows local polynomial smooths of children's years of schooling across parents' average years of schooling by child birth year. 
Figure A.8: Cognitive test score distributions by rural-urban origin

a) Distribution: cohort of 1940

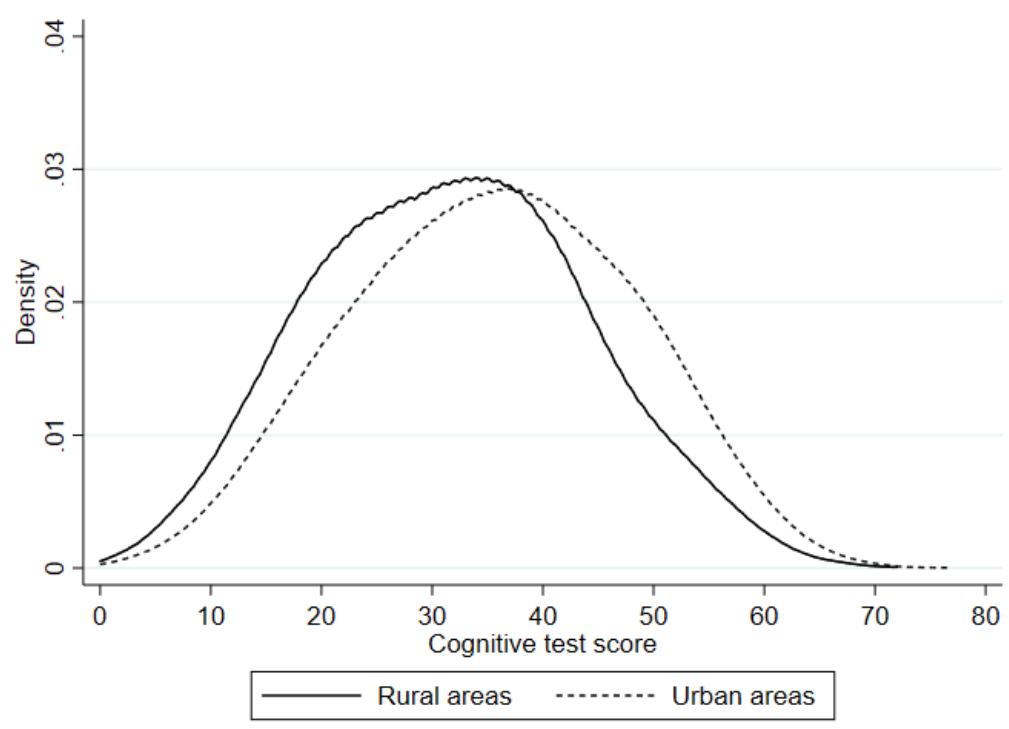

b) Distribution: cohort of 1958

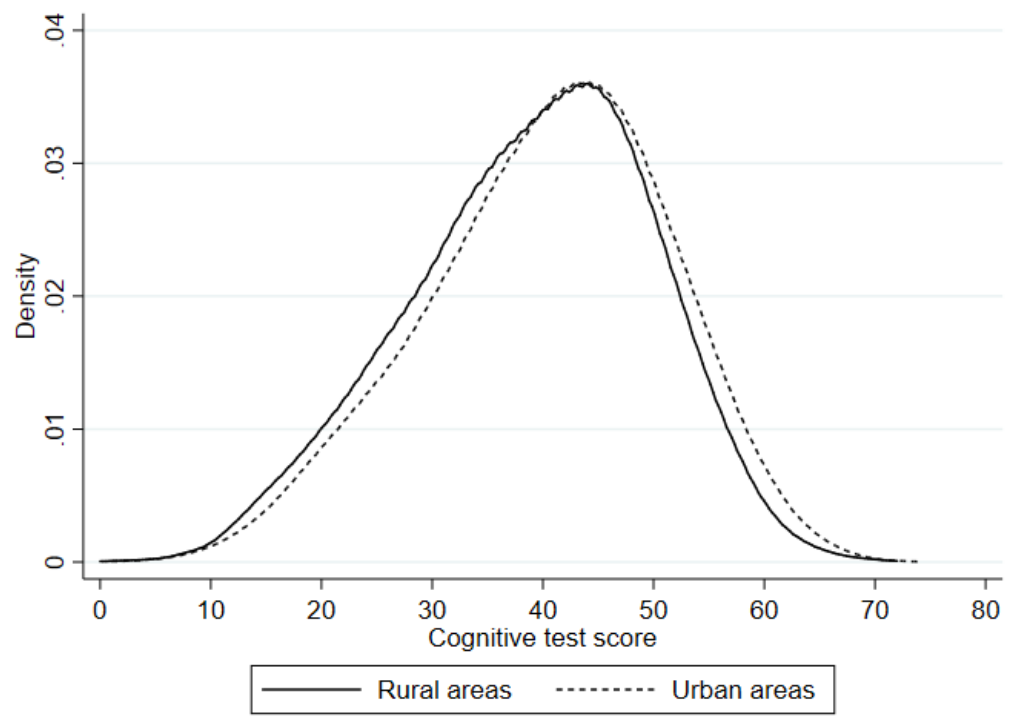

Note: The figure show full range cognitive test score distribution by region of birth for birth cohorts 1940 and 1958 . 
Figure A.9: Cumulative distributions of cognitive test scores around the 1958 and 1972 reforms

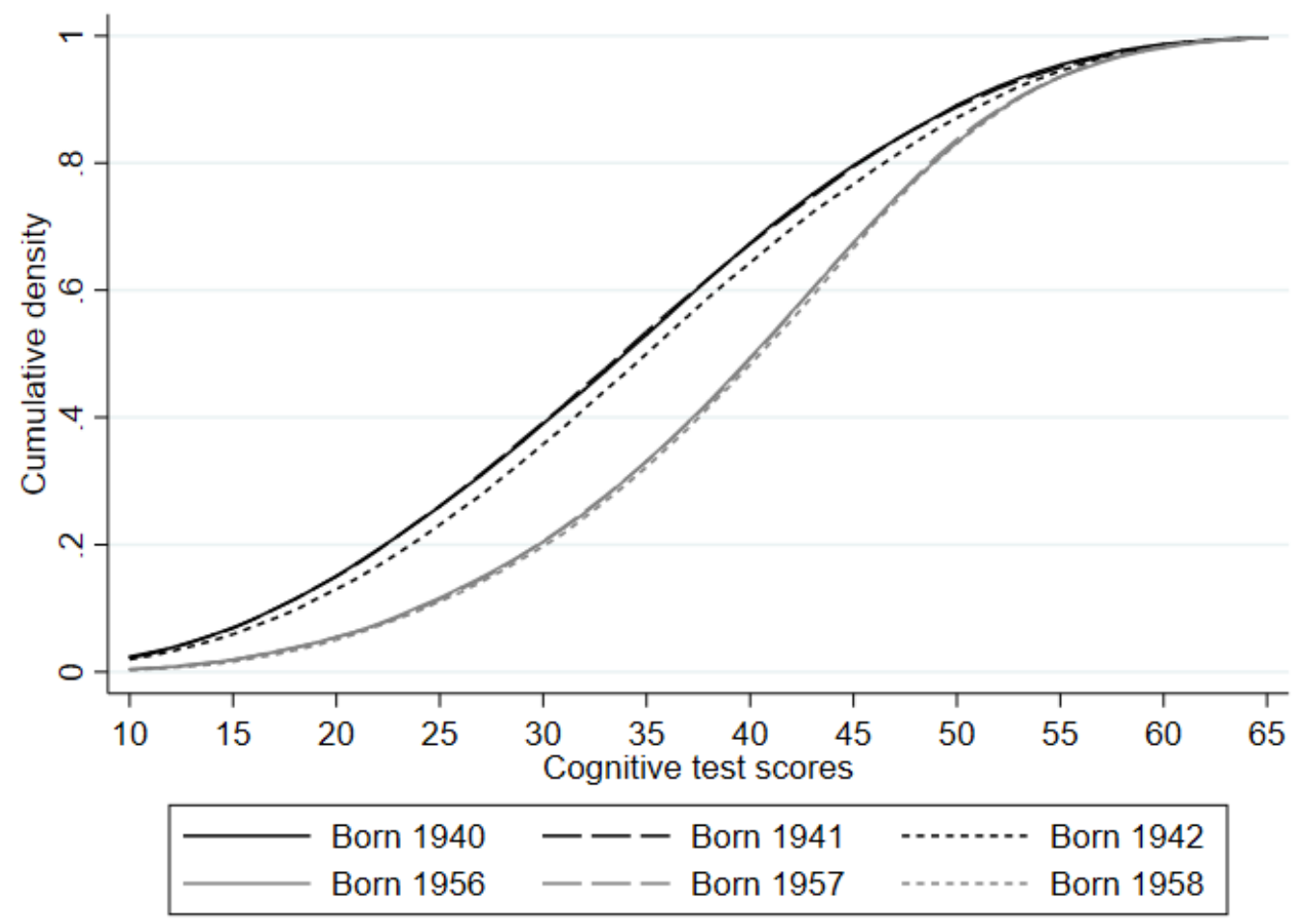

Note: Figure shows the cumulative distribution of cognitive test scores for children born in 1940, 1941, 1942, 1956, 1957, and 1958 (with 1940-1942 cohorts being the last two cohorts before and the first cohort after the 1958 reform; similarly cohorts born 1956-1958 are the cohorts on either side of the 1972 reform). 
Figure A.10: Dispersion in children's schooling by child birth year

a) Standard deviation of years of schooling

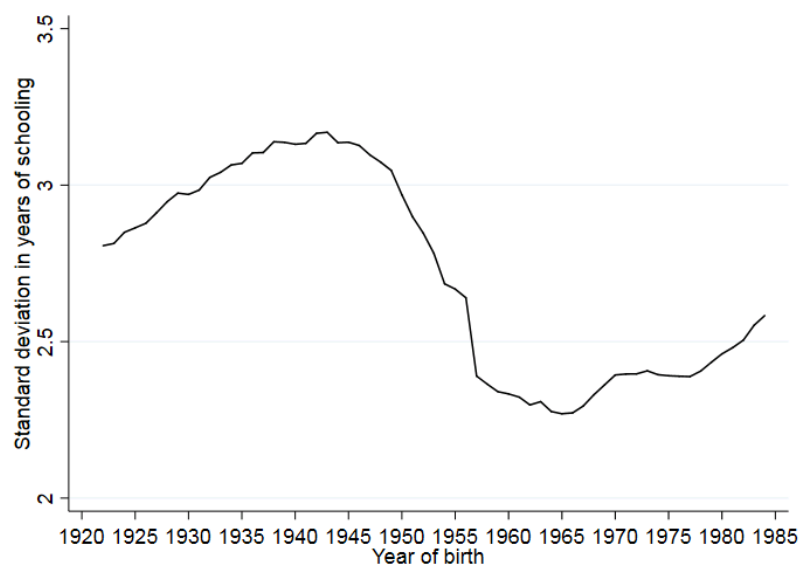

b) Years of schooling, bottom and top $30 \%$

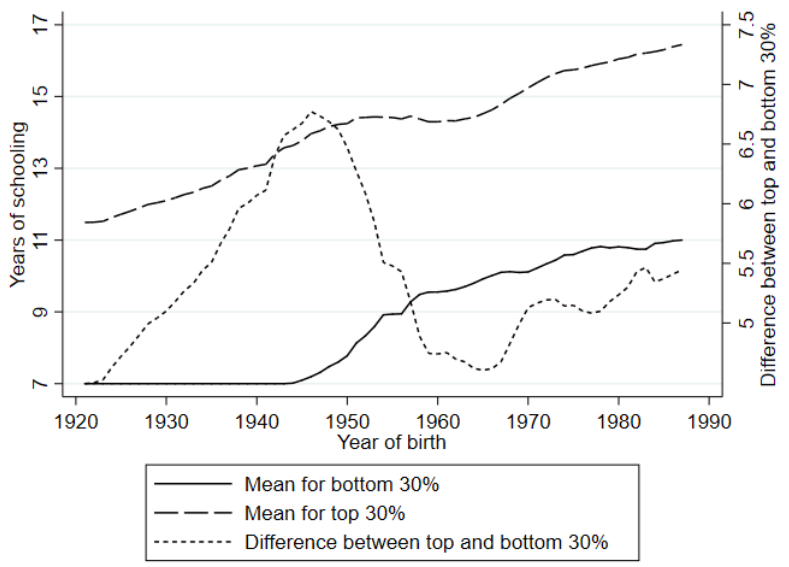

Note: Fig. a) shows the standard deviation of years of schooling. Fig. b) shows the average years of schooling for the $30 \%$ with lowest (solid line) and highest (dashed line) years of schooling, and the differences between these two (dotted line). Education is measured in 1981 for cohorts born before 1951, and at age 30 for cohorts born after 1950. 


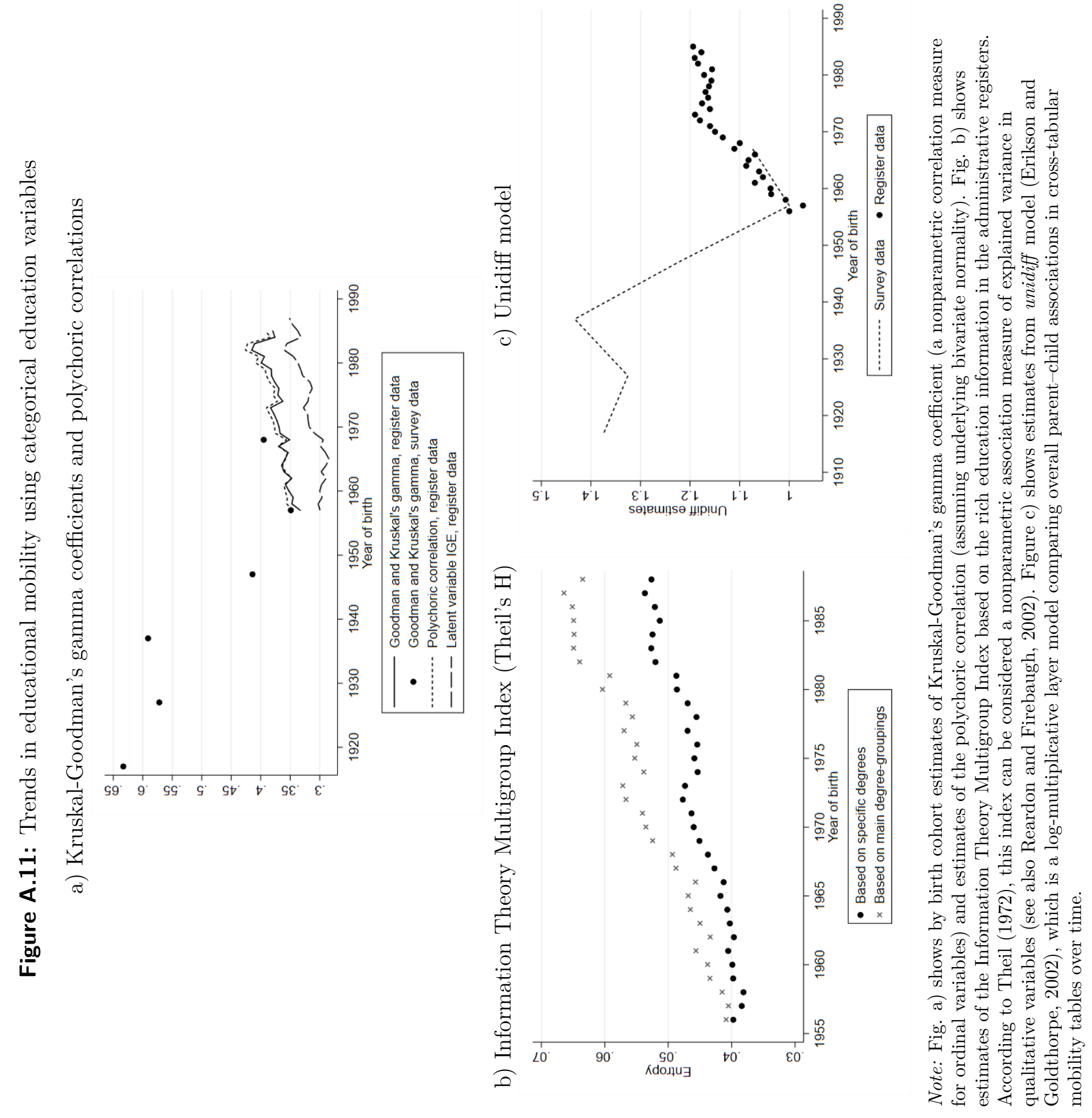


Figure A.12: Transition probability from high school to college, by year of birth and country

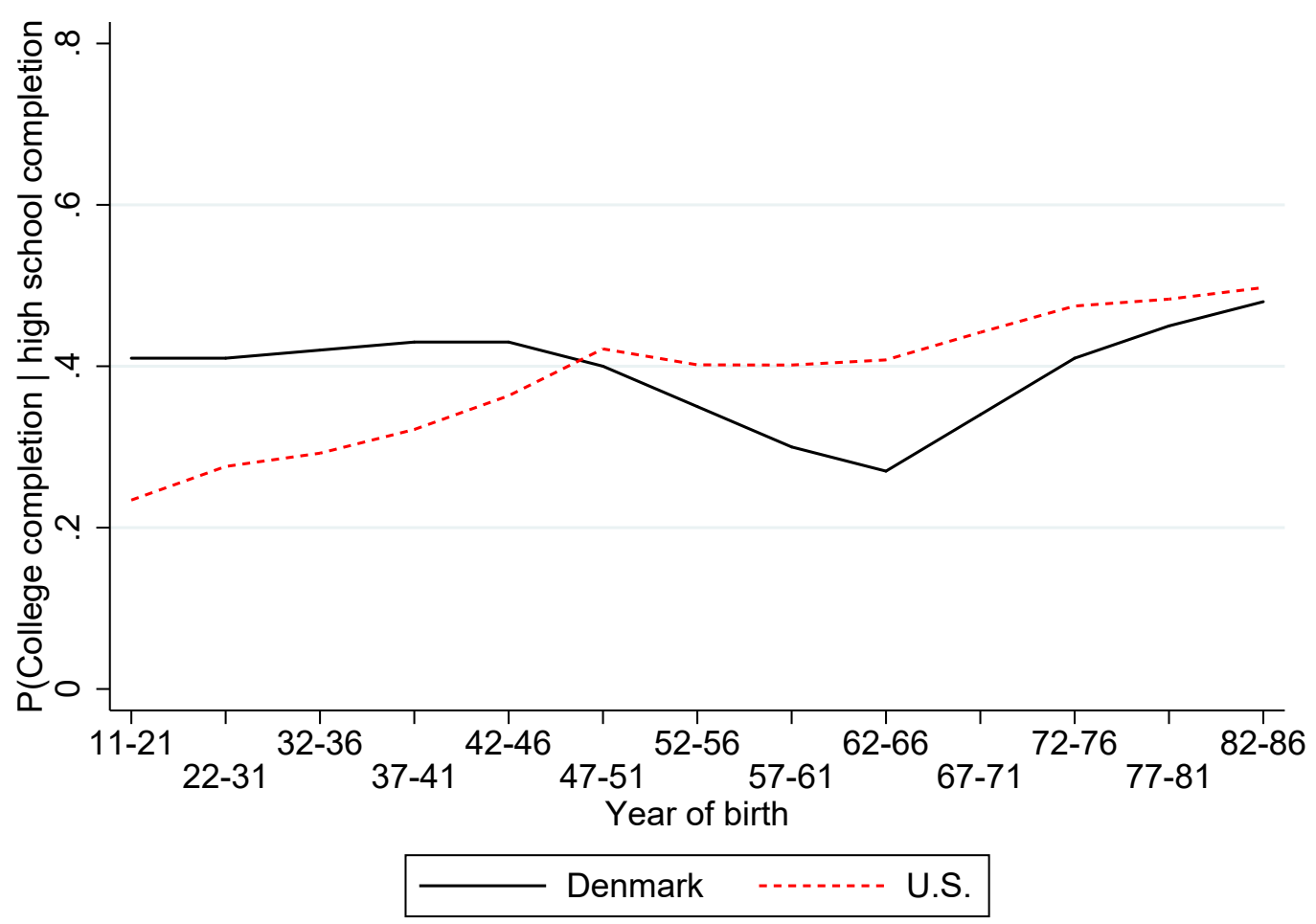

Note: Figure shows the probability of college completion conditional on high-school completion for cohorts born in 1911-1986 in Denmark and the U.S., respectively. The levels for Denmark differ from those reported in Figure Fig. 7. as high school completion in this figure is all types of high schools (and not only academic-high school) to align the definitions with the U.S. counterpart. College is here defined as completing at least 15 years of schooling. 


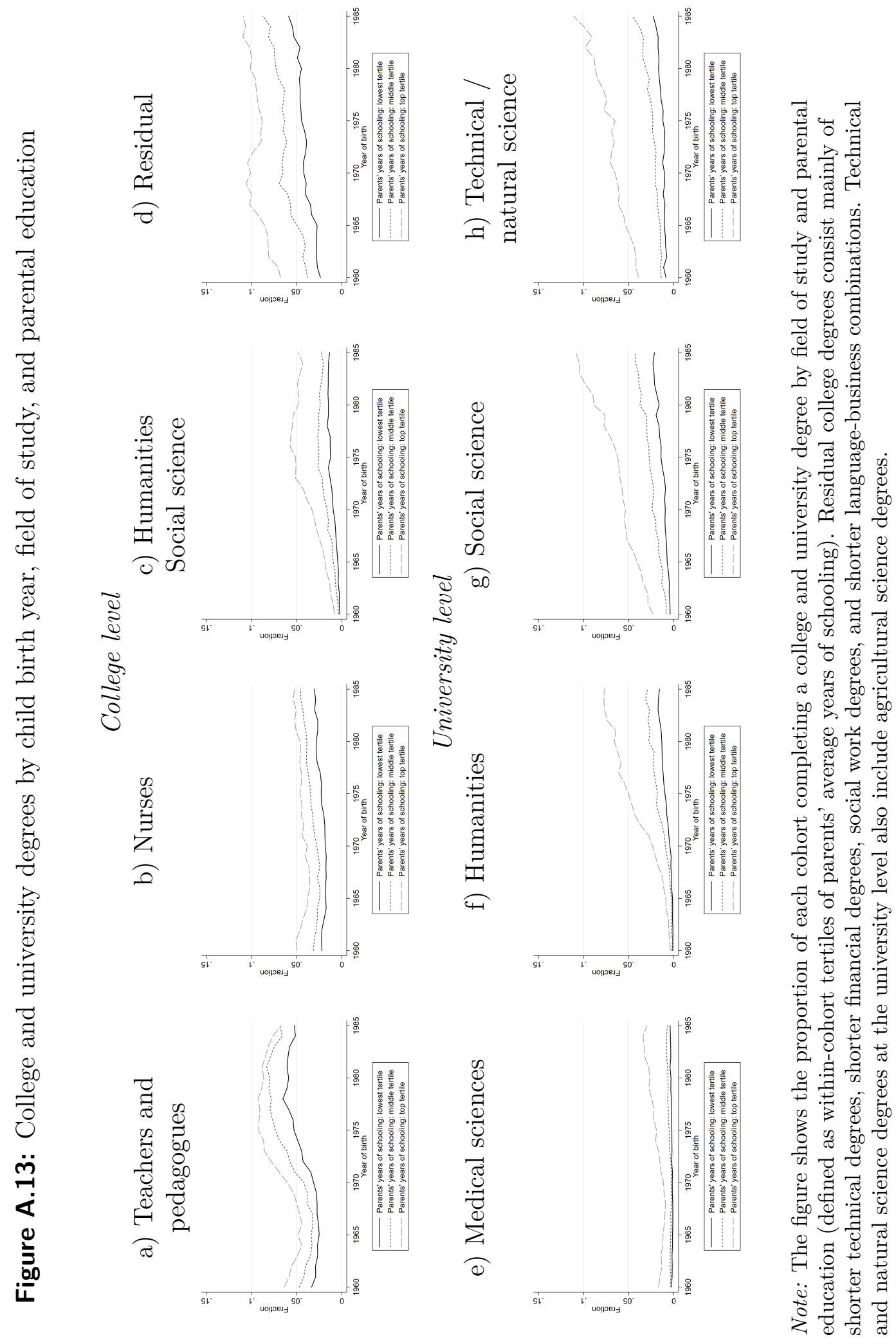


Figure A.14: Correlation between education at expanding margin and cognitive test score dummy, by birth cohort

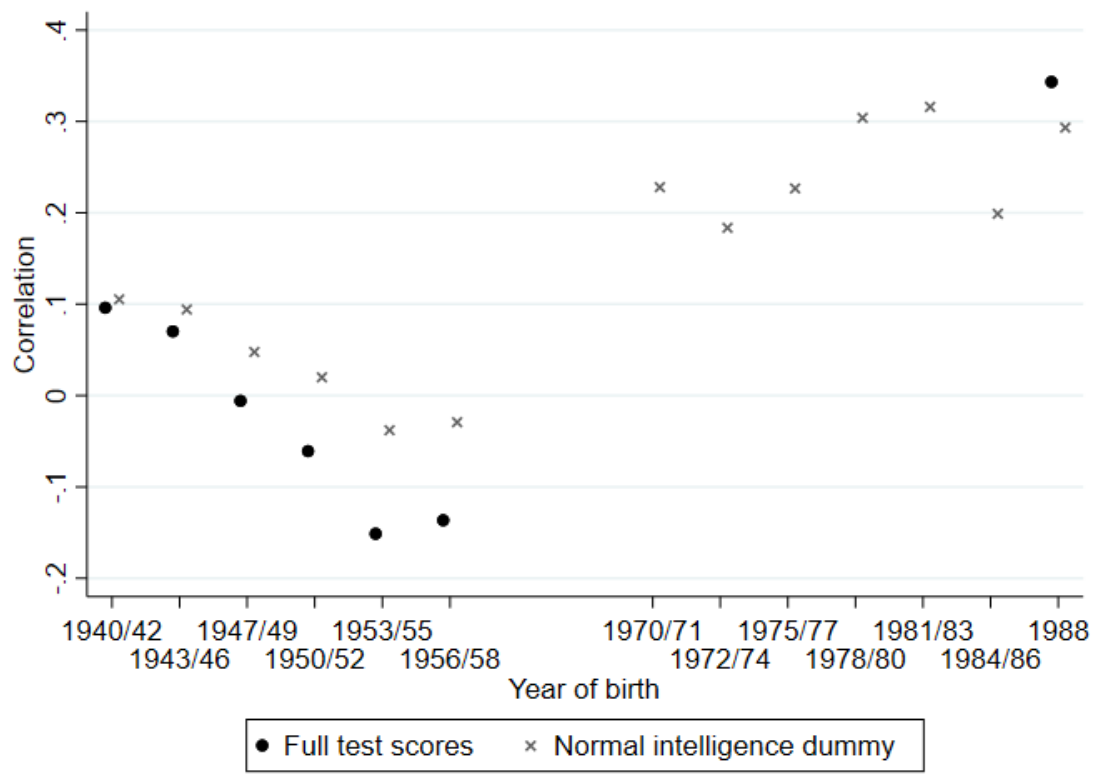

Note: The figure shows the correlation between offspring cognitive test scores $C_{i t}$ and expansion at education margin. Expansion at education margin is defined as the percentage points difference between the fraction obtaining a given overall degree level in one cohort $E\left(E_{t-1}^{C}=e\right)$ and the fraction obtaining the same overall degree level in the next cohort $E\left(E_{t}^{C}=e\right)$ :

$M_{i t}=E\left(E_{t}^{C}=e\right)-E\left(E_{t-1}^{C}=e\right)$, for an individual $i$ obtaining degree $e$

E.g., if $30 \%$ completed college in year $t-1$ and $32 \%$ in year $t$, whereas $10 \%$ completed university in year $t-1$ and $11 \%$ in year $t$, individuals with a college degree as their highest education are assigned 0.02 , while individuals with a university degree in year $t$ are assigned 0.01 . The figure then presents $\operatorname{corr}\left(C_{i t}, M_{i, t}\right)$ by year of birth. 
Figure A.15: Correlation between years of schooling, cognitive skills, and other child outcomes, by child birth year

a) Wage earnings percentile, age 29

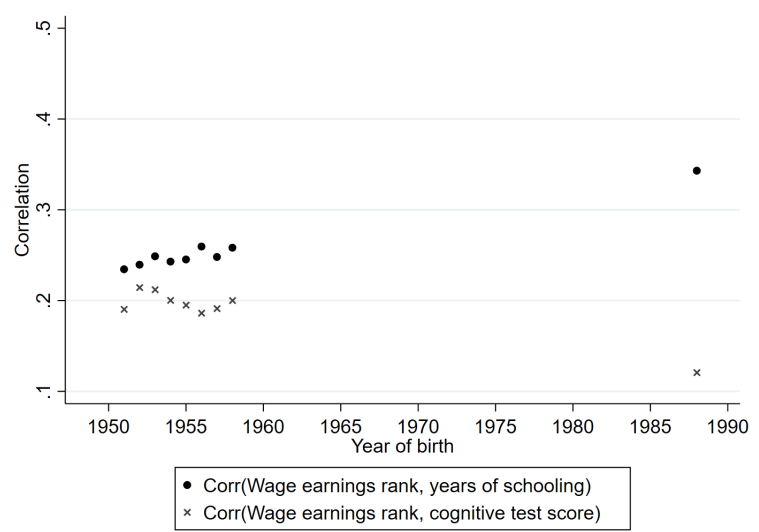

b) $\mathrm{P}$ (employment), age 29

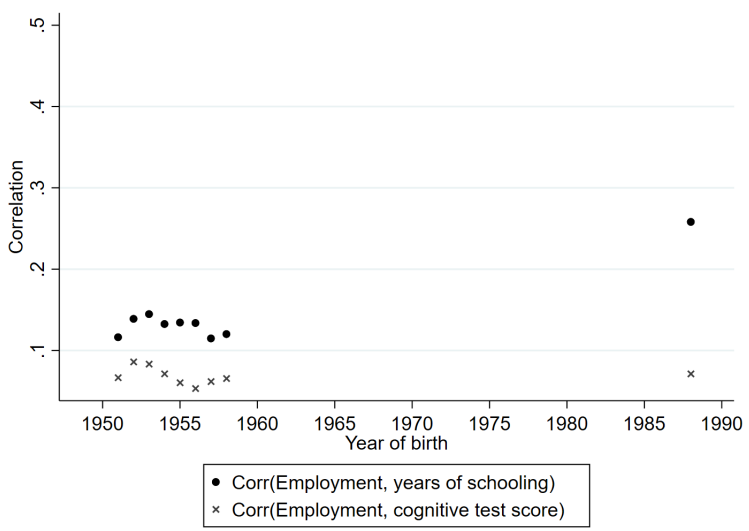

Note: The figure shows correlation coefficients between years of schooling / cognitive test scores and wage earnings percentiles (a) and employment status (b) when measuring wage earnings percentile and employment at age 29 (i.e., earlier than in Fig. 13, as this facilitates a link between the full test cognitive scores for the 1988 cohort and the outcomes in question. We thereby replicate the long run trend where the correlations between the two outcomes in question and years of schooling, on the one hand, and cognitive test scores, on the other hand, diverge using the full test score (and not the normal intelligence dummy as in Fig. 13). 
Table A.1: Summary of outcomes other than education

\begin{tabular}{lccccccc}
\hline \hline & $1957-58$ & $1970-71$ & $1972-74$ & $1975-77$ & $1978-1980$ & $1981-83$ & $1984-86$ \\
Normal cognitive test score dummy (0/1) & 0.62 & 0.78 & 0.81 & 0.82 & 0.82 & 0.82 & 0.81 \\
Wage earnings (1,000 2010\$), ages 32-34 & 34.70 & 39.51 & 40.92 & 40.56 & 39.09 & 39.59 & 39.48 \\
Employment (0/1), ages 32-34 & 0.86 & 0.88 & 0.89 & 0.88 & 0.87 & 0.87 & \\
Youth crime (0/1), ages 15-17 & & 0.15 & 0.14 & 0.12 & 0.13 & 0.12 & 0.14 \\
Married (0/1), age 35 & 0.69 & 0.68 & 0.68 & 0.68 & 0.67 & 0.68 & \\
Health (0/4), age 18 & & 2.58 & 2.51 & 2.49 & 2.41 & 2.23 & 2.11 \\
Mental health problems (0/1), age 18 & & 0.10 & 0.10 & 0.14 & 0.16 & 0.18 & 0.19 \\
\hline \hline
\end{tabular}

Note: Table shows mean values for men by birth cohort (grouped into categories of 2-3 years) for the outcomes other than education. 
Table A.2: Effect of the compulsory schooling reform on education outcomes

\begin{tabular}{lccc}
\hline \hline & All & Urban & Rural \\
\hline Years of schooling & $0.240^{* * *}$ & $0.217^{* * *}$ & $0.305^{* * *}$ \\
More than 7 years of schooling & $(0.019)$ & $(0.019)$ & $(0.019)$ \\
& $0.029^{* * *}$ & $0.028^{* * *}$ & $0.031^{* * *}$ \\
At least 9 years of schooling & $(0.003)$ & $(0.003)$ & $(0.004)$ \\
& $0.043^{* * *}$ & $0.044^{* * *}$ & $0.042^{* * *}$ \\
& $(0.008)$ & $(0.007)$ & $(0.007)$ \\
\hline Observations & $2,198,120$ & $1,697,210$ & 500,910
\end{tabular}

Note: Table shows the estimated effects of the 1972 compulsory schooling reform on years of schooling, the probability of completing more than 7 years of schooling, and the probability of completing at least 9 years of schooling. Estimates are shown for all individuals and by rural-urban origin. The estimates are based on a bandwidth of \pm 14 cohorts around the reform and allows for different slopes of each side of the reform approximated by fourth order polynomial. Estimates are clustered by child birth year.

${ }^{*}: \mathrm{p}<0.05 ;{ }^{* *}: \mathrm{p}<0.01 ;{ }^{* *}: \mathrm{p}<0.001$ 
Table A.3: Children's language test score quintiles in grade 2 and 8, by parents' education, Denmark and the U.S.

\begin{tabular}{lccccc}
\hline \hline \multicolumn{2}{c}{ 1st quintile } & 2nd quintile & 3rd quintile & 4th quintile & 5th quintile \\
\hline $\begin{array}{l}\text { Parents less than college } \\
\text { Grade 2 }\end{array}$ & & & & \\
Denmark & 0.25 & 0.21 & 0.21 & 0.19 & 0.14 \\
U.S. & 0.24 & 0.22 & 0.20 & 0.18 & 0.15 \\
& & & & & \\
Grade 8 & & & & & \\
Denmark & 0.25 & 0.22 & 0.20 & 0.18 & 0.15 \\
U.S. & 0.25 & 0.22 & 0.20 & 0.19 & 0.15 \\
& & & & & \\
Parents college or higher & & & & \\
Grade 2 & & & & & \\
Denmark & 0.12 & 0.16 & 0.19 & 0.23 & 0.29 \\
U.S. & 0.11 & 0.16 & 0.22 & 0.23 & 0.29 \\
Grade 8 & & & & & \\
Denmark & 0.10 & 0.16 & 0.20 & 0.24 & 0.30 \\
U.S. & 0.12 & 0.15 & 0.20 & 0.24 & 0.29 \\
\hline \hline
\end{tabular}

Source: Hjorth-Trolle and Holm (2021).

Note: The table shows children's language test score quintiles measured in grade 2 and 8 (at age 8 and 14) by parents' highest education (less than college vs. college or higher). Results for Denmark are based on full population register data, and results for the U.S. are based on NLSY97 data. Parents with less than high school constitute $67 \%$ of the sample in both countries. 


\section{B Data appendix, Denmark}

\section{B.1 Major schooling reforms in Denmark}

Table B.1: Major educational reforms in Denmark in the 20th century

\begin{tabular}{|c|c|}
\hline Reform & Description \\
\hline 1903 & $\begin{array}{l}\text { Rural schools offer } 7 \text { years of schooling; urban schools track students in grade } \\
5 \text { into an advanced } 4 \text {-year track and a basic } 2 \text {-year track. }\end{array}$ \\
\hline 1937 & $\begin{array}{l}\text { Urban schools tracked in grade } 5 \text { into an advanced } 4 \text {-year track and a basic } \\
\text { 4-year track; rural schools continue to offer } 7 \text { years of schooling. }\end{array}$ \\
\hline 1958 & $\begin{array}{l}\text { The rural and urban school systems are unified; primary school tracking is abolished; } \\
\text { lower secondary school is divided into an advanced and a basic track. }\end{array}$ \\
\hline 1972 & Minimum required years of schooling increases from 7 to 9. \\
\hline 1975 & Tracking in primary and secondary schools was eliminated, excepting for certain courses. \\
\hline 1993 & Primary and secondary schools completely de-tracked (the "undivided school"). \\
\hline
\end{tabular}

The 20th century is characterized by six major reforms of primary and lower secondary schooling in Denmark. Before we describe these reforms, we highlight three features of the Danish educational system. First, before the 1958 reform, the educational system was divided into a rural and urban school system. In the rural school system, children had very few opportunities for continuing into lower and upper secondary education after completing primary school. Schools in rural areas only provided primary schooling from grades 1 through 7 . Second, before the 1972 reform, the minimum required years of schooling in Denmark was 7, which is the duration of primary schooling. The reform increased the minimum required years to 9 , which is the combined duration of primary schooling (7 years) and lower secondary schooling (2 years). Third, Denmark has a German legacy in terms of apprenticeship-based vocational training. Upon completing primary or 
lower secondary school, a child could become an apprentice of a skilled worker. Over the 20th century, formal schooling in vocational upper secondary schools constitutes an increasing portion of the apprenticeship-based vocational training. Thus, upper secondary education in Denmark is bifurcated in terms of a vocational track and the traditional academic track (the Gymnasium). We base the following outline of the educational reforms on de Coninck-Smith and Rasmussen (2015); Gjerløff and Jacobsen (2014); Gjerløff et al. (2014). Table B.1 provides an overview of these reforms.

After the 1903 reform, the rural school system offered primary schooling from grades 1 through 7. While the urban school system similarly offered seven years of primary schooling, it tracked students from grade 5 into a basic or advanced track. The basic track was a two-year program, whereas the advanced track was a four-year program (known as Middle school). Thus those attending the advanced track would complete 9 years of schooling, compared to 7 years in the basic track. Upon completing the advanced track, students had two options. They could either enrol in academic upper secondary education (the Gymnasium), a 3-year program, or complete a 1-year academic program (Realklasse). Upon completing the one-year academic program, students could then enroll in the 3-year academic upper secondary program.

What were the reasons behind this segregated school system and the lack of focus on education in rural areas? The practical reason was that children constituted a substantial share of the labor force, and few peasant families could afford to lose able workers. A more fundamental reason was related to the school's purpose. Children had to attend school to enable them to read the Bible, become good and virtuous citizens, and form the foundation for a common set of core Lutheran values among the population. Throughout the first half of the 20th century, the view of schooling's purpose changed. This was spearheaded by the Social Democrats who saw education as a potential means to promote equality of opportunity. However, those commited to maintaining a common set 
of Lutheran values were strong and prevailed in the end. Thus, the 1937 school reform put in place only a fraction of what was originally discussed.

The urban school system was reorganized, whereas the rural school system continued to offer 7 years of primary schooling, and often only with classes every second weekday and two grade levels (young and older children). In the urban school system, students were tracked from grade 5 into two overall streams, one which offered an advanced 4-year program (Eksamensmellemskole), and one which offered a basic or regular 4-year program (Fri mellemskole). Students in urban schools were not required to complete the 4-year programs, but could leave school after 7 years, the required minimum at the time. For students completing the 4-year advanced program, the upper secondary school options were the same as before the reform: They could enroll in academic upper-secondary education, a 3-year program; another option was a 1-year academic program, and upon completing the 1-year academic program, students could enroll in the 3-year academic upper-secondary program.

In the decade after WWII, views on the purpose of education changed, and both domestically and internationally the pressure for modernization of the education system was building. Several OECD reports emphasized modernization, and phrases like "mobilization of the intelligence reserve" were examples of this movement. This led to the 1958 reform, which is widely regarded as the most important educational reform in Denmark during the 20th century. The reform had three overall components. First, rural and urban school systems were merged into a single system (or, more precisely, the rural school system was abolished). Hence, rural municipalities (the Danish local government level) now were required to offer lower secondary schooling. Children in rural Denmark consequently had the opportunity to pursue schooling beyond the minimum required 7 years of schooling. As we document in a subsequent paragraph, the reform had a major impact on 
the school-related current and investment expenditures, and within 15 years after the reform, the proportion of a cohort completing no more than 7 years of schooling fell from about $20 \%$ percent to none. Second, the tracking in grades 5 through 7 in primary school (or, more precisely, Middle school) was abolished. Thus primary schooling now consisted of seven years of untracked schooling in both rural and urban areas. Third, lower secondary school from grades 8 through 9 or 10 were tracked into an advanced track (Realskole, which comes from the German term Realschule), and a basic or general track. Both tracks lasted 2 years with an optional third year. Upon completing the lower secondary advanced track, students could enroll in the 3-year academic upper secondary education program (Gymnasium).

Fig. B.1 examines the 1958 reform's impact on Danish schools' teaching resources using administrative data on school expenditures from the Statistical Yearbooks (published each year by Statistics Denmark). We examine the total school expenditures (i.e., the sum of current and investment expenditures) for all municipalities in Denmark and deflate the expenditures according to the CPI.

Fig. B.17 shows pre- and post-reform trends in total expenditures, indexed to the 1957/1958 school year. Before the reform, the expenditures were at a relatively constant level. However, after 1958, expenditures increase substantially (cf. Fig. B.1b). Over a 10-year period, the expenditures per school-age child increased by nearly a factor of three. This trend provides evidence of the major expansion of lower secondary education in rural areas following the 1958 reform.

Fig. B.1c provides further evidence of the 1958 reform's large impact. It shows the number of school-age children per teacher (in municipal schools) in Denmark from 1949 through 1963. The figure shows that the teacher to child ratio varied between 33 and 34 school-age children per teacher from the late 1940s until 1957. However, from 1957 onward, the number of children per teacher 
decreased to 23, corresponding to a 30\% drop (or 9,000 new teachers) in just 6 years. 


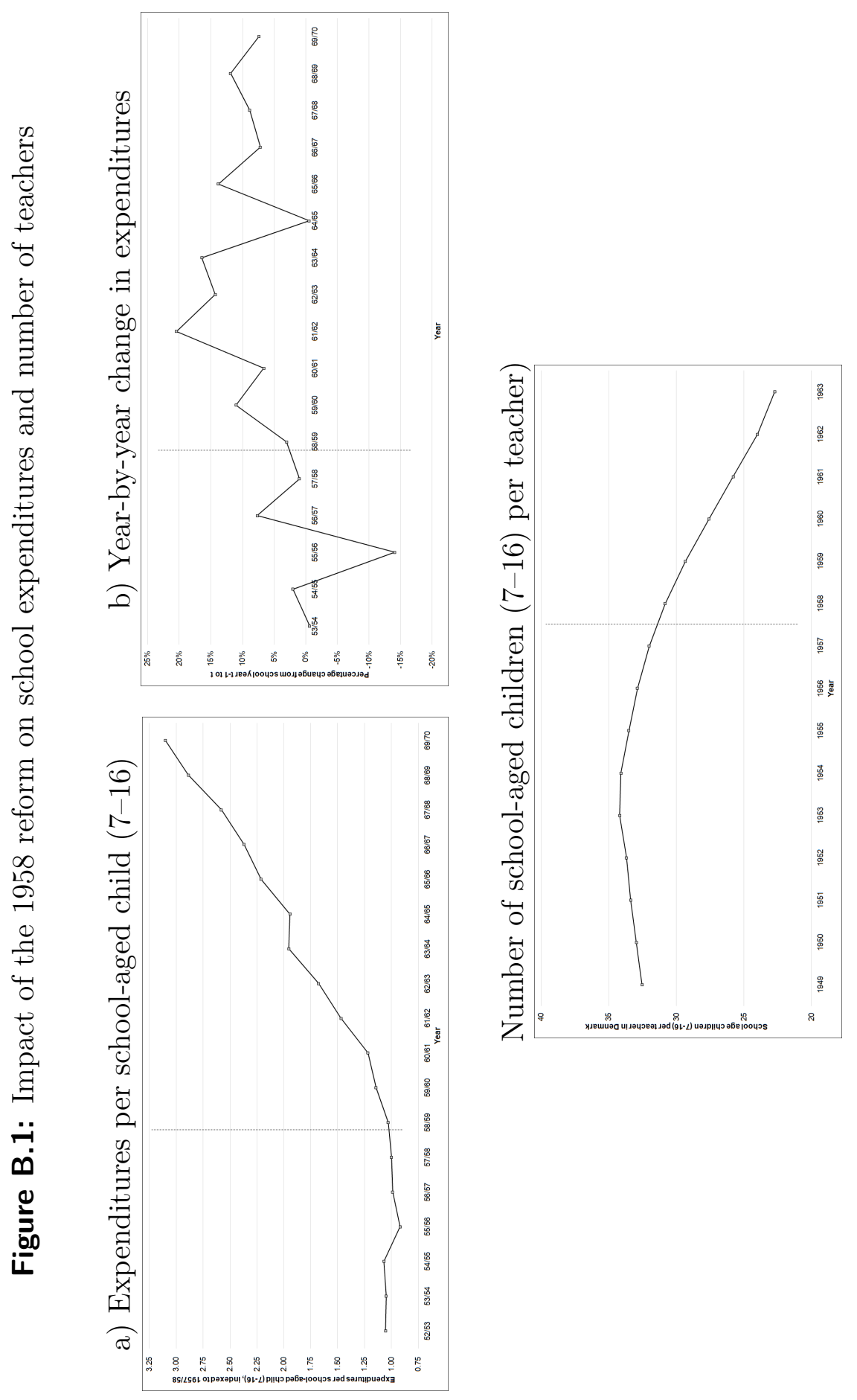

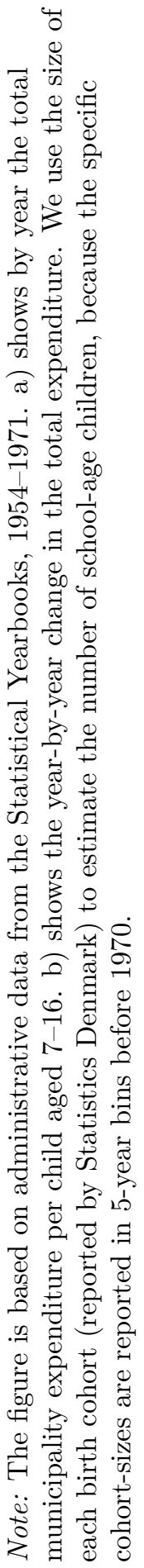


In the wake of the 1958 reform, a 1960/1961 white paper titled Den Bla Betcenkning had a major impact on both didactics and the curriculum in primary and lower secondary schools, emphasizing collaboration and interdisciplinary work and reducing the importance of testing and grading. However, despite its major impact on the content and style of instruction, the white paper did not lead to formal changes in the school system.

The 1972 reform raised the minimum required years of schooling from 7 to 9 . This reform corresponds to the Norwegian and Swedish schooling reforms studied in Black et al. (e.g., 2005); Meghir and Palme (e.g., 2005). However, the Norwegian and Swedish counterparts were introduced during the 1960s and gradually rolled out across respective countries, whereas the Danish reform was introduced later and implemented nationally at the same time. Yet, while such compulsory schooling reforms found to strongly affect the bottom of the schooling distribution for the cohorts in question in Norway and Sweden (among others), this was not the case for Denmark. As Section 2.3 shows, before the reform in 1972, around 95\% of students completed more than 7 years of schooling. Thus the reform reflected a trend that already was in place before 1972. Moreover, that reform (and later ones) did not instill the need for additional resources as the 1958 reform did.

Moreover, the 1972 reform was introduced in a staggered way such that schooling did not change discontinuously as seen in Sweden and Norway (albeit the reforms there were introduced gradually in different areas). First, while the 1959 birth cohort was the first cohort to be affected by the full implementation of the reform, it is evident in the data that the greatest response occurred immediately after the reform. Second, the stakeholders (politicians, teachers, parents) discussed those who would drop out after 7 or 8 years of schooling between the approval of the reform (December 1972) and its enactment (August 1st 1974). Here, the legislation stipulated that "compulsory schooling" could for the last year be interpreted as "skill-related activities", such that 
parents could apply for exemptions from the new mandatory schooling level in cases where it was obvious that going back to school would be disruptive if the child instead entered employment for the equivalent amount of time. Finally, the reform also changes the timing of school entry such that it became defined by the calendar year. Before the reform, the law stipulated that children could start school in the calendar year they turned 7, and all children who had turned 7 by August should attend school. Thus, there was a difference in school starting patterns between those born im January-July and August-December, which implied that many born in late 1957 were still at grade 7 when the law was passed. Hence, grade 7 disappears from the data in three steps: (1) the last half of the 1957 cohort, (2) the 1958 cohort captured the main effect, and (3) the 1959 cohort captures the remaining effect when the reform was fully implemented.35

The 1975 reform abolished tracking in lower secondary schools and introduced a single overall program from grades 1 through 9 with an optional grade 10. However, while overall tracking was abolished, schools were allowed to track students in certain courses into an advanced and general level (mathematics, physics, and foreign language).

The 1993 reform abolished the course-based tracking of the 1975 reform, meaning that all students followed the same program from grades 1 through 9 or 10 . The reform is regarded as the reform that fully established the "undivided" comprehensive school in Denmark.

\section{B.2 Register data}

Sampling: The register data comprise individuals born in Denmark by non-immigrant parents. As the full population register data (for the most parts) start in 1980, all cohorts born before 1980 is sampled conditional on surviving to 1980 (e.g., the cohort of 1930 is sampled conditional on

\footnotetext{
${ }^{35}$ See Lov om andring af Folkeskolen m.fl. love of 1972, Folketingstidende 1971/72 Tillaeg A pages 1833-1834, and Folketingstidende 1971/72 Tillæg B page 983.
} 
surviving through age 50). As mortality before age 60 is largely uncorrelated with education or background, we assess the attrition from this sampling procedure to be of minor importance (had we sampled further back in time - e.g., conditional on survival to age 70 - this would likely not be the case).

Measuring education: We measure completed education at age 30 for cohorts born in 1951 and later, and in 1981 for cohorts born earlier. Our main measure of education is years of completed schooling, which comprises compulsory schooling and further education and training such as vocational education, college degrees, and university degrees. We define years of schooling as the minimum number of years it takes to complete an education (e.g., a 3-year college degree today takes $9+3+3=15$ years to complete in that compulsory schooling lasts 9 years, high school 3 years, and college 3 years).

Our definition of education as years of completed schooling was chosen to simplify definitions and facilitate comparisons across cohorts and other countries. However, the school reform of $1972-$ which increased the years of compulsory schooling from 7 to 9 years - results in a data break in that educational levels (and years) in the register data are coded relative to the post-1972 definitions. For example, an indiviudal with seven years of compulsory schooling and three years of training (i.e., 10 years of schooling) will be assigned 12 years of schooling in the register data (9 years of compulsory schooling and 3 years of training). This data break results in education being mismeasured around the 1972 reform, which Fig. B.2 also illustrates. The solid line in the figure shows the average unadjusted years of schooling. A decline in average education length is apparent for the cohorts born in 1950-1955; this decline in mainly driven by education paths with a few years of training after completing primary or lower secondary schooling. Furthermore, for the cohorts born in 1955-1965, several categories either disappear from one year to the next or fade. The dashed line 
displays the adjusted years of schooling. Education is adjusted substantially downward for cohorts born before the 1972 school reform, which is a natural consequence of the adjustment. Moreover, the dashed line does not display the same downward kink for the 1950-1955 cohorts (though there is a minor discontinuity in the education category counting academic and vocational high school degrees; see Fig. 3).

It should be noted that around the 1960 cohort, a small drop in average years of schooling occurs. This is a result of the 1975 school reform that abolished lower secondary school tracking (which may have had a positive effect on educational attainment for many) with the short-run effect that many of those who previously would have the selective high-track 10th grade as their highest education around 1960 show up with the universal 9th grade instead. Although we mainly consider years of schooling, the register data we examined also contain results by various discrete education categories defined by overall schooling level. Table B.2 summarizes how we define these categories. 
Figure B.2: Average years of schooling by birth cohort, unadjusted and adjusted for change in education definitions

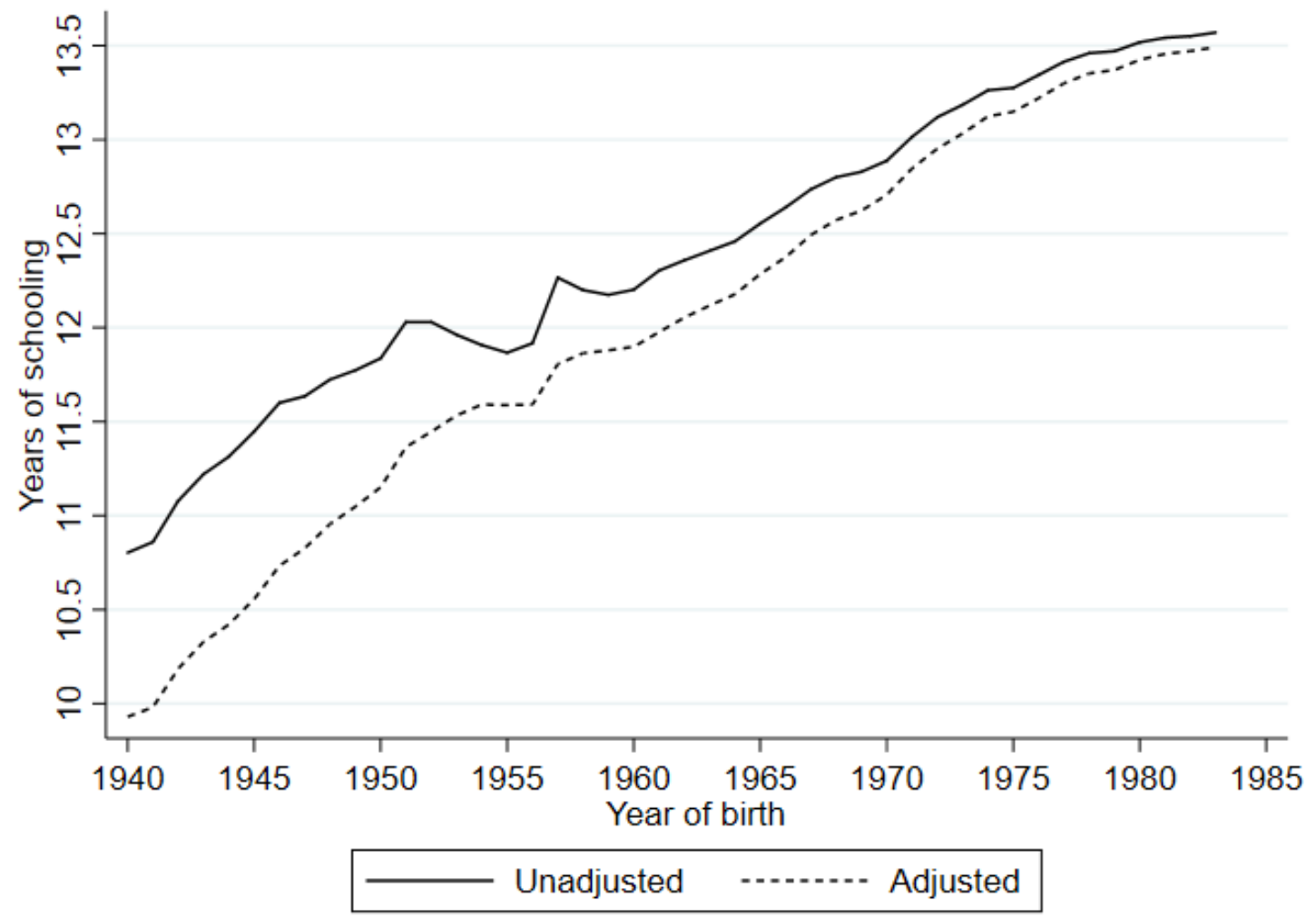

Note: Figure is based on total population register data and compares average years of schooling with and without the recoding that obviates the data break around the 1972 reform of compulsory schooling.

While most have completed their education by age 30 (the age at which the highest level of education attained), a small percentage may still be studying at this age and their educational attainment will therefore be under-reported. Insofar as this underreporting is correlated with parents' education, we may be either under- or overestimating educational mobility. Fig. B.3 presents results based on an analysis in which we have extended the age range up to and including age 32 . 
Table B.2: Education categories and years of schooling range

\begin{tabular}{lc}
\hline \hline Category & Years of schooling range \\
\hline Less than high school: & $6-7$ \\
7 years & $8-11.9$ \\
Lower secondary & \\
& \\
High school degree: & $12-14.9$ \\
High school (academic and vocational) & \\
Tertiary education: & \\
College & $15-16.9$ \\
University & $17-21.5$ \\
\hline
\end{tabular}

Fig. B.3a illustrates the bias broken down by birth cohort and fathers' education. On average, the bias increases over time, corresponding to the growing proportion of university graduates. Moreover, the figure shows that the bias increases with father's education. Fig. B.3b shows years of education beyond 15 by father's education. We find that the under-reporting increases over time and is largest for children with highly educated parents. Finally, Fig. B.3k presents education mobility estimates (i.e., regression coefficients from Fig. 1a) for education measured at age 30 and at age 32. The figure shows that the changes from year to year are almost identical irrespective of whether education is measured at age 30 or 32 , suggesting that the overall trend is similar. However, the overall level is shifted upwards by roughly 0.02 for the estimates based on education measured at age 32, suggesting slightly lower educational mobility across the entire birth cohort window. These results are compatible with Figures $\overline{B .3}$ and b. 


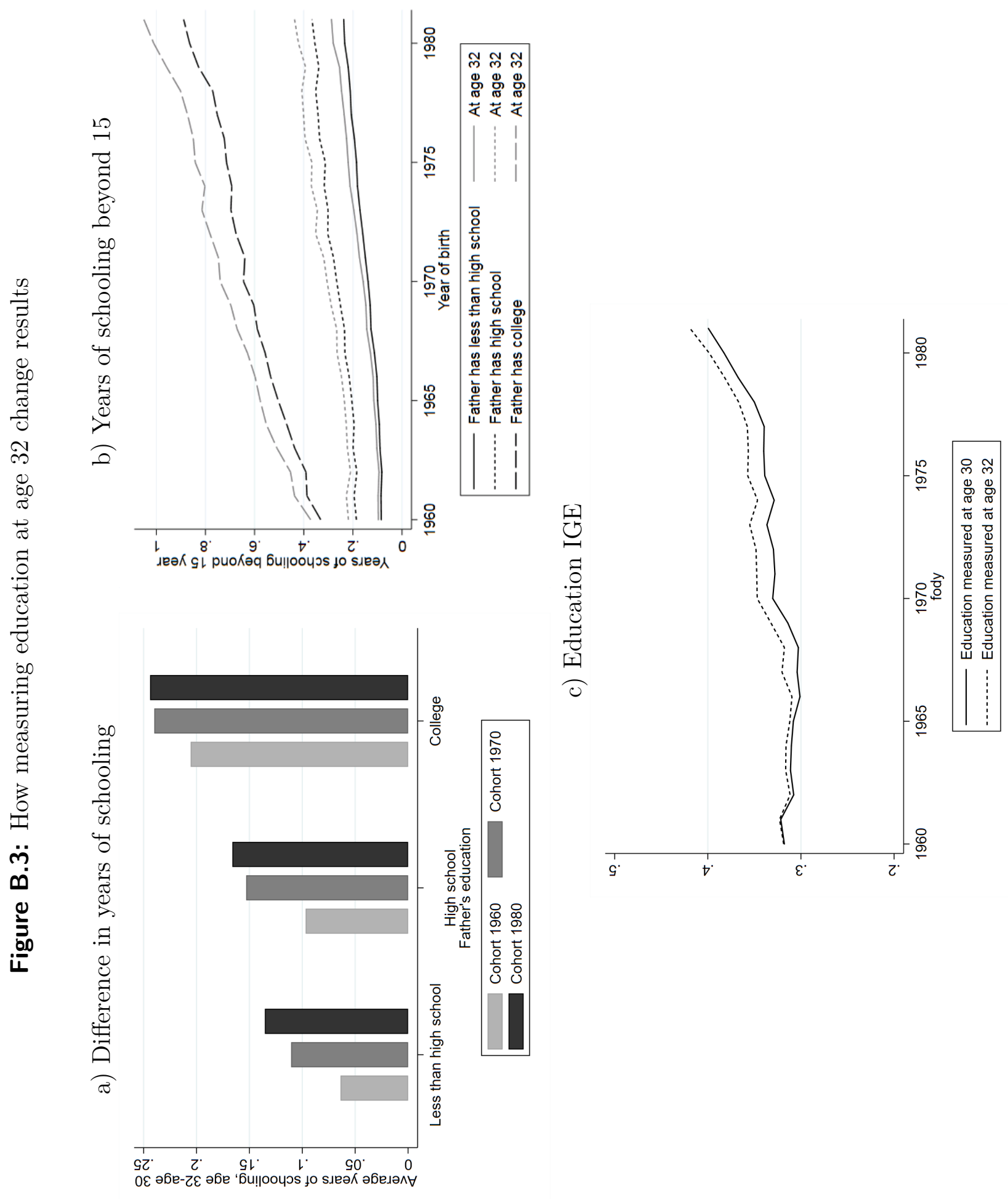

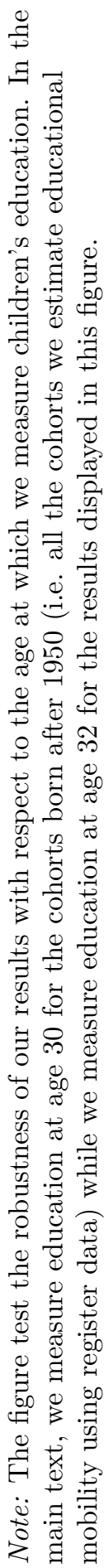




\section{B.3 Cognitive skill measure in conscription records}

We use information on cognitive skills from military conscription records. The cognitive test known as Børge Prien's Prøve (BPP), consisting of 78 items, was administered to all conscripts at the time of intake for more than half a century without any changes to the test, meaning that we can compare the scores across time. Table B.3 maps the BPP test scores to IQ scores. The BPP includes language, math, and logic/reasoning, whereas the IQ test includes only the latter.

Table B.3: Mapping the BPP distribution to IQ scores

\begin{tabular}{lcccccccccccc}
\hline \hline Percentile & 5 & 10 & 20 & 30 & 40 & 50 & 60 & 70 & 80 & 90 & 95 & 99 \\
\hline IQ score & 75 & 81 & 87 & 92 & 96 & 100 & 104 & 108 & 113 & 119 & 125 & 135 \\
Constription (BPP) test score & 23 & 28 & 34 & 37 & 40 & 43 & 45 & 47 & 50 & 54 & 57 & 62 \\
\hline \hline
\end{tabular}

Note: The table shows estimated scores at different percentiles for IQ scores and the BPP test scores.

Source: Olesen, Mikkel Hollmen (2012). Sammenligning af Forsvarets intelligenstest og IQ-skalaen [A comparison of the Army's intelligence test and the IQ scale].

\section{B.4 Survey data used for estimating educational mobility}

The survey data come mainly from surveys stored in the Danish National Archives. These data are freely available for research purposes (upon formally registering with the Archive the purpose for which the data will be used). We selected all representative surveys containing sufficiently detailed information on respondents' and parents' (mainly fathers') education. In addition, we have used Danish survey data from large international surveys such as the European Social Survey. Table B.4 summarizes available surveys used in our analyses.

While all surveys are representative of the population, a separate concern is the reliability of the education information (or whether the educational categories in the survey enable a sufficiently 


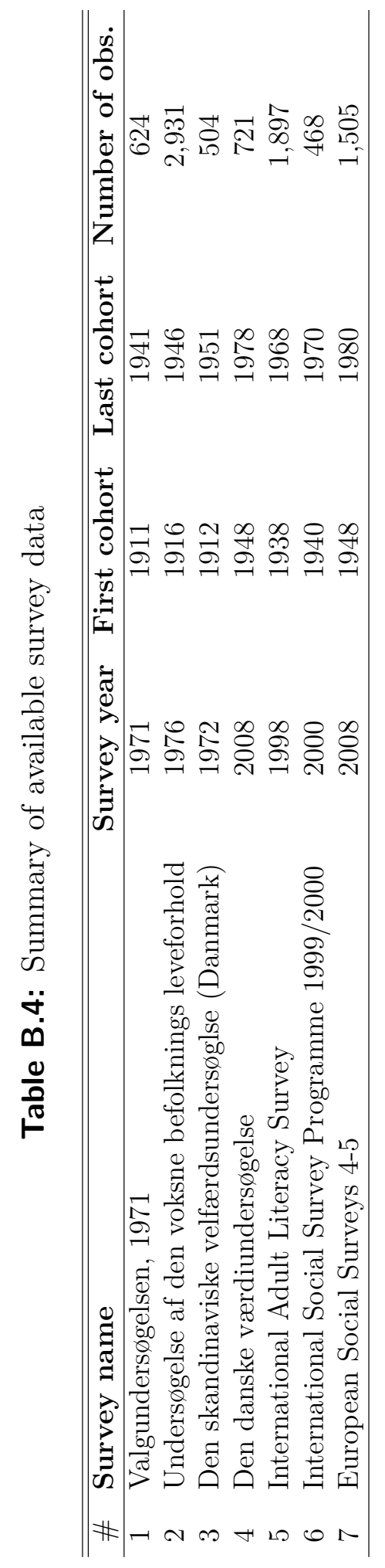


detailed analysis of trends given the drastic changes in education levels over the century). Fig. B.4a plots average years of schooling by birth cohort measured via the register data and the various survey data sources. Surveys 1-3, 4-6, and 7 are graphed separately as some overstate education relative to the register data (over and above the adjustment to the register data discussed earlier), which we believe contain the most credible information (a similar overstatement is evident when examining fathers' education). Importantly, the oldest surveys 1-3 (pre 1947) contain vary accurate information on years of completed schooling. More recent surveys overstate schooling duration (years of schooling), a problem arising from the lower tail of the educational distribution being under-reported.

As the register data are available for cohorts born in 1956-57, we only focus on surveydata for the 1911-56 cohorts. Estimates for the cohorts with overlapping survey and register data are very similar - around 0.28 from the survey data and 0.30 from the register data for the 1957-61 cohort. To ensure an overlap in cohorts from 1911 to those covered in the register data, we keep surveys 1, 2 , and 3 (reliable) and 4, 5, 6, 7 (somewhat biased) in the analysis, resulting in a final sample of 5,772. Fig. B.4b plots the sample size by 5 -year bins. We estimate all regressions using survey fixed effects to account for some of the variation, but the estimates for the cohorts around 1950 should, nonetheless, be interpreted with some caution. Finally, Fig. B.4 plots sample sizes by survey and cohort. 


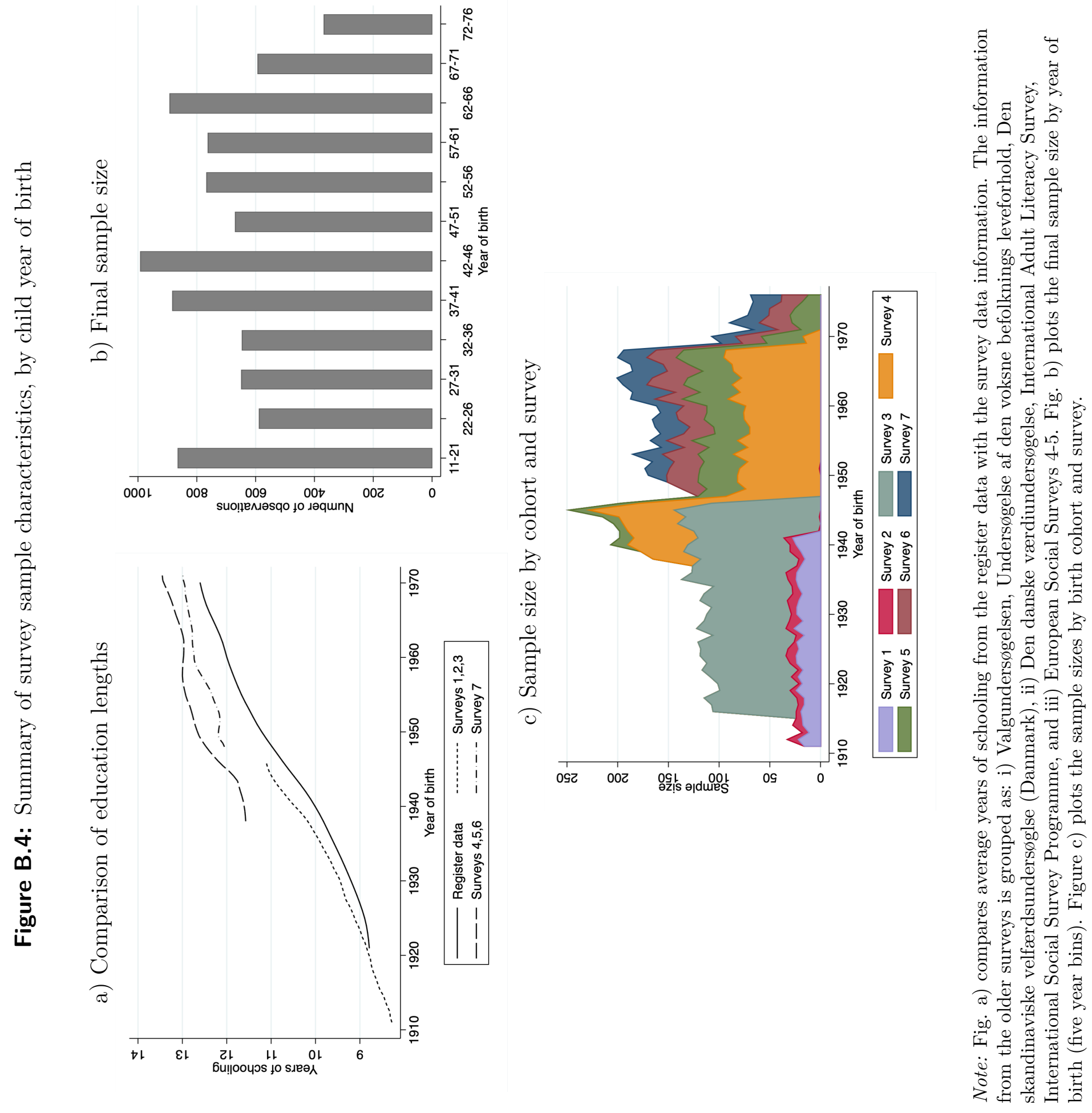


Further details Supplementary details for the seven surveys:

\#1 Valgundersøgelsen 1971 (The Danish Pre-Election and Post-Election Study 1971) is a twowave, nationally representative study in which 1,499 respondents were interviewed in the first wave in August 1971, and 1,302 respondents in the second wave in October 1971. The sampling procedure is a two-stage sample of 2,100 Danish residents aged 21 and older (21 being the voting eligibility age at the time). In the first stage, municipalities were selected on the basis of region and degree of urbanization, whereas in the second stage, respondents were randomly selected within municipalities. (The survey is fully documented in English by the Danish National Archives at http://dda.dk/catalogue/7?lang=en.)

\#2 Undersøgelse af den voksne befolknings leveforhold 1976 (Danish Level of Living Survey 1976 or Danish Welfare Survey 1976) is a nationally representative survey of Danes aged 20-69. The purpose of the survey is to describe the living conditions of the Danish population (similar surveys have been conducted in the other Nordic countries). The sampling procedure is a two-stage sample of Danish residents between 20 and 69 as of 1 September 1976. The sample is first stratified by 72 geographically based strata and then individuals within these strata are randomly selected. The issued sample size is 5,960, and the achieved sample size is 5,166 (a response rate of 87\%). (The survey is fully documented in English by the Danish National Archives at http://dda.dk/catalogue/70?lang=en. Andersen, B.H. 2003. Udviklingen i befolkningens levekår over et kvart århundrede. København: SFI describes the sampling design.)

\#3 Den skandinaviske velfærdsundersøglse (Danmark) (Scandinavian Welfare Survey 1972, Denmark) is a nationally representative survey of 1,000 individuals. The purpose of the survey is to compare living conditions and quality of life in the Scandinavian countries and was part of a comparative project led by Erik Allardt and Hannu Uusitalo. The survey population is all Danes born in 1907- 
1956 who at the time of the interview in 1972 were healthy enough to complete the interviews. Only people living in private households were interviewed. The issued sample size is not documented, nor is the sampling procedure, although the sampling likely is a two-stage design. (The survey is fully documented in English by the Danish National Archives at http://dda.dk/catalogue/82?lang=en. Allardt, E. (1981). "Experiences from the Comparative Scandinavian Welfare Study, with a Bibliography of the Project." European Journal of Political Research 9(1):101-111. presents an overview of the survey and its main findings.)

\#4 Den danske værdiundersøgelse 2008 (The Danish Value Survey 2008) is the Danish part of 2008 European Value Study (see https://europeanvaluesstudy.eu/). It is a simple random sample of the Danish population older than 18 years in 2008. The issued sample size is not documented. The achieved sample size is 1,507. (The survey is fully documented in English by the Danish National Archives at http://dda.dk/catalogue/21432?lang=en.)

\#5 International Adult Literacy Survey (IALS) 1998 is the Danish contribution to this international survey whose purpose is to assess adults' skills in a number of countries across the globe. Although IALS was conducted in both 1994 and 1998, Denmark participated only in 1998. It is a nationally representative sample of the adult non-institutional civilian population aged 16 to 65 in 1998. The achieved sample size is 3,028, and the issued sample is about 4,600 (the response rate is 66 percent, cf. Jensen et al. 2002. "Danskernes læse-regne-færdigheder - udvalgte resultater".). The sampling design is not documented, but it appears to be a two-stage design according to the online documentation that we have been able to identify. (IALS is documented in English at https://nces.ed.gov/surveys/ials/. Hertz et al. (2007) bases the analyses for Denmark on this survey.)

\#6 International Social Survey Programme 1999/2000 is the Danish contribution to this inter- 
national survey; its theme in 1999 was social inequality. The Danish contribution was collected in 2000. It is a simple random sample of the Danish population (age specifications are not provided in the documentation). The issued sample size is 3,163 , and the achieved sample size is 1,823 (a response rate of $59 \%$ ).

\#7 European Social Survey 4-5 comprises the Danish contributions to this comparative survey, which examines attitudes and socio-demographics in a number of European countries. Rounds 4 and 5 were conducted in 2008 and 2010, respectively. They are both simple random samples of the Danish population aged 15 or older who are living in a private household in Denmark. For round 4, the issued sample size is 3,008, and the achieved sample is 1,640. For round 5, the issued sample is 2,900 and the achieved sample is 1,576. The survey is documented in English at https://www.europeansocialsurvey.org/data/country.html?c=denmark

\section{B.5 Survey data for the 1954 and 1995 cohorts}

This section describes the supplementary data from the 1954 cohort study (The Danish Longitudinal Survey of Youth, DLSY) and the 1995 cohort study (The DAnish Longitudinal Study of Children, DALSC) 36

The 1954 cohort study is based on a random sample of 3,151 seventh-graders in 1968. The initial survey of children, parents, and teachers was followed by a second round in 1969, and the sample has been followed since (with the latest interview was in 2004). The sample was born in 1954 (as the sample is initiated in grade 7, counting grade 1 from age 7 ). The data includes the unique individual identifier that facilitates a link with the register data including education registers.

\footnotetext{
${ }^{36}$ see www.dlsy.sfi.dk and wwww.aargang95.sfi.dk for further descriptions of the two surveys.
} 
The 1995 cohort study is a sample of the approximately 6,000 children born in Denmark between September 1 and October 15, 1995. Interviews of parents and later with children were conducted when the children were 6 months, and 3, 7, 11, 15, and 18 years old. The data include the unique individual identifier that facilitates a link with the register data including education registers.

Both surveys were administered by the Danish Institute for Social Research (then called SFI, today ViVe); consequently, there is substantial overlap in the questions and measures used. We use the verbal intelligence test, which was measured at age 15 in both surveys.

Both samples also responded to questions in the Rosenberg self-esteem scale (Rosenberg, 1965) around age 20. The Rosenberg scale is a 10-item Likert scale, but as the DLSY only contains questions $1,4,5,6,7$, and 8 , we use these six questions to construct the scale in both samples (although results are almost identical when using the full scale in the 1995 cohort). The 1995 cohort surveys also contain a host of other measures of skills and traits. Table B.5 reports correlations between the Rosenberg scale and the intelligence test, as well as the Raven intelligence test, the traits from the Big-5 inventory, and the Strengths and Difficulties Questionnaire (SDQ) used to assess problem behavior of children (scale reversed in the table below).

We measure education at age 30 for the 1954 cohort survey. However, this was not possible for the 1995 cohort. We therefore use a combination of highest completed education and current enrollment, and we include all currently enrolled in college in the group with a college degree (few in Denmark have completed college by age 23; 2018 is the last year for which we had education data). While high school completion is measured consistently in the two surveys, college completion potentially includes measurement error relating to drop out and late enrollment in the 1995 cohort. 
Table B.5: Correlation between Rosenberg self-esteem scale, cognitive test scores, and other skill measures

\begin{tabular}{lcc}
\hline \hline & Rosenberg (short) & Cognitive test score \\
\hline Rosenberg (short) & - & -0.01 \\
Cognitive test & -0.01 & - \\
Rosenberg full & 0.97 & -0.02 \\
Raven test & 0.01 & 0.39 \\
SDQ (reversed) & 0.11 & 0.17 \\
Openness & 0.00 & 0.10 \\
Conscientiousness & 0.15 & -0.01 \\
Extroversion & 0.28 & 0.01 \\
Agreeableness & 0.18 & 0.01 \\
Neuroticism & -0.45 & -0.01 \\
\hline \hline Observations & 3,385 & 3,385
\end{tabular}

\section{Data appendix, U.S.}

Analyses of U.S. data in the main text are based on the cumulative data file of the General Social Surveys 1972-2016 (GSS), a national probability sample of the non-institutionalized U.S. population. The cumulative file combines all surveys conducted annually from 1972 through 1994 - excepting 1979, 1981, and 1992 - and biennially thereafter. The GSS contain information on both offspring's and parents' educational attainment for respondents born over most of the 20th century. For our research, the sample was limited to respondents with (1) valid information on their own and parents' educational attainment, and (2) who were aged 30-59 at the time of the interview, resulting in 31,582 parent-offspring pairs.

We measure schooling of both respondent and parents by years of schooling, ranging from 0 through 20 years. For parents, we use the highest number of schooling years reported by either 
of the two parents. To retain a larger percentage of the sample, we access additional information on the highest educational degree completed by both respondent and parents. For respondents and parents with missing information on years of schooling, we impute their years of schooling in a three-step approach (for respondents and parents, respectively). First, we group the data with valid information on both years of schooling and educational degree into 5-year cohorts. Second, for each 5-year cohort group, we estimate the average years of schooling for each educational degree. Third, for respondents with missing information on years of schooling but valid information on educational degree, we impute their missing value with average years of schooling from the second step.

We also use four additional variables: residence at age 16, coded into a rural-urban indicator; gender; race/ethnicity; and family structure at age 16. These variables have only few missing values.

The GSS provides sampling weights. As seen in Fig. C.1, applying these weights does not change any substantive conclusions regarding overall trends in years of schooling over the 20th century. Moreover, as Fig. C.2 shows, the education IGE is also virtually unaffected by applying the sampling weights. For this reason, we do not apply these weights in the analyses. 
Figure C.1: Child and parent average years of schooling by birth cohort, unweighted and weighted

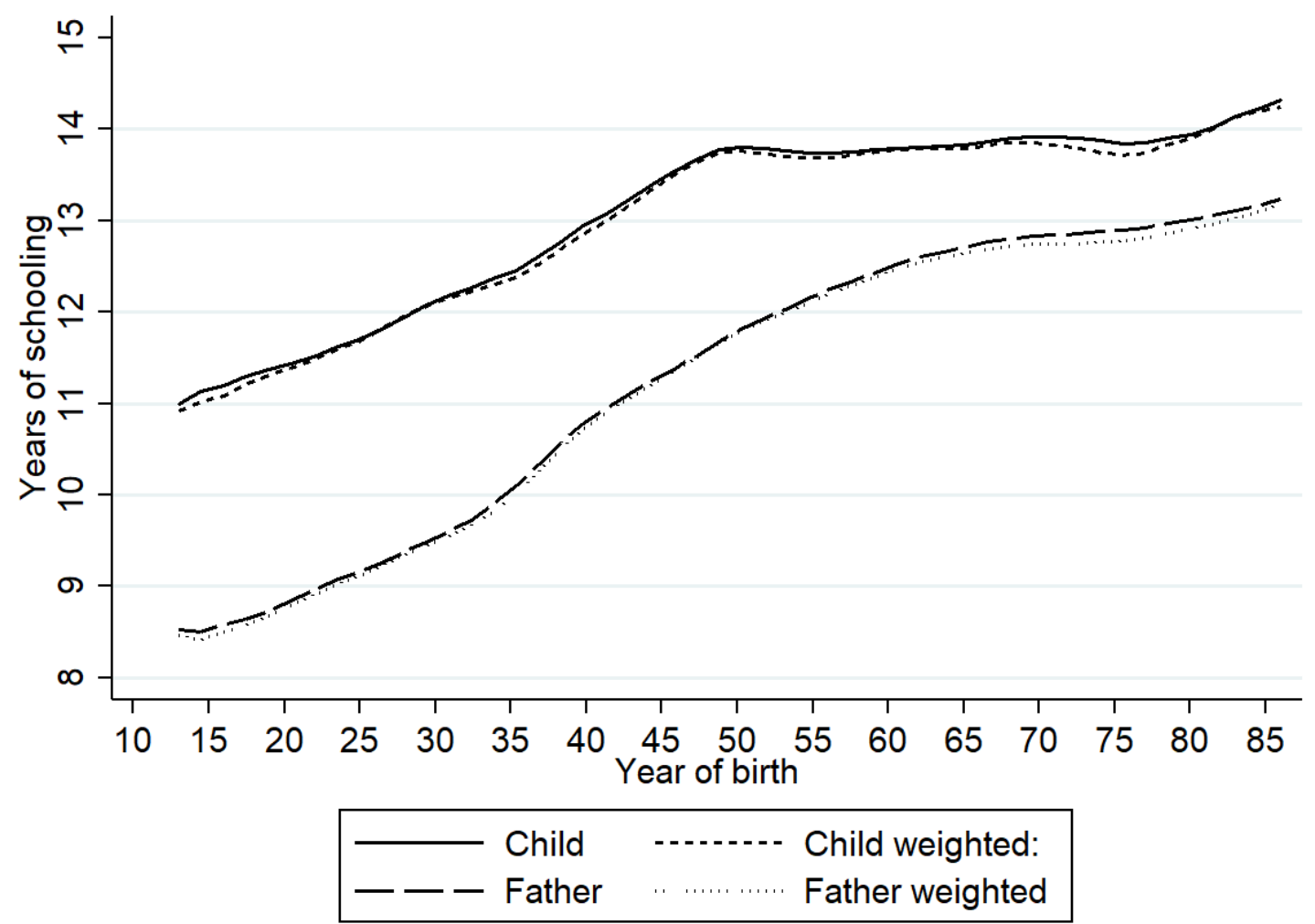

Note: Figure is based on cumulative data from the General Social Surveys 1972-2016. N = 31,582. Sample weight provided by the GSS (wtssall).

Although our analysis mainly considers years of schooling, we also report results by various discrete education categories defined by overall schooling level. Fig. C.3 compares education levels from the survey data with U.S. Census statistics by birth cohorts. The figure shows that high school and college completion levels and trends in the two data sets follow each other closely. 
Figure C.2: Education IGE, by child birth year, unweighted and weighted

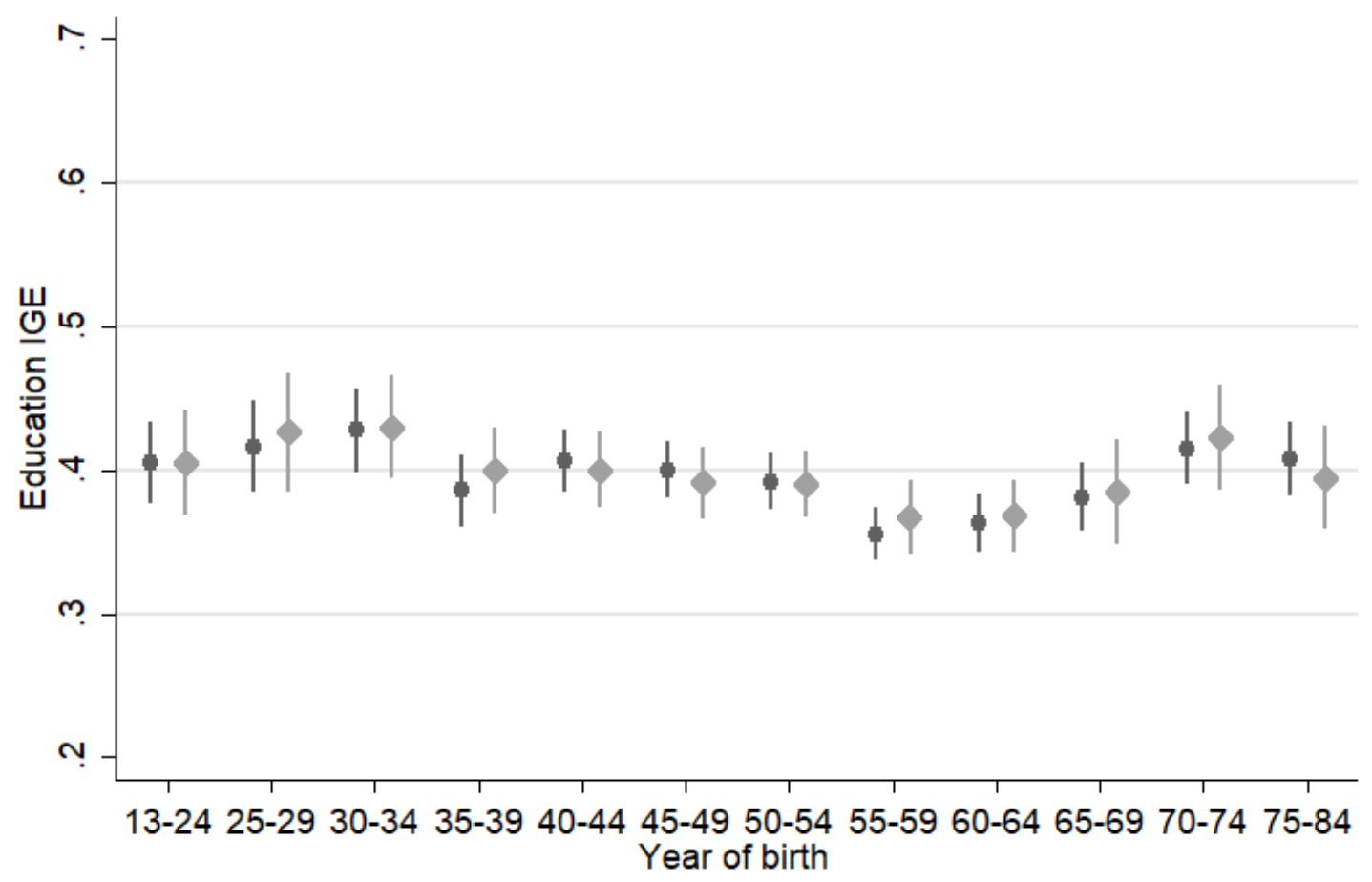

- Unweighted Weighted

Note: The figure is based on cumulative data from the General Social Surveys 1972-2016. N = 31,582. Sample weight provided by the GSS (wtssall). 


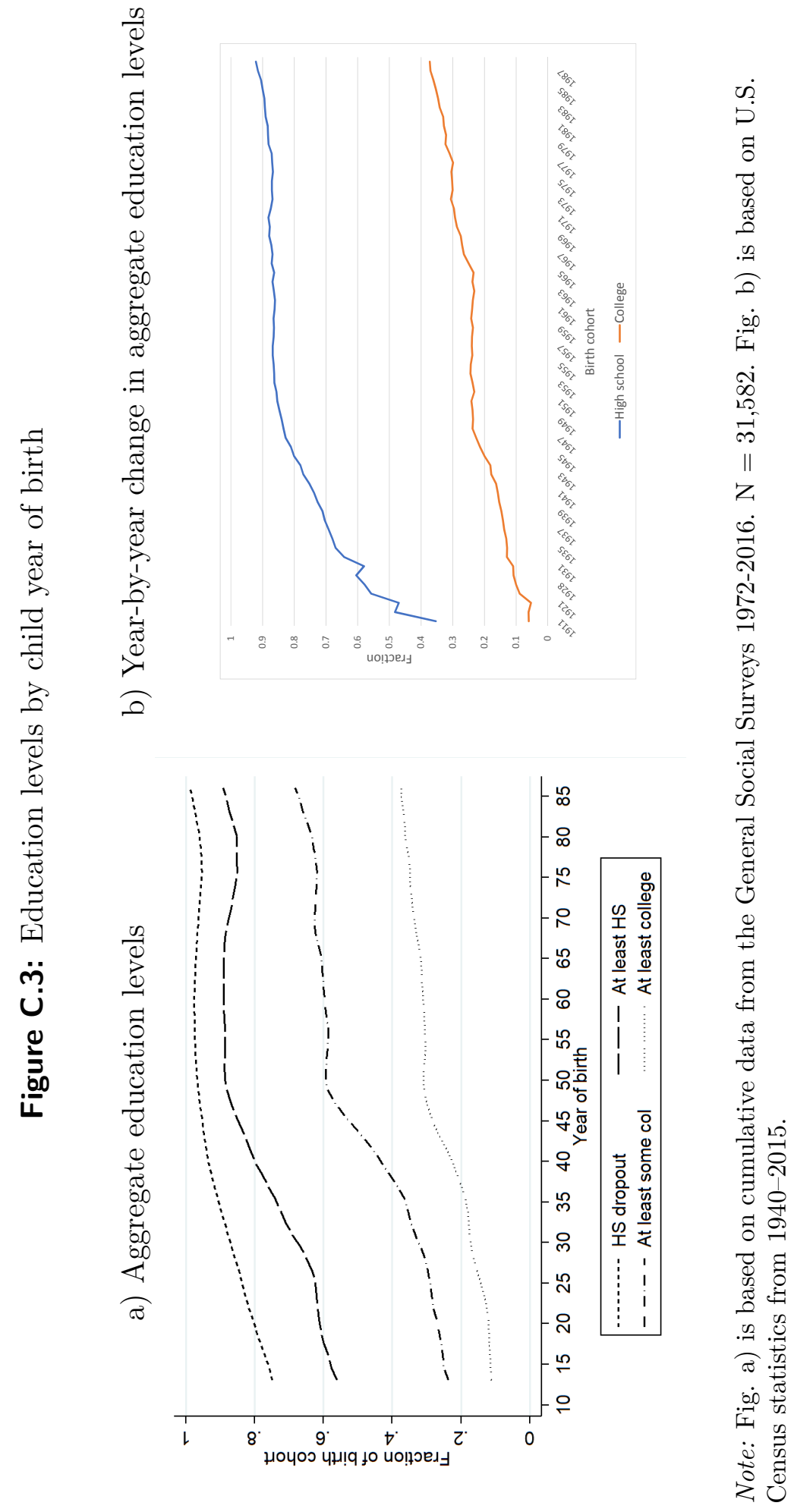

